\title{
Bro1 stimulates Vps4 activity to promote Intralumenal Vesicle Formation during Multivesicular Body biogenesis
}

Authors: *Chun-Che Tseng ${ }^{1,2}, *$ Shirley Dean ${ }^{1,2,3}$, $*$ Brian A. Davies ${ }^{1}$, Ishara F. Azmi ${ }^{1,2,4}$, Natalya Pashkova ${ }^{5}$, Johanna A. Payne ${ }^{1}$, Jennifer Staffenhagen ${ }^{6}$, Matt West ${ }^{7}$, Robert C. Piper ${ }^{5}$, Greg Odorizzi ${ }^{7},{ }^{\text {DDavid J. Katzmann }}{ }^{1,2}$

1) Department of Biochemistry and Molecular Biology, Mayo Clinic, Rochester, MN, 55905

2) Biochemistry and Molecular Biology Graduate Program, Mayo Clinic Graduate School of Biomedical Sciences, Mayo Clinic, Rochester, MN, 55905

3) present address: Adjunct Chemistry Instructor, Cornerstone University, Grand Rapids, MI, 49525

4) present address: Sherlock Bioscience, 40 Guest street, Boston MA, 02135

5) Department of Molecular Physiology and Biophysics, Carver College of Medicine, University of Iowa, Iowa City, IA, 52242

6) present address: Veterinary and Biomedical Sciences, College of Veterinary Medicine, University of Minnesota, St. Paul, MN, 55108

7) Department of Molecular, Cellular, and Developmental Biology, University of Colorado Boulder, Boulder, CO, 80402

*These authors contributed equally to these studies

"To whom correspondence should be addressed

\section{Running Title}

Bro1 stimulates Vps4 during MVB biogenesis

\section{Summary}

Cargo sorting is coordinated with intralumenal vesicle budding during ESCRT-mediated multivesicular body biogenesis. Bro1 V domain stimulates Vps4 to promote ESCRT-III-driven intralumenal vesicle formation in a manner required for this coordinated process.

\footnotetext{
Abstract

Endosomal sorting complexes required for transport (ESCRT-0, -I, -II, -III) execute cargo sorting and intralumenal vesicle (ILV) formation during conversion of endosomes to multivesicular bodies (MVBs). The AAA-ATPase Vps4 regulates the ESCRT-III polymer to facilitate membrane remodeling and ILV scission during MVB biogenesis. Here we show that the conserved V domain of ESCRT-associated protein Bro1 (the yeast homolog of mammalian proteins ALIX and HD-PTP) directly stimulates Vps4. This activity is required for MVB cargo sorting. Furthermore, the Bro1 V domain alone supports Vps4/ESCRT-driven ILV formation in vivo without efficient MVB cargo sorting. These results reveal a novel activity of the $\mathrm{V}$ domains of Bro1 homologs in licensing ESCRT-III-dependent ILV formation and suggest a role in coordinating cargo sorting with membrane remodeling during MVB sorting. Moreover, ubiquitin binding enhances $\mathrm{V}$ domain stimulation of Vps4 to promote ILV formation via the Bro1/Vps4/ESCRT-III axis, uncovering a novel role for ubiquitin during MVB biogenesis in addition to facilitating cargo recognition.
} 
bioRxiv preprint doi: https://doi.org/10.1101/2020.07.27.223255; this version posted February 16, 2021. The copyright holder for this preprint (which was not certified by peer review) is the author/funder, who has granted bioRxiv a license to display the preprint in perpetuity. It is made available under aCC-BY 4.0 International license. 


\section{Introduction}

The Endosomal Sorting Complexes Required for Transport (ESCRTs) have been implicated in a number of cellular membrane remodeling processes: intralumenal vesicle (ILV) generation during the conversion of endosomes into multivesicular bodies (MVBs, relevant to both lysosomal degradation and exosome biogenesis; Baietti et al., 2012, reviewed by Hanson and Cashikar, 2012), abscission during cytokinesis (reviewed by Vietri et al., 2020), viral budding (Votteler and Sundquist, 2013), nuclear pore surveillance (Webster et al., 2014), autophagy (Lee et al., 2007a; Takahashi et al., 2018), and membrane repair (Skowyra et al., 2018). These studies have highlighted the conserved role of ESCRT-III and associated factors in membrane deformation. ESCRT-III-dependent membrane remodeling is typically coordinated with upstream events, such as cargo recognition in MVB sorting (reviewed by Piper and Lehner, 2011; Williams and Urbe, 2007). Ubiquitylated cargoes destined for lysosomal destruction are actively recognized by a host of ubiquitin (Ub)-binding domains within ESCRTs -0, -I, and -II as well as in the Bro1 Domain Family Proteins, and sequestration of these ubiquitylated cargoes form microdomains at which ESCRT-II activates ESCRT-III polymerization to drive ILV formation (reviewed by Schmidt and Teis, 2012; Williams and Urbe, 2007). In yeast depletion of Ub from the site of MVB sorting precludes cargo sorting as well as ILV formation itself, indicating a level of coordination between cargo recognition and ESCRT-III-mediated ILV generation (MacDonald et al., 2012a; Stringer and Piper, 2011). ESCRT-III assembly, remodeling and disassembly drive membrane budding, although how this cycle is regulated to coordinate cargo transfer into ILVs remains an unresolved question.

ESCRT-III subunits are monomeric in the cytosol and undergo an ordered polymerization on membranes into filamentous spirals responsible for membrane remodeling (reviewed by Schmidt and Teis, 2012). ESCRT-III function is intimately connected to the AAA-ATPase Vps4, which supports both 1) dynamic exchange of subunits during ESCRT-III polymerization (Adell et al., 2017; Mierzwa et al., 2017; Pfitzner et al., 2020) and 2) ESCRT-III disassembly at the completion of the reaction (Adell and Teis, 2011; Babst et al., 1997; Babst et al., 1998; Davies et al., 2010). A series of regulators including ESCRT-III itself, the Vps4 co-factor Vta1/LIP5, and Bro1 serve to coordinate the activities of ESCRT-III and Vps4 to optimize ESCRT function during MVB sorting (Azmi et al., 2006; Azmi et al., 2008; Merrill and Hanson, 2010; Shim et al., 2008; Wemmer et al., 2011). How these factors act in concert during MVB sorting is unclear. The Bro1 Domain Family members, including mammalian ALIX/PDCD6IP and HDPTP/PTPN23 and the aforementioned yeast Bro1, make multiple contributions to ESCRTmediated events. This family is characterized by the presence of: the amino-terminal Bro1 Domain (BOD) that binds the ESCRT-III subunit CHMP4/Snf7 (Lee et al., 2016; McCullough et al., 2008; Wemmer et al., 2011); the middle V domain - two helix bundles that form two arms of a V-shaped structure capable of interacting with both $\mathrm{Ub}$ and $\mathrm{YPX}_{\mathrm{n}} \mathrm{L}$ motifs found within Gag, Syntenin, and Rfu1 (Baietti et al., 2012; Carlton et al., 2008; Kimura et al., 2014); and the carboxyl-terminal Proline Rich Region (PRR) that both facilitates associations with ESCRT-I and other factors (e.g. Ub isopeptidase Doa4 interaction with yeast Bro1 PRR) and, in the context of ALIX, auto-inhibits the BOD and V domain (Buysse et al., 2020; Johnson et al., 2017; Luhtala and Odorizzi, 2004; Nikko and André, 2007; Richter et al., 2013; Zhai et al., 2011). Bro1 Domain Family members contribute to 1) Ub-dependent and -independent cargo recognition in concert with or in parallel to the early ESCRTs and 2) regulating ESCRT-III dynamics by facilitating CHMP4/Snf7 activation and inhibiting Vps4 disassembly of ESCRT-III. 
These diverse contributions may suggest Bro1 Domain Family members serve roles coordinating cargo entry into budding ILVs.

Loss of Bro1 severely diminishes ESCRT-dependent functions and disrupts ILV formation as does loss of the ESCRT-III subunit Snf7 (Babst et al., 2002; Odorizzi et al., 2003). However, when the interaction of Snf7 with Bro1 BOD is disrupted, ILV formation is still observed albeit at a reduced level (Wemmer et al., 2011), suggesting that other features of and interactions with Bro1 drive ILV formation. Here we find that Bro1 V domain supports ESCRTdependent MVB biogenesis in vivo through a process that uncouples cargo sorting from vesicle formation. The V domain interacts with Vps4 MIT domain and stimulates Vps4 ATPase activity in vitro in a manner regulated by Bro1 V binding Ub. Stimulation of Vps4 is critical for Bro1 function since $\mathrm{V}$-domain mutations that preserve Vps4 and Ub-binding but specifically perturb the ability to stimulate Vps4 ATPase activity showed defects in MVB cargo sorting and ILV formation in vivo. These results indicate that ESCRT-driven ILV formation is separable from cargo sorting and suggest that Bro1 Domain Family members coordinate ubiquitylated cargo sorting into ILVs whilst promoting ILV formation via the Vps4/ESCRT-III axis.

\section{Results}

\section{Brol V domain promotes ESCRT-dependent ILV formation}

The BOD of Bro1 interacts with the ESCRT-III subunit Snf7 (Kim et al., 2005) to promote ESCRT-III polymerization through both facilitating Snf7 activation (Tang et al., 2016) and modulating Vps4-mediated disassembly of ESCRT-III (Wemmer et al., 2011). Mutation of Bro1 or Snf7 disrupting their association abrogates MVB cargo sorting (Kim et al., 2005; Wemmer et al., 2011), however a Snf7 mutant defective for BOD binding [Snf7(L231A, L234A)] retained the capacity to support ILV formation (Wemmer et al., 2011), implying other domains of Bro1 are critical to drive ILV formation. To explore this idea, we examined the phenotype of expressing Bro1 lacking its N-terminal BOD (brol ${ }^{\triangle B O D}$, aa370-844) as the sole allele of BRO1. The brol $\triangle$ cells expressing rrol $^{\triangle B O D}$ under the control of $T E F 1$ promoter displayed spherical endosomal structures containing ILVs (Figure 1A, Movie S1). In contrast, cells lacking Bro1 altogether, brol $\triangle$, were deficient in ILVs and displayed multi-lamellar endosomal stacks characteristic of "class E vps" endosomal compartments ((Luhtala and Odorizzi, 2004) and Figure 1A, Movie S2; a rare brol $\Delta$ cell with ILVs is shown in Figure S1A). Compared to WT cells bro $1^{\triangle B O D}$ cells showed reductions in ILVs per MVB, budding profile frequency and budding profile surface area (Figure 1B, 1C, Movie S3), however the sizes of ILVs were equivalent to those in WT cells (Figure 1C). While aspects of the brol ${ }^{\triangle B O D}$ MVBs differed from those in WT cells, the striking result was their presence in brol $1^{\triangle B O D}$ cells in contrast to their absence in brol $\triangle$ cells (Figure 1B). This result indicates that Bro1 BOD is not required to support ILV formation, consistent with the Snf7(L231A, L234A) analysis (Wemmer et al., 2011).

Bro1 requires BOD interaction with Snf7 for MVB cargo sorting (Kim et al., 2005; Wemmer et al., 2011); however, we observed ILV formation upon expression of Bro1 ${ }^{\triangle \mathrm{BOD}}$. To determine whether Bro1 ${ }^{\triangle \mathrm{BOD}}$ could mediate specific MVB cargo sorting, we examined the localization of MVB cargoes delivered from endocytic (Ste2, Mup1) and biosynthetic pathways (Cps1, UbCps1, Cos5, Sna3) as well as a vacuolar limiting membrane protein (DPAP-B/Dap2) typically excluded from MVB sorting. Though brol ${ }^{\triangle B O D}$ cells clearly made MVBs, MVB cargo proteins 
failed to sort into MVBs and instead were localized to the limiting membrane of the vacuole and a perivacuolar endosomal compartments (Figure 2A). Immunoblot analysis of two MVB cargos, Sna3 and Mup1, with anti-GFP antibodies showed that a modest level of delivery to the endosomal lumen did occur as gauged by the presence of a $\sim 24 \mathrm{kDa}$ fragment of GFP that is produced in the vacuolar lumen in a Snf7-, Vps4- and Bro1-dependent manner (Figure $2 \mathrm{~B}$ and C). These sorting defects in $b r o l^{\triangle B O D}$ cells did not appear to be related to perturbed cargo ubiquitylation since immunoblotting of Sna3 and Mup1 showed that a substantial proportion of these cargos were ubiquitylated. To confirm that rrol $^{\triangle B O D}$ cells made ILVs, we also followed the sorting of NBD-Phosphatidylcholine (NBD-PC), a fluorescent lipid that partitions into ILVs in an ESCRT-dependent manner (Bilodeau et al., 2002; Hanson et al., 2002; Shields et al., 2009), and Figure $3 \mathrm{~A}-\mathrm{C}$, Figure S1). Expression of Bro $1^{\triangle \mathrm{BOD}}$ in brol $\Delta$ cells resulted in a significant percentage of cells with lumenal NBD-PC sorting (77\%), consistent with the ability of Bro1 ${ }^{\mathrm{BBOD}}$ to support ILV formation. Over-expression of full-length Bro1 under the control of the TEF1 promoter (Figure S2A) reduced the percentage of cells with NBD-PC sorted into the vacuolar lumen (98\% vs $85 \%$; Figure 3C), consistent with the dominant negative effect of over-expressing Bro1 (Wemmer et al., 2011). Bro1 ${ }^{\triangle \mathrm{BOD}}$-mediated NBD-PC sorting was dependent on Vps4 as well as ESCRT-0, ESCRT-I, ESCRT-II and ESCRT-III (Figure 3C, Figure S2B), indicating that Bro1 $^{\triangle \mathrm{BOD}}$ uses the expected ESCRT-dependent pathway for ILV formation. Moreover, expression of $\mathrm{Bro}^{\triangle \mathrm{BOD}}$ under the control of $\mathrm{BRO1}$ promoter was able to support NBD-PC sorting (Figure S2E, S2F) albeit to a lesser degree than highly-expressed Bro ${ }^{\triangle \mathrm{BOD}}$. Together, these results indicate that while Bro1 ${ }^{\triangle \mathrm{BOD}}$ can support MVB biogenesis (e.g., brol ${ }^{\triangle B O D}$ cells exhibit $\sim 50 \%$ ILVs per MVB compared to WT cells), Bro1 ${ }^{\triangle \mathrm{BOD}}$ is unable to support efficient sorting of MVB cargos into ILVs.

Bro1 $^{\triangle \mathrm{BOD}}$ contains both the $\mathrm{V}$ domain as well as a $\mathrm{C}$-terminal proline rich domain (PRR) that mediates interaction with the Ub isopeptidase Doa4 (Buysse et al., 2020). We found that Bro $^{\triangle \mathrm{BOD}}$-mediated NBD-PC sorting was not dependent on Doa4 and that Bro1 V domain alone supports NBD-PC sorting into the vacuole lumen (Figure 3C), demonstrating that PRR and its associations are not required for this activity. This finding was supported by EM tomography analysis wherein Bro1 V domain alone (brolV) was able to support some ILV formation (Figure 3D, Movie S5), albeit at levels less than WT or brol ${ }^{\triangle B O D}$ cells (Figure 3E). However, the size of the ILVs in brol $V$ cells were indistinguishable from those in WT or brol ${ }^{\triangle B O D}$ cells (Figure S2C). While Bro1V alone is able to support ILV formation, Bro1V was unable to support MVB cargo sorting (Figure 3F, Figure S2D), as observed with brol ${ }^{\triangle B O D}$ cells. In total, these results implicate the $\mathrm{V}$ domain in promoting Bro1/Vps4/ESCRT-III-driven ILV formation.

\section{Brol V domain stimulates Vps4 in vitro}

The ability of Bro1 ${ }^{\triangle B O D}$ and, in particular, the Bro1 V domain alone to support ILV formation without promoting efficient MVB protein cargo sorting suggested that the V domain might activate ESCRT function at the level of ESCRT-III/Vps4 membrane remodeling and scission activity in vivo in a manner that could be uncoupled from efficient cargo packaging. Thus, we searched for how the $\mathrm{V}$ domain might directly stimulate the vesicle scission machinery by examining effects on Vps4 activity. Bro1 interacts with Vps4 (Vajjhala et al., 2007), however the mode and significance of this association have not been determined. Binding studies using a series of recombinant GST-tagged Brol protein fragments and His 6 -tagged Vps4 protein fragments showed that the Bro1 V binds the N-terminal Vps4 MIT domain (Figure 4A,B). Two 
distinct surfaces of the MIT domain mediate interactions with MIM1 and MIM2 elements in ESCRT-III subunits (Kieffer et al., 2008; Obita et al., 2007; Stuchell-Brereton et al., 2007), however mutations (I18D, MIM2; L64D, MIM1) disrupting these modes of association did not impair MIT-V domain association. These results suggest that Bro1V binds Vps4 MIT domain in a manner distinct from MIM1 and MIM2.

The possibility that Bro1V domain modulates Vps4 activity was assessed using ATPase assays with purified recombinant proteins (Babst et al., 1997). Vps4 exhibits concentration dependent increases in specific activity due to $\mathrm{Vps} 4$ oligomer formation with maximal activity observed

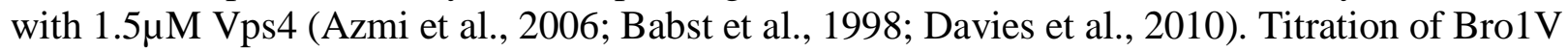
into ATPase assays with a submaximal concentration of Vps4 $(0.5 \mu \mathrm{M})$ showed a concentration dependent stimulation of activity with a maximum of 2.6-fold over basal activity (Figure 4C). Stimulated activity of $0.5 \mu \mathrm{M}$ Vps4 did not surpass the inherent maximal Vps4 specific activity observed with $1.5 \mu \mathrm{M}$ Vps4, and Bro1V was unable to stimulate $1.5 \mu \mathrm{M}$ Vps4 specific activity (data not shown). These observations suggested that Bro1 V stimulates Vps4 oligomerization without further enhancing activity of the Vps4 oligomer. To examine this directly, Vps4 titration was performed in the presence of $4 \mu \mathrm{M}$ Bro1V. While Bro1V enhanced Vps4 specific activity up

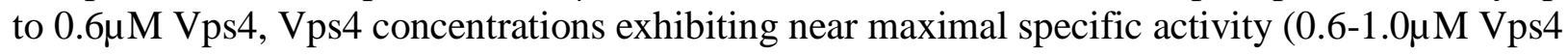
in this particular series of experiments) were not further stimulated by Bro1V (Figure 4D). Nonlinear regression indicated that Bro1V addition reduced the $\mathrm{Vps} 4$ apparent $\mathrm{K}_{\mathrm{m}}$ from $0.45 \mu \mathrm{M}$ to $0.30 \mu \mathrm{M}$, supporting enhanced oligomerization as the mechanism by which Bro1 stimulates Vps4. Furthermore, V domains from S. castellii Bro1 (residues 370-709) and human HD-PTP (residues 364-695) stimulated Vps4 ATPase activity in a similar dose-dependent manner (Figure 4E). Together, these results reveal that Bro1 V domain enhances Vps4 ATPase activity directly, and suggest this stimulatory activity is conserved among homologs.

\section{Generation of Brol V domain mutants defective for Vps4 stimulation}

We next wanted to determine the functional significance of the stimulatory effect of Bro1V on Vps4 activity. In addition, we wanted to determine whether this effect was due solely to simple binding of Bro1V to Vps4 or whether additional biochemical processes could be observed that were responsible for stimulating Vps4. Therefore, we mutated select residues that were conserved between Bro1 and HD-PTP with the goal of generating Bro1 mutants specifically altered in in their ability to stimulate Vps4 activity but retained their ability to bind Vps4 (Figure 5, Figure S3A). Vps4 stimulation was measured using ATPase reactions containing WT or mutant forms of Bro1V. Six of the Bro1V mutants tested stimulated Vps4 activity like WT Bro1V, whereas four mutants - Bro1V ${ }^{\mathbf{M 4}}$ : V505A, H508A, I512A; Bro1V ${ }^{\mathbf{M 8}}$ : E686A, L691D; Bro1V $^{\text {M9}}$ : T587D; and Bro1V ${ }^{\text {M10 }}$ : K481D — did not stimulate Vps4 ATPase activity (Figure 5B) but retained their ability to bind Vps4 (Figure 5C, Figure S3A). Indeed, ability of these mutants to associate with Vps4, in some cases better than WT, led us to perform titration experiments to assess the impact on Vps4 ATPase activity. While the Bro1V mutants were unable to stimulate $\mathrm{Vps} 4$ at higher concentrations $(>1 \mu \mathrm{M})$, these mutants could stimulate Vps4 ATPase activity at lower concentrations $(\leq 1 \mu \mathrm{M}$; Figure $5 \mathrm{D})$. This profile contrasted with the behavior of WT Bro1V that continued to stimulate Vps4 ATPase activity even at the highest concentrations tested. Together these analyses suggest that Bro1V stimulation of Vps4 relies on determinants beyond mere binding and provided tools to determine whether Bro1V-stimulated Vps4 activity was important in vivo for MVB sorting and biogenesis. 
Altered regulation of Vps4 activity by Brol V perturbs ILV formation in vivo MVB sorting was examined in brol $\triangle$ cells carrying full-length alleles of BRO1 containing mutations in the V domain that altered Vps4 stimulation (Figure 6A). Three distinct model MVB cargoes were utilized for this analysis: GFP-Cps1 for its strict dependence upon Ub modification for proper sorting, the chimera Ub-GFP-Cps1 for its lack of dependence upon exogenous Ub modification, and Sna3-GFP as a cargo that has been shown to access the MVB pathway both directly and via association with other ubiquitylated cargoes (Katzmann et al., 2001; Katzmann et al., 2003; MacDonald et al., 2012b; Odorizzi et al., 1998; Oestreich et al., 2006; Reggiori and Pelham, 2001). Although all Bro1 mutants were expressed to levels similar to WT Bro1, none of the mutant strains (brol ${ }^{M 4}$, brol $^{M 8}$, brol $^{M 9}$, and brol $^{M 10}$ ) mediated MVB sorting of any cargo (Figure 6A-C, Figure S3B). The correlation between these defects in MVB cargo sorting and altered Vps4 stimulation observed with these mutants at higher concentrations support the conclusion that proper Bro1 V domain stimulation of Vps4 is required for ESCRT-driven MVB cargo sorting in vivo.

Dual axis electron tomography was used to examine how loss of normal Bro1-stimulated Vps4 activity altered the formation of ILVs (Figure 7A). ILVs of mutant brol $^{M 8}{ }^{8}$ cells were the same size as those in WT cells. However, brol ${ }^{M 8}$ cells had roughly twice as many ILV budding intermediates per MVB compared to WT cells as well as reduction in the surface area of the budding profiles (Figure 7B, Movie S4). These observations suggest that proper stimulation of Vps4 by Bro1V contributes to ILV formation at the level of bud expansion.

We also tested whether Bro1 stimulation of Vps4 regulation affected the steady-state membrane association of ESCRT-III, which is a measure of the polymeric state of ESCRT-III subunits. Subcellular fractionation of $b r o l^{M 4}$ and $b r o l^{M 8}$ cells showed WT levels of the ESCRT-III subunit Snf7 on membranes in contrast to brol $\Delta$ cells that showed more soluble Snf7 (Figure 8). These findings suggest that ESCRT-III polymerization and disassembly/recycling were normal in brol $^{M 4}$ and bro $1^{M 8}$ cells, implying that Bro1V-mediated Vps4 stimulation exerts its function at a different biochemical step.

\section{$U b$ binding enhances Brol $V$ domain stimulation of Vps4 activity in vitro}

Bro1 binds $\mathrm{Ub}$ via a conserved motif at the amino-terminal portion of the $\mathrm{V}$ domain (Figure S4A, S4B) (Pashkova et al., 2013). While Bro1 has been implicated as a Ub-sorting receptor (Pashkova et al., 2013), whether Ub-binding impacts other aspects of MVB biogenesis is unclear. Therefore, we examined if Ub-binding to the $\mathrm{V}$ domain impacts its stimulation of Vps4 (Figure 9A). While Ub does not directly stimulate Vps4 in vitro, addition of Ub to ATPase reactions increased Bro1V-stimulation of Vps4 activity using Bro1V from both $S$. cerevisiae and the related yeast $S$. castellii, for which the crystal structure is known (Pashkova et al., 2013). In contrast, addition of $\mathrm{Ub}$ to mutant Bro1 $\mathrm{V}^{\Delta \mathrm{UBD}}$ (I377R) in which Ub-binding was ablated had no effect on Vps4 stimulation. These results indicate a conserved mode of Ub-dependent regulation of the V domain's impact on Vps4. 
We next examined how Ub impacts the stimulation of Vps4 by Bro1V using titration experiments in presence or absence of $\mathrm{Ub}$ (Figure 9B). Ub increased the potency of Bro1V wherein the Bro1V concentration yielding half-maximal stimulation of Vps4 was reduced from $1.0 \mu \mathrm{M}$ to $0.4 \mu \mathrm{M}$. We also examined the impact of Ub-bound Bro1V on Vps4 oligomer assembly and/or activity of the assembled Vps4 oligomer. In these experiments, Vps4 titration was performed in the presence of $\mathrm{Ub}$ and either WT Bro1V or a Bro1 V mutant unable to bind $\mathrm{Ub}$, Bro1V $^{\Delta \mathrm{UBD}}$ (L386R). Whereas both WT Bro1V and Bro1V ${ }^{\Delta \mathrm{UBD}}$ similarly reduced the apparent $\mathrm{K}_{\mathrm{m}}$ of $\mathrm{Vps} 4$, addition of Ub to WT Bro1V, but not to Bro1 $\mathrm{V}^{\Delta \mathrm{UBD}}$, further reduced the Vps4 apparent $\mathrm{K}_{\mathrm{m}}$ (Figure 9C, 9D, S4C). These results suggest that Ub-binding alters V domain conformation to enhance its association with Vps4 and promote Vps4 oligomerization without impacting activity of the assembled Vps4 oligomer.

We next tested whether the Bro1V mutants defective for Vps4 stimulation retained their capacity to bind $\mathrm{Ub}$ as well as undergo Ub-mediated enhancement of Vps4 stimulation. The Bro1 V mutants impacting Vps4 stimulation are not confined to a single surface nor do they disrupt association with Vps4, suggesting that these mutations alter the conformation or dynamics of the $\mathrm{V}$ domain, which in turn is used to stimulate Vps4. Whereas Bro1V(I377R) failed to bind Ub, Bro1V $^{\mathrm{M} 4}$, Bro1V ${ }^{\mathrm{M} 8}$, Bro1V ${ }^{\mathrm{M} 10}$, and WT Bro1V all bound Ub (Figure S4B, S4D). The Bro1V ${ }^{\mathrm{M} 4}$, Bro1V ${ }^{\mathrm{M} 8}$, and Bro1 $\mathrm{V}^{\mathrm{M} 10}$ mutants defective in $\mathrm{Vps} 4$ stimulation also showed none or diminished Ub-mediated enhancement of Vps4 stimulation (Figure 9E). Together these results demonstrate that $\mathrm{Ub}$ enhances $\mathrm{V}$ domain activity in a manner dependent on $\mathrm{V}$ domain $\mathrm{Ub}$-binding and $\mathrm{V}$ domain stimulation of Vps4.

\section{Ub promotes ILV formation via the Brol/Vps4/ESCRT-III axis.}

Bro1 has been proposed to work early in the MVB sorting process as a receptor for Ub-cargo. Defects in cargo sorting by Bro1 mutants defective in Ub-binding are revealed when a parallel cargo recognition pathway mediated by ESCRT-0 is compromised (Pashkova et al., 2013). Because this function is upstream of the Vps4/ESCRT-III ILV formation axis, it was not clear whether Ub-binding to Bro1V might play a functional role in downstream events. Since Bro1 lacking its BOD drives ILV formation without efficient cargo sorting, we examined whether Ubbinding might contribute to this latter activity by following NBD-PC sorting. Cells expressing Bro1 $^{\triangle \mathrm{BOD}}$ defective for Ub binding ( $\triangle \mathrm{UBD}$ : I377R, L386R) showed reduced levels of NBD-PC sorting in comparison with WT indicating that $\mathrm{Ub}$ may play a role in ILV formation itself (Figure 9F); similar results were observed with deletion of the Ub-binding residues (aa388-844, Figure S2B). In addition, mutant Bro $1^{\triangle \mathrm{BOD}, \mathrm{M} 8}$ which contains a V domain unable to properly stimulate Vps4 showed a further reduction in NBD-PC sorting, barely above sorting observed in brol $\triangle$ cells. These degrees of NBD-PC sorting with Bro $1^{\triangle \mathrm{BOD}, \triangle \mathrm{UBD}}$ and Bro1 ${ }^{\triangle \mathrm{BOD}, \mathrm{M} 8}$ correlate with Bro1 $\mathrm{V}^{\triangle \mathrm{UBD}}$ exhibiting basal but not Ub-enhanced stimulation of Vps4 in vitro (Figure 9A). These results indicate that 1) $\mathrm{V}$ domain stimulation of $\mathrm{Vps} 4$ contributes to Bro1 ${ }^{\triangle \mathrm{BOD}}$ ILV formation, and 2) Bro1 Ub-binding enhances ILV formation via the Bro1/Vps4/ESCRT-III axis.

\section{Discussion}

Here we reveal a new function of Bro1 in MVB biogenesis that is mediated by its V domain binding to and stimulating Vps4 (Figure 10). This stimulation is further enhanced by Ub-binding, indicating that Bro1 interaction with Ub-cargo may regulate Vps4 activity via this biochemical mechanism. Moreover, this mode of Vps4 regulation is important for proper ILV formation and 
cargo sorting into ILVs. These data suggest Bro1 plays a role in "licensing" ESCRT-III and Vps4 to drive membrane remodeling in concert with cargo transfer into the ILV. The idea that Bro1 couples cargo sorting with ILV formation is underscored by the observations here and elsewhere that disconnecting Brol from some of its interactions separates the process of ILV formation with the process of efficiently sorting cargos into those ILVs. We propose that the central Bro1 activity of the V domain stimulating Vps4/ESCRT-III-driven ILV formation is coordinated with BOD and PRR activities to properly time ILV budding to enable normal MVB biogenesis.

Bro1 is one of several proteins that regulate Vps4 activity. Vta1 and ESCRT-III subunits also stimulate Vps4 activity (Azmi et al., 2006; Azmi et al., 2008; Merrill and Hanson, 2010; Shim et al., 2008), but do so by connecting differently to Vps4. We found that the Bro1 V domain binds to the Vps4 MIT domain and increases Vps4 specific activity by reducing its apparent $\mathrm{K}_{\mathrm{m}}$, suggesting that Bro1V facilitates Vps4 oligomerization. The Vps4 MIT domain also binds several ESCRT-III subunits along two distinct surfaces that mediate association with MIM1 and MIM2 motifs found in Vps2 or Vps24 and Vps20 or Snf7, respectively (Kieffer et al., 2008; Obita et al., 2007; Stuchell-Brereton et al., 2007). Mutations that disrupt MIM1 or MIM2 binding did not alter the ability of Bro1 V to bind the MIT domain, suggesting that Bro1 V binds by a distinct mode. Yet it remains to be determined if Bro1 V binding diminishes or enhances the ability of Vps4 to bind to MIM1 or MIM2-containing ESCRT-III subunits. Vps4 recruitment to the site of MVB sorting occurs in two phases: an early, minimal recruitment of Vps4 associated with stable ESCRT-III membrane association followed by a later recruitment of additional Vps4 implicated in ILV formation and eventual ESCRT-III disassembly (Adell et al., 2017). Our in vitro activity analyses indicate that Bro1 facilitates Vps4 oligomerization, as Bro1 V reduces the apparent $\mathrm{K}_{\mathrm{m}}$ of Vps4 itself. Yet, exactly how Bro1V regulation of Vps4 activity impacts the dynamics and function of the Vps4 substrate polymer ESCRT-III remains to be determined. Overall, the level of polymerized membrane-associated ESCRT-III remains unperturbed in cells where Bro1 is unable to properly stimulate Vps4 ATPase activity. Moreover, the size of the ILVs themselves, an indicator of the fidelity of ESCRT-III mediated scission, is unaltered as well. Together, these data suggest this role of Bro1V regulation is transient, precise and distinct from Vta1/ESCRT-III stimulation of Vps4 implicated in ILV scission and ESCRT-III disassembly. Bro1 mutants with altered Vps4 regulation did exhibit reduced budding profile size, suggesting Bro1 stimulation of Vps4 contributes to ILV bud expansion. Bud expansion controlled by Vps4 should be coordinated with entry of cargo as well as deubiquitination of cargo just prior to its entry into ILVs, and the biochemical activities now described for Brol position it well for such a role. While future studies are required to expand our understanding of Bro1's role in the Vps4/ESCRT-III ILV formation axis, our studies unequivocally demonstrate Bro1 stimulation of Vps4 makes unique contributions to MVB biogenesis.

Analyses in vitro and in vivo indicate that $\mathrm{V}$ domain mutations we characterized retain partial Vps4 stimulation activity. These mutants retain interaction with Vps4 and Ub and stimulation of Vps4 ATPase activity at lower concentrations, however these mutants are defective for MVB cargo sorting in vivo and stimulation of Vps4 ATPase activity at higher concentrations in vitro. We conclude Bro1V stimulation of Vps4 observed in vitro under high concentrations is the activity relevant for Bro1 function in MVB sorting in vivo. These mutations map to both arms of the $\mathrm{V}$ domain, suggesting they impart subtle conformational changes in $\mathrm{V}$ domain that maintain 
association with Vps4 but disrupt stimulation. Further structural studies are underway to elucidate this mechanism.

Our results also suggest that Vps4 responds to Ub through Bro1. Titration experiments indicate that Ub-binding to the V domain enhances its ability to stimulate Vps4 via facilitating Vps4 oligomerization. Previous studies demonstrated a role for Ub in MVB sorting at the level of cargo recognition (Bilodeau et al., 2002; Katzmann et al., 2001; Reggiori and Pelham, 2001) as well as the dependence of ILV formation on the presence of ubiquitylated-cargo (MacDonald et al., 2012a; Stringer and Piper, 2011). However, upstream effects on cargo recognition and early ESCRT membrane recruitment precluded examination of the role of Ub in ILV formation itself (Stringer and Piper, 2011). The present studies indicate that Ub-binding also contributes to ILV formation as disruption of Ub-binding through point mutation (Figure 9F) or deletion (Figure $\mathrm{S} 2 \mathrm{~B})$ reduced Bro ${ }^{\triangle \mathrm{BOD}}$ NBD-PC sorting into the vacuole lumen, consistent with Ub-enhanced V stimulation of $\mathrm{Vps} 4$ in vitro. The source of $\mathrm{Ub}$ in vivo remains to be determined, but could be Ub-cargo, ubiquitylated ESCRT machinery, or perhaps free Ub released from the Bro1associated ubiquitin-peptidase, Doa4 (Ali et al., 2013; Kalinowska et al., 2015; Luhtala and Odorizzi, 2004). Our results implicate a role for Ub in modulating Vps4 activity via Bro1 in addition to Ub's previously appreciated role as a cargo sorting determinant.

We suggest that Bro1 serves to "license" ILV formation, typically coordinated with cargo entry, to enable efficient MVB sorting. This licensing concept is supported by our observation that highly-expressed Bro1 ${ }^{\triangle \mathrm{BOD}}$ promoted more ILV formation, as assessed by NBD-PC sorting, than Bro ${ }^{\triangle \mathrm{BOD}}$ expressed at lower levels. A broader role for $\mathrm{V}$ domains in the regulation of Vps4/ESCRT-III dependent functions is implied by our observation that the V domain from another member of the Bro1 Domain family, HD-PTP, also stimulated Vps4 activity. Bro1 Domain Family members have important yet unclear roles in myriad ESCRT-mediated processes. ALIX binds viral structural proteins, such as Gag, to facilitate retroviral budding as well as other factors (e.g., Syntenin, CEP55) to facilitate ESCRT-driven exosome biogenesis and cytokinesis (Baietti et al., 2012; Carlton and Martin-Serrano, 2007; Fisher et al., 2007; Larios et al., 2020; Lee et al., 2007b). Increased ALIX activity through over-expression or activating truncation enhance the release of HIV particles as well as small extracellular vesicles (Fisher et al., 2007; Larios et al., 2020), consistent with ALIX serving as a licensing factor for these ESCRT-mediated events as well. Mutations in HD-PTP are linked to a congenital neurodevelopment disorder characterized by seizures and spasticity (Bend et al., 2020; Sowada et al., 2017). Moreover, HD-PTP homozygous mouse knockouts are embryonic lethal, and HDPTP heterozygosity is linked to increased tumorigenesis (Gingras et al., 2009; Manteghi et al., 2016). In yeast, loss of Bro1 disrupts MVB sorting and ILV formation leading to disrupted endosomal morphology (i.e., "class E vps phenotype"). Thus, understanding the biochemical mechanism that Bro1 uses to control Vps4 has wide ranging ramifications and is likely to describe a shared function for other Bro1 Domain Family proteins (Vietri et al., 2020). 


\section{Methods:}

\section{Plasmids and Strains}

For a complete listing of plasmids utilized in this study see Supplemental Table 1. All restriction enzymes were obtained from New England BioLabs Inc. (Ipswich, MA). All PCR reaction were performed using Platinum SuperFi II PCR Master Mix (Thermo Fisher Scientific, Waltham, MA). S. cerevisiae Vps4 MIT domain was amplified from SEY6210 genomic DNA, and subsequently cloned into NdeI and SalI sites of pET28a to generate pET28-MIT. Similarly, MIT domain was amplified from pVPS4(I18D) and pVSP4(L64D) and subsequently cloned into pET28a to generate pET28b-MIT I18D and pET28b-MIT L64D. The sequence encoding the V domain of Bro1 (Bro1V, aa 370-709) was amplified from pGO216 (Wemmer et al., 2011) and cloned into the BamH1 and SalI sites of pGST-parallel1 (Sheffield et al., 1999) to generate pSD1. BRO1 was amplified from pGO187 (Odorizzi et al., 2003) and cloned into the SpeI and SalI site of pRS414 (Simons et al., 1987) to generate pSD12. Mutagenesis of Bro1V or BRO1 encoding constructs (pSD2-9, pSD13-14, pCT2, pCT4-8, pCT10, pCT13-16, pCT18, pCT20-24, pCT26, and pCT29-33 was performed using the GeneTailor Site-Direct Mutagenesis System (Life Technologies, Carlsbad, CA). The veracity of plasmids was confirmed by sequencing. The sequence encoding Bro1 $\triangle \mathrm{PRR}$ (aa 1-709) was amplified from pGO216 and cloned into BamH1 and SalI sites of pET28b (Novagen, Germany) and pGST-parallel1 for use generating and purifying the anti-Bro1 sera, respectively (see Brol antibody generation).

Two silent mutations (D133D, D153D) were introduced into the HIS3 cassette of pRS413 to remove undesired $B g l I I$ sites by site-directed mutagenesis; the resulting plasmid was named pCT34. The sequence encoding HIS3 cassette was amplified from pCT34 by PCR to introduce BamHI and PacI sites, and cloned into BglII and PacI sites of pFA6a-HisMX6; the resulting plasmid is named pCT35. The sequence encoding Bro1V (aa370-709) was amplified from SEY6210 genomic DNA, and cloned into NcoI and EcoRI sites of pCT35; the resulting plasmid is named pCT36. Subsequently, 500bp of BRO1 3'UTR was amplified from SEY6210 genomic DNA and cloned into EcoRI and SacI sites of pCT35; the resulting plasmid is named pCT37. BRO1 promoter was amplified from genomic DNA of SEY6210, and cloned into SalI and EcoRI sites of pRS414; the resulting plasmid is named pCT38. pCT38 generated by deleting BOD (aa1369) in pSD12 using GeneTailor Site-Direct Mutagenesis System. Subsequently, $\triangle U B D$ mutations (I377R L386R) were introduced by site directed mutagenesis; the resulting plasmid is named pCT39. Fragment containing M8 mutation was cloned into ClaI and NdeI site of pCT38 from pSD14; the resulting plasmid is named pCT40. TEF1p-Bro1 $\triangle B O D$ (aa370-844) was amplified from CTY2 and cloned into SalI and BamHI sites in pRS414; the resulting plasmid is named pCT41. Mutations ( $\triangle \mathrm{UBD}$ and M8) were amplified from pCT39 and pCT40 and cloned into NcoI-BamHI digested pCT41 by NEBuilder HiFi DNA Assembly (New England BioLabs Inc.). DPAP-B-GFP was cloned from pGO89 (Odorizzi et al., 1998) into NotI and SalI sites of pRS425; the resulting plasmid is DPAP-B-GFP. For a list of primers used to generate pCT34-43, please see Supplemental Table 2.

For a complete listing of strains used in this study see Supplemental Table 3. CTY1, CTY2, and CTY3 were generated by transforming PCR product from pCT34 into SEY6210.1 while CTY4 was generated by transforming PCR product from pCT36; for a list of primers used, please see Supplemental Table 2. Transformants were plated on Histidine drop-out synthetic plates, and screened by immunoblotting. The altered brol allele was amplified and sequenced. CTY5, CTY11-13, CTY518, CTY21-22, CTY24, CTY27, CTY29-30 and JPY403 were generated using standard yeast genetics. 


\section{Protein expression and purification}

Protein expression was performed in the BL21-DE3 bacterial strain using $0.5 \mathrm{mM}$ isopropyl $\beta$-d1-thiogalactopyranoside (IPTG) at $16^{\circ} \mathrm{C}$ for $18-22 \mathrm{hrs}$. GST-Bro1V fusion protein and mutants thereof were purified using the Glutathione Sepharose 4B (GE Healthcare, United Kingdom), treated with AcTEV protease (Thermo Fisher Scientific, Waltham, MA) overnight at room temperature to remove the GST tag, incubated with ATP to dissociate chaperones, and subjected to size-exclusion chromatography (Superdex200 HiLoad 16/60) in 25mM HEPES and 150mM $\mathrm{KCl}$. Purified proteins were tested for purity using SDS-Page and Coomassie staining and were analyzed to exclude contaminating ATPase activity (data not shown). All Bro1V mutants examined in this study exhibited equivalent expression levels in bacteria (data not shown) and mutants expressed in yeast were at levels similar to WT (Figure 6b). GST-Vps4 was expressed and purified as previously described for use in the ATPase assays (Babst et al., 1997). His $6_{6}$-Vps4 was purified as previously described (Davies et al., 2014), except the His ${ }_{6}$ fusion tag was not cleaved in order to use $\mathrm{His}_{6}{ }_{-} \mathrm{Vps} 4$ in the In vitro Binding Assays. His-Bro1 $\triangle \mathrm{PRR}$ purified from BL21-DE3 using $\mathrm{Ni}^{2+}$-affinity chromatography (5ml HiTrap Chelating FF column; GE Healthcare, United Kingdom). GST-Bro1V(370-709) was purified using the Glutathione Sepharose 4B (GE Healthcare, United Kingdom) and eluted with reduced glutathione (Thermo Fisher Scientific, Waltham, MA). V domains of S. castellii Bro1 and human HD-PTP were produced in $E$. coli BL21 (DE3) were purified by TALON-Co ${ }^{2+}$ and size exclusion chromatography and cleaved from their 6xHis tag with AcTEV protease (Pashkova et al., 2013). Mono-Ub was expressed in E. coli BL21 (DE3) from pPL5293. The protein was purified from bacterial cell lysate by precipitation with 5\% Perchloric acid and CMC cation exchange chromatography in $0.05 \mathrm{M}$ ammonium acetate buffer $\mathrm{pH} 4.5$ followed by elution with $0.1 \mathrm{M}$ ammonium acetate buffer pH 5.5 (Sundd et al., 2002).

\section{Antibody generation}

Anti-Snf7 antiserum was generated against GST-Snf7. Antiserum was generated in a New Zealand rabbit (Covance, Princeton, NJ). Bleeds were evaluated for detection of Snf7 (SEY6210 and $s n f 7 \Delta$ ). The Snf7 antibody was used at 1:5,000. Anti-Bro1 antiserum was generated against His $_{6}$-Bro1 $\triangle \mathrm{PRR}$. Antiserum was generated in a New Zealand rabbit (Covance, Princeton, NJ). Antibodies were purified using GST-Bro1 $\triangle$ PRR immobilized on an AminoLink column (Thermo Fisher Scientific, Waltham, MA) and verified for sensitivity and specificity using yeast extracts (SEY6210 and bro1 $\Delta$ ) and recombinant Bro1V. The purified Bro1 antisera was used at $1: 1,000$.

In vitro binding assays

Ni-NTA Agarose beads (Qiagen, Germany) $+/-\mathrm{His}_{6}{ }^{-} \mathrm{Vps} 4(10 \mu \mathrm{g})$ was incubated for $1 \mathrm{hr}$ at $4^{\circ} \mathrm{C}$ in $\mathrm{NiA}$ buffer $\left(25 \mathrm{mM} \mathrm{NaH}_{2} \mathrm{PO}_{4}, 300 \mathrm{mM} \mathrm{NaCl}, \mathrm{pH} 7.5\right)$, washed with $\mathrm{NiA}$ buffer, and equilibrated with ATPase buffer (see ATPase assay). Binding reactions were performed in Handee Spin Columns (Pierce) with $6 \mu \mathrm{g}$ Bro1V or mutants in ATPase buffer $+0.02 \%$ Tween 20 incubated for 1 hour at $30^{\circ} \mathrm{C}$. Reactions were washed four times with NiA buffer with $10 \mathrm{mM}$ imidazole (Sigma Aldrich, St. Louis, MO), and the bound material was eluted with NiA buffer with 200mM imidazole. Instant-Bands Protein Stain (EZBiolab, Parsippany, NJ) were used to visualize input and eluted material on a Typhoon FLA 7000 (GE Healthcare, United Kingdom). Samples were resolved via SDS-PAGE, and detected using immunoblotting against Bro1. Bro1V 
input and $\mathrm{His}_{6}$-Vps4 were detected via SDS-PAGE followed by Coomassie staining (data not shown).

Glutathione Sepharose 4B GST-tagged protein purification resin (Cytiva Life Sciences, Marlborough, MA) +/- lysate from E. coli BL21 (DE3) expressing GST-tagged Bro1 fragments were incubated for $1 \mathrm{hr}$ at $4^{\circ} \mathrm{C}$ in PBS, washed with PBS and equilibrated with ATPase buffer. Binding reactions were performed in Handee Spin Columns with $\mathrm{His}_{6}{ }_{6}{ }^{-V p s} 4$ in ATPase buffer + $0.02 \%$ Tween 20 incubated for 1 hour at $30^{\circ} \mathrm{C}$. Reactions were washed six times with PBS + $0.02 \%$ Tween 20 , and the bound material was eluted with GST elution buffer (10mM reduced glutathione, 50mM Tris-HCl, pH8.0). Instant-Bands Protein Stain were used to visualize input and eluted material on a Typhoon FLA 7000. Samples were resolved via SDS-PAGE, and His ${ }_{6}^{-}$ Vps4 was detected using Penta-His Antibody (Qiagen, Germany) per manufacturer instruction. Three or more independent experiments were performed with each experiment performed in replicates within the experiment and representatives are shown.

\section{ATPase assays}

Measurement of Vps4 ATPase activity was performed in ATPase buffer (20 mM HEPES, 100 $\mathrm{mM}$ KOAc, 5mM MgOAc, pH 7.5) as previously described (Azmi et al., 2008; Babst et al., 1998; Davies et al., 2010; Davies et al., 2014; Norgan et al., 2013; Tan et al., 2015). All reactions were incubated at $30^{\circ} \mathrm{C}$ for 30 minutes prior to initiation by ATP addition ( $4 \mathrm{mM}$ final concentration). Images were captured using a Typhoon FLA 7000 (GE Healthcare, United Kingdom). Vps4 titration data represent ATPase activities from a minimum of three independent experiments with each experiment performed in duplicates. Data represent ATPase activities from a minimum of three independent experiments with each experiment performed in replicates within the experiment. Data was graphed and statistical significance was assessed by T tests using Prism 5 (GraphPad, San Diego, CA). The Vps4 concentration used was $0.5 \mu \mathrm{M}$ because this concentration of Vps4 exhibits sub-maximal specific activity. ATPase assays in the presence of ubiquitin were performed with the minimal concentration $(50 \mu \mathrm{M})$ yielding maximal enhancement.

\section{ESCRT-III disassembly assays}

ESCRT-III disassembly assays were performed as previously described (Davies et al., 2010; Tan et al., 2015). Briefly, spheroplasted yeast (vps4 $\Delta$ pep $4 \Delta$ brol $\Delta$ ) were lysed with a Dounce homogenizer in 20mM HEPES, 200mM Sorbitol, 50mM KOAc, 2mM EDTA, pH 6.8, and subjected to a 5 minute, 500xg clearing spin. The resulting supernatant was then spun 10 minutes at 13,000xg. Using Disassembly Assay buffer (20mM HEPES, 100mM KOAc, 5mM MgOAc, $200 \mathrm{mM}$ Sorbitol, $\mathrm{pH} 7.4$ with protease inhibitors), the pelleted membranes were washed and then resuspended at $50 \mathrm{OD}_{600}$ equivalents $/ \mathrm{ml}$. Reactions were setup with $0.5 \mathrm{OD}_{600}$ equivalents $/ \mathrm{ml}$, an ATP regeneration system (1mM ATP) and various amounts of Vps4 and Bro1 V. Vps4 and Bro1V were allowed to preincubate prior to reaction initiation. The reactions were initiated by brief centrifugation followed by incubation at $30^{\circ} \mathrm{C}$ for $10 \mathrm{~min}$. Reactions were terminated by centrifugation at $13,000 \mathrm{xg}$ for $10 \mathrm{~min}$. immunoblotting analysis was used to assess the levels of Snf7 in the pellet and soluble fractions. Snf7 was detected using anti-Snf7 polyclonal antibody (1:5000), HRP-conjugated Goat anti- Rabbit IgG (Life Technologies, Carlsbad, CA, 1:30,000) and the UVP Autochemi System (Upland, CA) and quantified using ImageQuant software (GE Healthcare, United Kingdom). Linearity of the signal was confirmed via image histograms. Disassembly assay data represent three independent experiments with each experiment 
performed in replicates within the experiment. Data was graphed and statistical significance was assessed by T tests using Prism 5 (GraphPad, San Diego, CA). Data are graphed as the mean with the standard error of the mean, and representative immunoblots are shown.

\section{Fluorescence microscopy}

For live-cell imaging of cells expressing GFP-tagged cargoes were grown in minimal media at $30^{\circ} \mathrm{C}$ to mid-log phase $\left(0.5 \mathrm{OD}_{600}\right)$ for live-cell fluorescence microscopy. Mup1-GFP induction was accomplished by adding $50 \mu \mathrm{M}$ copper sulfate/chloride, as previously described (MacDonald et al., 2015). Co-labelling with FM4-64 and C6-NBD-PC (1-palmitoyl-2-(6-((7-nitro-2-1,3benzoxadiazol-4-yl)amino)hexanoyl)-sn-glycero-3-phosphocholine; Avanti Polar Lipids, Alabaster, AL) was performed by growing cells in YPD or Synthetic Media containing $1 \mu \mathrm{M}$ C6NBD-PC and 250nM FM4-64 for 30 minutes at $30^{\circ} \mathrm{C}$. Cells were then harvested at mid-log phase and imaged. Images were captured at room temperature using an Olympus IX70-S1F2 fluorescence microscope (Center Valley, PA) equipped with an Olympus UPIanApo 100x numerical aperture 1.35 oil objective with the complementing immersion oil $(\mathrm{N}=1.516$, Applied Precision, Issaquah, WA), Standard DeltaVision filters FITC and Rhodamine, and Photometrics CoolSNAP HQ CCD monochrome camera (Teledyne photometrics, Tucson, AZ). Image was acquired using Delta Vision softWoRx (version 3.5.1, Applied Precision, Issaquah, WA) and subsequently processed by FiJi (version: 2.1.0/1.53c, National Institutes of Health, Bethesda, MD) (Schindelin et al., 2012). Captured images were exported under the standard DeltaVision file format and converted into 16-bit TIFF images by using Bio-Formats Importer available within Fiji. The contrast and brightness of images were subsequently adjusted within Fiji as well. Images were captured on three different days using two different sets of transformations. Verification of Bro1 and mutant Bro1 expression in these cells was confirmed by immunoblotting. Cells with WT cargo sorting signal were scored manually. Data represent quantification from a minimum of three independent labeling experiments with each experiment quantified at least 100 cells. Statistical significance was assessed by T tests using Prism 5 (GraphPad, San Diego, CA).

\section{Cargo GFP liberation analysis}

Cells expressing GFP-tagged cargoes grown in minimal media at $30^{\circ} \mathrm{C}$ to mid-log phase $\left(0.5 \mathrm{OD}_{600}\right)$ were harvested and treated with $0.2 \mathrm{M}$ sodium hydroxide for 5 minutes. Subsequently, cells were resuspended in urea buffer (40 mM Tris- $\mathrm{HCl}$, pH 6.8, $8 \mathrm{M}$ urea, 15\% SDS w/v, 0.1 $\mathrm{mM}$ EDTA, $1 \% \beta$-mercaptoethanol v/v, $0.01 \%$ bromophenol blue w/v) and lysed with glass bead for 5 minutes (Katzmann et al., 1999). Sample were resolved via SDS-PAGE and immunoblotted for GFP (Roche AG, Basel, Switzerland, 1:1,000) and Pgk1 (Life Technologies, Carlsbad, CA, $1: 10,000)$.

\section{Subcellular fractionations}

Subcellular fractionations were performed by osmotic lysis as previously described (Dimaano et al., 2007), except the cell extracts were centrifuged at $13,000 \mathrm{xg}$ for $10 \mathrm{~min}$ at $4^{\circ} \mathrm{C}$ to separate the soluble and pellet fractions (Tan et al., 2015). Samples (0.1 or $0.2 \mathrm{OD}_{600}$ equivalents) were resolved via SDS-PAGE and immunoblotted for Snf7 (this study, 1:5,000), Vps4 ((Babst et al., 1997), 1:1000), Bro1 (this study, 1:1,000). Pgk1 (Life Technologies, Carlsbad, CA, 1:10,000), and Pep12 (Life Technologies, Carlsbad, CA, 1:1,000). Immunoblots were developed using HRP-conjugated Goat anti-Rabbit (Life Technologies, Carlsbad, CA, 1:30,000) or Goat anti- 
Mouse (Life Technologies, Carlsbad, CA, 1:1,000), SuperSignal West Pico and SuperSignal West Femto substrates (Thermo Fisher Scientific, Waltham, MA), and the UVP Autochemi System (Upland, CA). Signal was quantified using ImageQuant software (GE Healthcare, United Kingdom). Signal linearity was confirmed via image histograms. Data represent three or more independent experiments (representative immunoblots are shown) and are graphed as mean with standard error of the mean. Statistical significance was assessed by T tests using Prism 5 (GraphPad, San Diego, CA).

Statistical Analysis

Statistical significance was assessed by parametric unpaired two-tailed Student's T test.

\section{Molecular modeling}

Molecular graphics and analyses of the $S$. castellii Bro1 V domain (Protein Data Bank ID: 4JIO, chain A) were performed with the UCSF Chimera package and PyMOL (Pettersen et al., 2004; Schrödinger). Chimera was developed by the Resource for Biocomputing, Visualization, and Informatics at the University of California, San Francisco (supported by NIGMS P41GM103311).

\section{Dual axis electron tomography}

Yeast cells were high-pressure frozen (HPF) and freeze-substituted (FS) as previously described (Buysse et al., 2020; Johnson et al., 2017). Liquid cultures were harvested during log phase and filtered with 4.5-micron Millipore paper, collected into $0.5 \mathrm{~mm}$ aluminum hats, high pressure frozen with a Wohlwend HPF (Wohlwend, Switzerland), and transferred to FS media kept at liquid nitrogen temperature until cryo-fixation. Cells were then freeze-substituted in an AFS (Automated Freeze-Substitution machine, Leica Vienna, Austria) at $-90^{\circ} \mathrm{C}$ in cryo media made from $0.1 \%$ uranyl acetate $0.25 \%$ glutaraldehyde in anhydrous acetone, washed in pure acetone, and embedded at $-60^{\circ} \mathrm{C}$ in Lowicryl HM20 (Polysciences, Warrington, PA). Samples were polymerized at $-60^{\circ} \mathrm{C}$ with and warmed slowly over four days. Plastic blocks were trimmed, and sections were cut in $80 \mathrm{~nm}$ thin sections and $250 \mathrm{~nm}$ thick sections with a Leica UC6 ultramicrotome and placed on Rhodium-plated copper slot grids (Electron Microscopy Sciences, Hatfield, PA) for thin section transmission electron microscopy (TEM) and thick section electron tomography (ET). TEM of hundreds of cells per strain is used to quality control freezing, embedding, and staining for tomography (Richter et al., 2013). Tomographic samples are en bloc stained with $0.1 \%$ uranyl acetate and $0.25 \%$ glutaraldehyde only, with no additional post staining as before (Giddings, 2003). 100 cells were surveyed before at least 10 representative cells were selected to gather the tomography.

Thick sections were labeled with $15 \mathrm{~nm}$ fiducial gold on both sides and mapped on a Phillips CM10 (TEM; Mahwah, NJ) at 80-kv and tilt-imaged with a Tecnai 30 (300kV FEI; Beaverton, $\mathrm{OR}$ ) with dual tilt series images collected from +60 to -60 degrees with 1 degree increment using a Gatan US4000 4k x 4k CCD camera. Tilt-series were shot at 19,000 times magnification with a $0.6534 \mathrm{~nm}$ working pixel (binning 2) and repeated at a 90 degree rotation for dual-axis tomography. Tomograms and models were constructed using IMOD software package (Kremer et al., 1996). 
MVB membrane models from dual-axis electron tomograms are manually assigned from the inner leaflet every $4 \mathrm{~nm}$ and calculated using Imodmesh (3DMOD). We designated budding profiles (BPs) by their negative curvature since the majority of endosome limiting membrane curvature is positive, or spherical in shape. BP models are drawn from the $0^{\circ}$ rim at the outer leaflet, measured, and sorted by surface area using only BPs that have more than $750 \mathrm{~nm}^{2}$ or approximately half of the mean ILV surface (Wemmer et al., 2011). ILVs are spherical and measured using sphere-fitting models from the vesicle's outer leaflet (the inner leaflet of the MVB limiting membrane) and ILV diameters are measured using these sphere models. Movies were made using IMOD and QuickTime (Apple, Cupertino, CA). Data were analyzed and graphed using Prism 5 (GraphPad, San Diego, CA).

\section{Acknowledgements:}

We would like to acknowledge Drs. Gina Razidlo and Jason Tan (Mayo Clinic, Rochester) for their inquiries and thoughtful discussions. SD, CT contributed to these studies as members of the Biochemistry and Molecular Biology Graduate Program and received financial support from the Mayo Clinic Graduate School of Biomedical Sciences. JS contributed to these studies as a member of the Mayo Clinic Summer Undergraduate Research Program and received financial support from the Mayo Clinic Graduate School of Biomedical Sciences. The authors declare no competing financial interests.

Author Contributions: Brian A. Davies, Ishara F. Azmi and David J. Katzmann conceived of the study. Chun-che Tseng, Shirley Dean, Brian A. Davies, and David J. Katzmann designed and conducted the experiments along with Johanna A. Payne, Jennifer Staffenhagen, Natalya Pashkova, Robert C. Piper, Matt West, and Greg Odorizzi. David J Katzmann, Robert C. Piper, Chun-che Tseng, and Brian A. Davies wrote the manuscript. All authors reviewed the results and approved the final version of the manuscript.

\section{Funding:}

This research was supported, in whole or in part, by National Institutes of Health Grant R01 GM116826 (to D.J.K.), R01 GM065505 (to G.O.), R01 GM58202 (to R.C.P) and by a Fraternal Order of the postdoctoral fellowship (to B.A.D.). SED was supported by the National Science Foundation Graduate Research Fellowship under Grant No. (DGE-NSF-01-02). CT was supported by the Mayo Clinic Sydney Luckman Family Predoctoral Fellowship. JS was supported by the Mayo Clinic Summer Undergraduate Research Fellowship. The authors declare that they have no conflicts of interest with the contents of this article. The content is solely the responsibility of the authors and does not necessarily represent the official views of the National Institutes of Health. Any opinion, findings, and conclusions or recommendations expressed in this material are those of the authors(s) and do not necessarily reflect the views of the National Science Foundation.

\section{Figure Legends:}

FIGURE 1. Bro1 ${ }^{\triangle \mathrm{BOD}}$ supports ILV formation. (A) Three-dimensional models reconstructed from 200-nm-thick section electron tomograms of brol $\triangle$ (GOY65) and brol $^{\triangle B O D}$ (brol $\triangle:: T E F 1$ p-brol $\triangle B O D ;$ CTY2) cells. The brol $\triangle$ cells have class E compartments, which are flattened stacks of endosomal membranes that generally lack internal vesicles; these stacks are shown in different colors to differentiate individual membranes. For brol $\triangle B O D$, the limiting 
membrane of MVBs are labeled yellow, the ILVs are highlighted in red, and the vacuole limiting membrane is labeled as red mesh. Scale bar $=100 \mathrm{~nm}$. (B) WT (SEY6210), brol $\triangle$ (GOY65), and brol $^{\triangle B O D}$ (CTY2) were analyzed by electron tomography and quantified for number of ILV per MVB. * indicates statistically significant differences compared to WT and brol $\triangle$. (C) WT (SEY6210), and bro1 $\triangle B O D$ (CTY2) were analyzed by electron tomography and quantified to assess ILV size (diameter), individual budding profile size (surface area) and the frequency of incomplete ILV budding events (budding profiles per MVB). A minimum of 13 MVBs and 337 ILVs from at least 10 cells were quantified. Error bars indicate S.E.M. * indicates statistically significant differences compared to WT.

FIGURE 2. Bro1 $\triangle$ BOD does not support efficient MVB cargo sorting. (A) WT (SEY6210), bro1 $\triangle$ (GOY65), or bro1 ${ }^{\triangle B O D}$ (brol $\triangle:$ TEF1p-brol $\triangle B O D$; CTY2) cells were transformed with the indicated GFP-tagged cargo plasmid to assess MVB sorting using live cell fluorescence microscopy. Percentage of cells with WT sorting signal was quantified and calculated from at least 183 cells from four independent experiments performed on four different days from three different transformations. White dashed lines indicate cell boundaries. Scale bar $=5 \mu \mathrm{m}$. (B-C) Representative immunoblots showing expression levels of GFP-tagged cargo, liberated GFP and

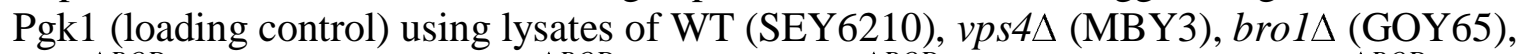
brol $^{\triangle B O D}$ (brol $\triangle:$ TEF1p- brol ${ }^{\triangle B O D}$; CTY2), brol ${ }^{\triangle B O D}$ snf7 $(\mathrm{CTY} 12)$, or brol ${ }^{\triangle B O D}$ vps $4 \triangle$ (CTY5) cells transformed with Sna3-GFP (B) or Mup1-GFP (C). Data was quantified from four independent experiments performed on four separate days from two transformations. Error bars indicate S.D. * indicates statistically significant difference. \# indicates statistically significant difference compared to WT.

FIGURE 3. Bro1 $\triangle B$ BD sorting of NBD-PC into the vacuolar lumen is dependent on Vps4/ESCRT machinery. (A) Domain cartoon of Bro1 (amino acids 1-844) with interacting factors annotated. (B) Sample micrographs of WT (SEY6210), brol $\triangle$ (GOY65), and brol $\triangle B O D$ (brol $\triangle:: T E F 1$ p- brol ${ }^{\triangle B O D}$; CTY2) cells co-stained with NBD-PC and FM4-64 revealing endpoints of the observed phenotypes. Scale $=5 \mu \mathrm{m}$. (C) NBD-PC and FM4-64 stained WT

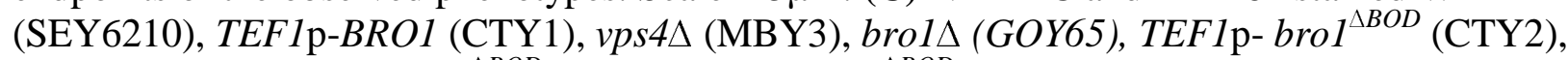

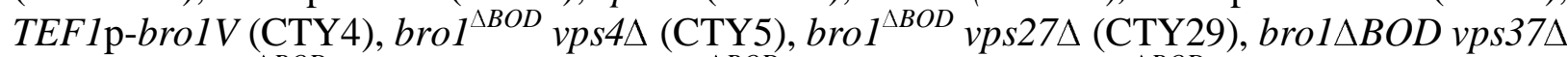
(CTY21), bro1 ${ }^{\triangle B O D}$ vps22 $\left(\right.$ CTY24), brol ${ }^{\triangle B O D}$ snf7 $\triangle$ (CTY12), brol ${ }^{\triangle B O D}$ vps4 4 (CTY5), and brol $^{\triangle B O D}$ doa4 $\triangle(\mathrm{CTY} 13)$ cells were analyzed by live cell fluorescence microscopy and quantified for the frequency of cells able to support NBD-PC trafficking to the vacuolar lumen. Error bars indicate S.E.M. * indicates statistically significant differences. \# indicates statistically significant difference compared to brol $\triangle$. Percentage of cells with WT sorting signal was quantified and calculated from at least 94 cells from four independent experiments performed on four different days. White dashed lines indicate cell boundaries. Scale bar $=5 \mu \mathrm{m}$. (D, E) brolV (CTY4) were analyzed by electron tomography and ILVs per MVB were quantified. 3D reconstructions of the tomogram are shown in (D). The limiting membrane of normal-like MVBs are labeled yellow, while the limiting membrane of tubular/aberrant MVBs are shown in different colors. ILVs are highlighted in red, A minimum of $13 \mathrm{MVBs}$ from at least 10 cells were quantified. Scale bar $=100 \mathrm{~nm}$. (F) WT (SEY6210), brol $\triangle$ (GOY65), or brolV (bro1 $:$ :TEF1pbrolV; CTY4) cells were transformed with the GFP-CPS plasmid to assess MVB sorting using live cell fluorescence microscopy. Percentage of cells with WT sorting signal was quantified and calculated from at least 156 cells from three independent experiments performed on three 
different days from two different transformations. White dashed lines indicate cell boundaries. Scale bar $=5 \mu \mathrm{m}$.

FIGURE 4. V domain stimulates Vps4 ATPase activity in vitro. (A) GST-Bro1 fragments and GST bound beads were incubated with $\mathrm{His}_{6}-\mathrm{Vps} 4$. Bound material was visualized by both EZBiolab Instant-Band Protein Stain and immunoblotting with penta-His antibody. (B) His $6^{-}$ Vps4, His ${ }_{6}$-MIT and Ni-NTA beads were incubated with Bro1V. Bound material was visualized by both EZBiolab Instant-Band Protein Stain and immunoblotting with anti-Bro1 antiserum. (C) Vps4 specific activity with titration of Bro1V $(10 \mathrm{nM}-8 \mu \mathrm{M})$. Vps4 $(0.5 \mu \mathrm{M})$ ATPase assays were conducted using the indicated conditions and resolved by thin layer chromatography for quantitation and calculation of hydrolysis rates. Dashed lines indicate Vps4 specific activity for $0.5 \mu \mathrm{M}$ or $1.5 \mu \mathrm{M}$ Vps4 alone, as indicated. Bro1V alone did not exhibit measurable ATP hydrolysis. (D) Vps4 titrations were performed with or without $4 \mu \mathrm{M}$ Bro1V. Vps4 specific activity is presented. The vertical dotted line indicates the Vps4 apparent $\mathrm{K}_{\mathrm{m}}+/$ - Bro1V. (E) V domains of $S$. cerevisiae Bro1, S. castellii Bro1, and H. sapiens HD-PTP $(0.5-4 \mu \mathrm{M})$ were titrated against $0.5 \mu \mathrm{M}$ Vps4. Specific activity of Vps4 is expressed as ADP generated per Vps4 molecule per minute. Error bars indicate S.E.M.

FIGURE 5. Bro1 V domain mutations disrupt Vps4 stimulation in vitro without disrupting binding. (A) Model of the V domain based on the $S$. castellii Bro1 V domain crystal structure (Protein Data Bank ID: 4JIO, chain A) with amino acid substitution mutations impacting V domain stimulation of Vps4 indicated in red. Conserved residues that when mutated did not impact Vps4 stimulation in vitro are indicated in blue. See Supplemental Table 4 for individual mutations. (B) Stimulation of Vps4 ATPase activity $(0.5 \mu \mathrm{M})$ by $4 \mu \mathrm{M}$ Bro1 V(370-709) and Bro1V mutants represented as normalized Vps4 ATPase activity of at least three experiments done in duplicate. Error bars indicate S.D. * indicates statistically significant differences compared to WT. (C) Immobilized $\mathrm{His}_{6}-\mathrm{Vps} 4$ or Ni-NTA beads alone were incubated with Bro1V, Bro1V(M4), Bro1V(M8), Bro1V(M9), and Bro1V(M10). Bound material was visualized by immunoblotting with anti-Bro1 antiserum. (D) Vps4 $(0.5 \mu \mathrm{M})$ ATPase activities with titration

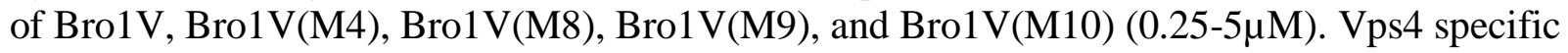
activity is expressed as ADP generated per Vps4 molecule per minute. Error bars indicate S.E.M.

FIGURE 6. Bro1 V domain mutations disrupting Vps4 stimulation in vitro disrupt MVB sorting in vivo. (A) brol $\triangle$ (GOY65) cells were transformed with empty plasmid (pRS414) or plasmids with the BRO1 promoter and BRO1, $\operatorname{brol}(M 4), \operatorname{brol}(M 8), \operatorname{brol}(M 9)$, or $\operatorname{brol}(M 10)$. Localizations of model MVB cargo GFP-Cps1, Ub-GFP-Cps1 or Sna3-GFP were determined using live cell fluorescence microscopy to assess MVB sorting in these mutant contexts. White dashed lines indicate cell boundaries. Scale bar $=5 \mu \mathrm{m}$. (B) Percentage of cells with WT sorting signal was quantified and calculated from at least 100 cells from three independent experiments performed on three different days from three different transformations. (C) Representative immunoblots showing mutant protein expression levels, probing against Bro1 and PGK1 as a loading control, using lysates of GOY65 transformed with empty plasmid (pRS414) or plasmids with the BRO1 promoter and BRO1, brol(M4), brol(M8), brol(M9), or brol(M10).

FIGURE 7. Bro1(M8) perturbs ILV formation in vivo. (A) Three-dimensional models reconstructed from 200-nm-thick section electron tomograms of brol $(\mathrm{GOY} 65)$ with $\mathrm{BRO1}$ or 
brol(M8) plasmids. The limiting membrane of the MVB is labeled yellow, the ILVs are highlighted in red and the budding intermediates are colored in green. Scale bar $=100 \mathrm{~nm}$. (B) Quantification of electron tomograms of GOY65 with either BRO1 or brol(M8) plotting ILV size, Budding Profile Size, and Budding Profiles per MVB. A minimum of 9 MVBs and 208 ILVs from at least 10 cells were measured. Error bars indicate S.E.M. * indicates statistically significant differences compared to WT.

\section{FIGURE 8. Bro1(M4) and Bro1(M8) display WT steady state membrane-associated} ESCRT-III in vivo. Subcellular fractionation was performed in brol $\triangle$ (GOY65) cells transformed with an empty vector or BRO1, brol(M4), or brol(M8) plasmids. vps4 $(\mathrm{MBY} 3)$ cells were used as a control highlighting the distribution upon complete loss of Vps4 function. Representative immunoblots indicating fractionation of Snf7, Bro1, and Vps4 are shown. Pep12 and Pgk1 were used as membrane and soluble markers respectively. Quantification represents six experiments; Error bars indicate S.E.M. * indicates statistically significant difference compared to brols.

Figure 9. Ubiquitin potentiates V domain stimulation of Vps4 ATPase activity. (A) Vps4 $(0.5 \mu \mathrm{M})$ ATPase specific activity in the presence of $1 \mu \mathrm{M} S$. cerevisiae Bro1V, S. cerevisiae Bro1V $^{\Delta \mathrm{UBD}}$ (I377R), S. castellii Bro1V(370-708) and S. castellii Bro1 V ${ }^{\Delta \mathrm{UBD}}$ (I377R) +/- 50 $\mu \mathrm{M}$ mono-Ub. Error bars indicate S.E.M. * indicates statistically significant difference compared to Vps4 alone. \# indicates statistically significant difference compared to Vps4 + Bro1V - Ub. (B) Bro1V titration performed in the presence of $0.5 \mu \mathrm{M}$ Vps 4 with or without $50 \mu \mathrm{M} \mathrm{Ub}$. The vertical dotted line indicates the Bro1 V concentration generating half-maximal stimulation within each context. (C) Vps4 titration $(0.05-1.0 \mu \mathrm{M})$ in the presence of $4 \mu \mathrm{M}$ Bro1V WT or Ub binding mutant (L386R) and 50 $\mu \mathrm{M} \mathrm{Ub}$. Vps4 specific activity (ADP generated per Vps4 molecule per minute) is presented. Error bars indicate mean +/- S.E.M. Vertical dotted lines indicate the Vps4 apparent $\mathrm{K}_{\mathrm{m}}$ in each context. (D) The Vps4 apparent $\mathrm{K}_{\mathrm{m}}$ of Vps4 alone, Vps4

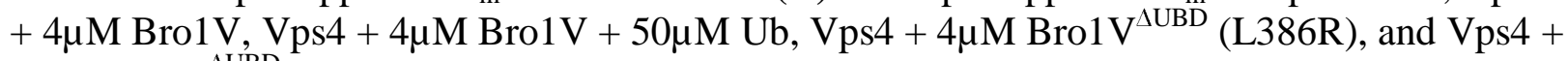
$4 \mu \mathrm{M}$ Bro1 $\mathrm{V}^{\Delta \mathrm{UBD}}+50 \mu \mathrm{M}$ Ub, was determined from Vps4 titration experiments in Figure 4D, Figure 9C, and Figure S4C. * indicates statistically significant difference. (E) Vps4 ATPase activity $(0.5 \mu \mathrm{M})$ in the presence of $4 \mu \mathrm{M} S$. cerevisiae Bro1V, Bro1 $\mathrm{V}^{\mathrm{M} 4}, \mathrm{Bro}_{1 \mathrm{~V}}^{\mathrm{M} 8}$ or Bro1 $\mathrm{V}^{\mathrm{M} 10}$ without or with $50 \mu \mathrm{M}$ of mono-Ub. Vps4 specific activity with $\mathrm{Ub}$ addition is normalized to activity without $\mathrm{Ub}$. Error bars indicate S.E.M. * indicates statistically significant difference +/Ub addition. (F) NBD-PC and FM4-64 stained WT (SEY6210), bro1 1 (GOY65) and GOY65 reexpressing Bro1 or over-expressing Bro $1^{\triangle \mathrm{BOD}}, \mathrm{Bro}^{\triangle \mathrm{BOD}, \triangle \mathrm{UBD}}$ (I377R, L386R), and Bro1 ${ }^{\triangle \mathrm{BOD}, \mathrm{M} 8}$ were analyzed by live cell fluorescence microscopy and quantified for the frequency of cells with NBD-PC in the vacuolar lumen. Error bars indicate S.E.M. * indicates statistically significant difference. \# indicates statistically significant difference compared to brolऽ.

Figure 10. Model of Bro1 "licensing" ESCRT-III membrane remodeling. (A) Bro1 interacts with ESCRTs via interactions between Proline Rich Region (PRR) and early ESCRTs (-0, -I \& II) as well as Bro1 Domain (BOD) and ESCRT-III subunit Snf7. 1) Bro1 V domain binds Vps4 MIT domain, and promotes Vps4 activity. This stimulation promotes ILV formation and is required to coordinate cargo sorting and ILV formation. 2) Stimulation of Vps4 by Bro1 V domain is further enhanced by $\mathrm{Ub}$, though the exact source of $\mathrm{Ub}$ remains unclear. (B) In the context of brol $\triangle B O D, \mathrm{~V}$ domain stimulation of $\mathrm{Vps} 4$ promotes ILV formation without efficient 
cargo sorting. (C) Vps4 and ESCRT-III cannot efficiently generate ILVs in the absence of Bro1 and MVB sorting is disrupted.

Figure S1. Representative images of cells stained with NBD-PC and FM4-64. This figure complements Figure 3. (A) Three-dimensional models reconstructed from 200-nm-thick section electron tomograms of bro1 $\triangle$ (GOY65) cells. This image depicts rare MVBs that contains an ILV. Normal like endosomes are highlighted by yellow limiting membrane, while other colors depict flattened or tubular endosomes devoid of vesicles. The ILVs are highlighted in red. Scale bar $=100 \mathrm{~nm}$. (B) Selection criteria for scoring positive NBD-PC cells. A usable cell is defined by having (1) readily identifiable FM4-64 labeling of vacuole membrane, (2) readily identifiable NBD-PC signal, and (3) defined vacuole(s). An unusable cell is defined by having (1) a fragmented vacuole, and (2) out of focus. A positive cell is defined by a diffuse NBD-PC signal within the lumen while lacking a distinct ring on the limiting membrane of the vacuole (defined by FM4-64); while a negative cell is defined by the colocalization of NBD-PC and FM4-64 on the limiting membrane of the vacuole. Scale $=5 \mu \mathrm{m}$. (C) Representative micrographs of brol $^{\triangle B O D}$

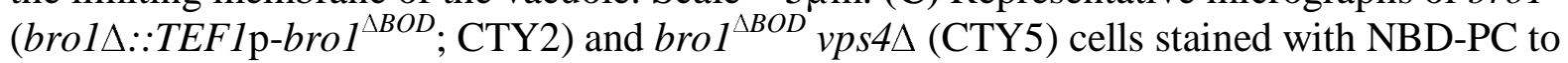
label ILVs and FM4-64 to label vacuoles. Scale $=5 \mu \mathrm{m}$.

Figure S2. bro1 ${ }^{\triangle B O D}$ supported ILV formation requires the Vps4/ESCRT machinery. This figure complements Figure 3. (A) Lysates generated from WT (SEY6210), vps4 $\triangle$ (MBY3), brol $\triangle$ (GOY65), TEF1p-BRO1 (CTY1), brol ${ }^{\triangle B O D}\left(370-844 ;\right.$ brol $\triangle:$ TEF1p-brol $^{\triangle B O D}$; CTY2), brol $^{\triangle B O D}(\triangle U B D)\left(388-844\right.$; brol $\triangle:$ TEF1p-brol ${ }^{\triangle B O D \triangle U B D}$; CTY3), TEF1p-brolV (CTY4), and brol $^{\triangle B O D}$ vps4 $\triangle$ (CTY5) cells were analyzed by immunoblotting using antibodies against Bro1, Vps4 and Pgk1. Numbers below the Bro1 blot indicates expression levels normalized to BRO1 expression. (B) WT (SEY6210), brol ${ }^{\triangle B O D}$ (370-844; CTY2), brol ${ }^{\triangle B O D \triangle U B D}$ (388-844; CTY3),

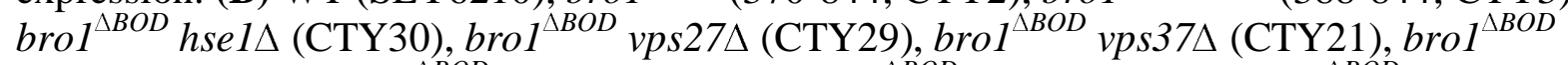
$m v b 12 \triangle(\mathrm{CTY} 22)$, brol $^{\triangle B O D}$ vps22 $\triangle$ (CTY24), brol ${ }^{\triangle B O D}$ snf7 $(\mathrm{CTY} 12)$, brol $^{\triangle B O D}$ vps $24 \Delta$ (CTY18), brol ${ }^{\triangle B O D}$ vps $2 \triangle(\mathrm{CTY} 26)$, brol $^{\triangle B O D}$ vtal $\triangle(\mathrm{CTY} 27)$, brol $^{\triangle B O D}$ vps $4 \triangle(\mathrm{CTY} 5)$, and brol $^{\triangle B O D}$ doa4 $\triangle$ (CTY13) cells were analyzed by live cell fluorescence microscopy and quantified for the frequency of cells able to support NBD-PC trafficking to the vacuolar lumen. Error bars indicate S.E.M. (C) WT (SEY6210), brolV (CTY4) were analyzed by electron tomography and quantified to assess ILV size (diameter). A minimum of $22 \mathrm{MVBs}$ and 225 ILVs from at least 10 cells were quantified. Error bars indicate S.E.M. * indicates statistically significant differences compared to WT. (D) WT (SEY6210), brol $\triangle$ (GOY65), or brol V (bro1 $\triangle:$ :TEF1p-bro1V; CTY4) cells were transformed with the indicated GFP-tagged cargo plasmid to assess MVB sorting using live cell fluorescence microscopy. White dashed lines indicate cell boundaries. Scale bar $=5 \mu \mathrm{m}$. (E) WT (SEY6210), GOY65, and GOY65 cells transformed with $B R O 1$ and $B R O 1$ p-brol $1^{\triangle B O D}$ was analyzed by live cell fluorescence microscopy and quantified for the frequency of cells able to support NBD-PC trafficking to the vacuolar lumen. Error bars indicate S.E.M. (F) Lysates generated from brol $\triangle$ (GOY65) transformed with empty vector, $B R O 1$, and $B R O 1 \mathrm{p}-b r o 1^{\triangle B O D}$, were analyzed by immunoblotting using antibodies against Bro1 and Pgk1.

Figure S3. Bro1V mutants bind Vps4. This figure complements figure 5 and 6. (A) Immobilized His ${ }_{6}$-Vps4 or Ni-NTA beads alone were incubated with Bro1V or Bro1V mutants and bound material was analyzed by immunoblotting with anti-Bro1 antiserum. (B) Mutant 
protein expression levels normalized to WT. Bro1 expression levels were normalized to Pgk1, and subsequently normalized to WT/Pgk1 ratios. Quantified from three independent experiments performed on three different days from two sets of transformations. Immunoblots were probed against Bro1 and PGK1, using lysates of GOY65 transformed with empty plasmid (pRS414) or BRO1, brol(M4), brol(M8), brol(M9), or brol(M10) plasmids. Statistical analyses did not reveal differences between WT and mutant forms of Bro1.

Figure S4. Bro1V mutants bind ubiquitin. This figure complements Figure 9. (A) Sequence alignment of V domain amino acids 370-388 from S. castellii and S. cerevisiae. Conserved amino acids are indicated by black circles, and isoleucine 377 and leucine 386 critical for Ubbinding are highlighted in red. (B) Bro1 V domain mutations M4, M8 and M10 (red) that disrupt V domain stimulation of Vps4 ATPase activity are spatially separated from its Ub-binding site using $S$. castellii Bro1V crystal structure (Protein Data Bank ID: 4JIO, chain A). (C) Vps4 titrations were performed with or without $4 \mu \mathrm{M}$ Bro1 $\mathrm{V}^{\Delta \mathrm{UBD}}$ (L386R). Vps4 specific activity is presented. The vertical dotted line indicates the Vps4 apparent $\mathrm{K}_{\mathrm{m}}+/-$ Bro1V. (D) Immobilized GST fused Bro1V, Bro1V(M4), Bro1V(M8), Bro1V(M9), Bro1V(M10), Bro1 V(I377R) and GST alone were incubated with V5 epitope-tagged linear penta-Ub. Bound material was visualized by both Ponceau S protein stain and immunoblotting for the V5 epitope. (E) Lysates generated from brol $\triangle$ (GOY65) transformed with empty vector, BRO1, TEF1p-brol ${ }^{\triangle B O D}$, TEF1p-brol ${ }^{\triangle B O D, \triangle U B D}(\triangle U B D: I 377 R, L 386 R)$ and TEF1p-bro1 ${ }^{\triangle B O D, M 8}$ plasmids were analyzed by immunoblotting using antibodies against Bro1 and Pgk1. Numbers below the Bro1 blot indicate expression levels normalized to $\mathrm{BROI}$ expression.

Movie S1. Tomogram of MVB in a bro1 $\triangle:$ TEF 1p-bro1 ${ }^{\triangle B O D}$ cell. MVBs in a bro1 $:: T E F 1 \mathrm{p}-$ brol $^{\triangle B O D}$ cell exhibits WT-like MVB morphology. This video shows nine MVBs that are adjacent to the vacuole (red mesh), while the limiting membrane of the MVB is colored yellow and the intralumenal vesicles are in red. Intermediate budding profiles are highlighted in green. Scale bar $=100 \mathrm{~nm}$.

Movie S2. Tomogram of MVB in a bro1 $\Delta$ cell. brol $\Delta$ cell has class E compartments, which are flattened stacks of endosomal membranes that generally lack internal vesicles. Cisternal class $\mathrm{E}$ compartment stacks are shown in different colors to differentiate individual membranes. The vacuolar limiting membrane is labeled red. Scale bar $=100 \mathrm{~nm}$.

Movie S3. Tomogram of MVB in a WT cell. MVBs in WT yeast are roughly spherical membrane structures that contain smaller membrane-bound vesicles. This video shows two WT MVBs that are adjacent to the vacuole (red mesh). The limiting endosomal membrane is shown in yellow, and the intralumenal vesicles are in red. Scale bar $=100 \mathrm{~nm}$.

Movie S4. Tomogram of MVB in a bro1 $\triangle$ cell expressing Bro1 ${ }^{\mathrm{M} 8}$. This tomogram depicts one MVBs in a brol $\triangle$ cell expressing Bro1 ${ }^{\mathrm{M} 8}$. This MVB contains several budding intermediates (green), while its limiting membrane is indicated by yellow and the intralumenal vesicles are labeled red. Scale bar $=100 \mathrm{~nm}$.

Movie S5. Tomogram of MVB in a bro1 $\triangle::$ TEF1 p-bro1 $V$ cell. This tomogram depicts 14 MVBs in a brol $\triangle:: T E F 1$ p-brolV cell. Majority of these MVBs exhibit normal-like MVB 
bioRxiv preprint doi: https://doi.org/10.1101/2020.07.27.223255; this version posted February 16, 2021. The copyright holder for this preprint (which was not certified by peer review) is the author/funder, who has granted bioRxiv a license to display the preprint in perpetuity. It is made available under aCC-BY 4.0 International license.

morphology (yellow), with relatively large budding profiles (green). One tubular MVB is visible (cyan). The intralumenal vesicles are in red. Scale bar $=100 \mathrm{~nm}$. 
Supplemental Table 1. List of plasmids used in this study.

\begin{tabular}{|c|c|c|}
\hline Name & Description & Reference \\
\hline pSD1 & $\begin{array}{l}\text { S. cerevisiae Bro1 V domain (Bro1V, aa 370-709) in } \\
\text { pGST-parallel1 }\end{array}$ & This study \\
\hline pSD2 & S. cerevisiae Bro1V L386R in pGST-parallel1 (M1) & This study \\
\hline pSD3 & $\begin{array}{l}\text { S. cerevisiae Bro1V S414A, D415A in pGST-parallel1 } \\
\text { (M2) }\end{array}$ & This study \\
\hline pSD4 & $\begin{array}{l}\text { S. cerevisiae Bro1V S537A, L538A, L539A in pGST- } \\
\text { parallel1 (M3) }\end{array}$ & This study \\
\hline pSD5 & $\begin{array}{l}\text { S. cerevisiae Bro1V V505A, H508A, I512A in pGST- } \\
\text { parallel1 (M4) }\end{array}$ & This study \\
\hline pSD6 & $\begin{array}{l}\text { S. cerevisiae Bro1V F446A, E451A, F452A in pGST- } \\
\text { parallel1 (M5) }\end{array}$ & This study \\
\hline pSD7 & $\begin{array}{l}\text { S. cerevisiae Bro1V D454A, E457A, K461A in pGST- } \\
\text { parallel1 (M6) }\end{array}$ & This study \\
\hline pSD8 & $\begin{array}{l}\text { S. cerevisiae Bro1V V463A, L470A in pGST- } \\
\text { parallel1 (M7) }\end{array}$ & This study \\
\hline pSD9 & $\begin{array}{l}\text { S. cerevisiae Bro1V E686A, L691D in pGST-parallel1 } \\
\text { (M8) }\end{array}$ & This study \\
\hline pSD12 & $\begin{array}{l}\text { BRO1 promoter driven } S . \text { cerevisiae Bro1 in pRS414 } \\
\text { (WT) }\end{array}$ & This study \\
\hline pSD13 & $\begin{array}{l}\text { BRO1 promoter driven } S . \text { cerevisiae Bro1 S537A, } \\
\text { L538A, L539A in pRS414 (M4) }\end{array}$ & This study \\
\hline pSD14 & $\begin{array}{l}\text { BRO1 promoter driven S. cerevisiae Bro1 V463A, } \\
\text { L470A in pRS414 (M8) }\end{array}$ & This study \\
\hline pCT4 & S. cerevisiae Bro1V T587D in pGST-parallel1 (M9) & This study \\
\hline pCT8 & S. cerevisiae Bro1V K481D in pGST-parallel1 (M10) & This study \\
\hline pCT20 & $\begin{array}{l}\text { BRO1 promoter driven } S . \text { cerevisiae Bro1 T587D in } \\
\text { pRS414 (M9) }\end{array}$ & This study \\
\hline pCT24 & $\begin{array}{l}\text { BRO1 promoter driven S. cerevisiae Bro1 K481D in } \\
\text { pRS414 (M10) }\end{array}$ & This study \\
\hline pCT33 & $\begin{array}{l}\text { S. cerevisiae Bro1 V I377R in pGST-parallel1 } \\
(\Delta \mathrm{UBD})\end{array}$ & This study \\
\hline pCT34 & $\begin{array}{l}\text { pRS413 with two silent mutations (D133D, D153D) in } \\
\text { HIS3 cassette }\end{array}$ & This study \\
\hline pCT35 & $\begin{array}{l}\text { pCT34 HIS3 Cassette (D133D, D153D) in pFA6a- } \\
\text { HisMX6 (TEF1 promoter Template Plasmid) }\end{array}$ & This study \\
\hline pCT36 & $\begin{array}{l}\text { TEF1 promoter driven S. cerevisiae Bro1V (aa370- } \\
709 \text { ) in pCT35 }\end{array}$ & This study \\
\hline pCT37 & $\begin{array}{l}\text { TEF1 promoter driven } S \text {. cerevisiae Bro1V (aa370- } \\
709 \text { ) and 500bp 3'UTR in pCT35 }\end{array}$ & This study \\
\hline pCT38 & $\begin{array}{l}\text { BRO1 promoter driven } S . \text { cerevisiae } \mathrm{Bro}^{\mathrm{ABOD}} \text { (aa370- } \\
844) \text { in pRS414 }\end{array}$ & This study \\
\hline рCT39 & BRO1 promoter driven $S$. cerevisiae $\mathrm{Bro}^{\mathrm{ABOD}} \mathrm{I} 377 \mathrm{R}$ & This study \\
\hline
\end{tabular}




\begin{tabular}{|c|c|c|}
\hline & L386R (aa370-844) in pRS414 ( $\Delta \mathrm{UBD})$ & \\
\hline pCT40 & $\begin{array}{l}\text { BRO1 promoter driven } S . \text { cerevisiae } \text { Bro }^{\mathrm{ABOD}} \text { E686A, } \\
\text { L691D (aa370-844) in } \mathrm{pRS} 414(\mathrm{M} 8)\end{array}$ & This study \\
\hline pCT41 & $\begin{array}{l}\text { TEF1 promoter driven } S \text {. cerevisiae } \mathrm{Brol}^{\mathrm{ABOD}} \text { (aa370- } \\
844 \text { ) in } \mathrm{pRS} 414\end{array}$ & This study \\
\hline pCT42 & $\begin{array}{l}\text { TEF1 promoter driven } S \text {. cerevisiae } \text { Bro1 }^{\triangle \mathrm{BOD}} \mathrm{I} 377 \mathrm{R} \\
\mathrm{L} 386 \mathrm{R}(\text { aa370-844) in } \mathrm{pRS} 414(\triangle \mathrm{UBD})\end{array}$ & This study \\
\hline pCT43 & $\begin{array}{l}\text { TEF1 promoter driven } S \text {. cerevisiae } \text { Bro1 }^{\triangle \mathrm{BOD}} \text { E686A, } \\
\text { L691D (aa370-844) in } \mathrm{pRS} 414(\mathrm{M} 8)\end{array}$ & This study \\
\hline pRS413 & $\begin{array}{l}\text { Low copy yeast shuttle plasmid containing HIS } \\
\text { marker }\end{array}$ & $\begin{array}{l}\text { (Sikorski and } \\
\text { Hieter, 1989) }\end{array}$ \\
\hline $\begin{array}{l}\text { pFA6a- } \\
\text { His3MX6 }\end{array}$ & $\begin{array}{l}\text { A. gossypii TEF1 promoter driven } S \text {. pombe HIS3 in } \\
\text { pFA plasmid }\end{array}$ & $\begin{array}{l}\text { (Longtine et al., } \\
\text { 1998) }\end{array}$ \\
\hline pRS414 & $\begin{array}{l}\text { Low copy yeast shuttle plasmid containing TRP } \\
\text { marker }\end{array}$ & $\begin{array}{l}\text { (Simons et al., } \\
\text { 1987) }\end{array}$ \\
\hline pGO216 & $B R O 1$ promoter driven Bro1 in pRS426 & $\begin{array}{l}\text { (Wemmer et al., } \\
\text { 2011) }\end{array}$ \\
\hline pMB54 & Vps4 in pGST-parallel1 & (Azmi et al., 2008) \\
\hline pET28-Vps4 & Vps4 in pET28a & (Davies et al., 2014) \\
\hline pGO642 & $\begin{array}{l}\text { BRO1 promoter driven Bro1 }{ }^{\triangle \mathrm{BOD} \triangle \mathrm{UBD}} \text { (aa 388-844) in } \\
\text { pRS426 }\end{array}$ & $\begin{array}{l}\text { (Johnson et al., } \\
\text { 2017) }\end{array}$ \\
\hline pGO187 & $B R O 1$ promoter driven Bro1 in pRS416 & $\begin{array}{l}\text { (Odorizzi et al., } \\
\text { 2003) }\end{array}$ \\
\hline GFP-Ste2 & STE2 promoter driven GFP-Ste2 in pRS426 & $\begin{array}{l}\text { (Odorizzi et al., } \\
\text { 1998) }\end{array}$ \\
\hline pPL4146 & CUP1 promoter driven Mup1-GFP in $\mathrm{pR} 315$ & $\begin{array}{l}\text { (Stringer and Piper, } \\
\text { 2011) }\end{array}$ \\
\hline pGO45 & CPS promoter driven CPS-GFP in pRS426 & $\begin{array}{l}\text { (Odorizzi et al., } \\
\text { 1998) }\end{array}$ \\
\hline Ub-GFP-CPS & CPS promoter driven Ub-CPS-GFP in pRS426 & $\begin{array}{l}\text { (Katzmann et al., } \\
\text { 2003) }\end{array}$ \\
\hline pMA24 & TDH3 promoter driven Cos1-GFP in pGDP416 & $\begin{array}{l}\text { (MacDonald et al., } \\
\text { 2015) }\end{array}$ \\
\hline pMA25 & TDH3 promoter driven Cos2-GFP in pGDP416 & $\begin{array}{l}\text { (MacDonald et al., } \\
\text { 2015) }\end{array}$ \\
\hline pMA27 & TDH3 promoter driven Cos5-GFP in pGDP416 & $\begin{array}{l}\text { (MacDonald et al., } \\
\text { 2015) }\end{array}$ \\
\hline $\begin{array}{l}\text { pRS416 Sna3- } \\
\text { GFP }\end{array}$ & SNA3 promoter driven Sna3-GFP in pRS416 & $\begin{array}{l}\text { (Reggiori and } \\
\text { Pelham, 2001) }\end{array}$ \\
\hline pGO89 & $D A P 2$ promoter driven DPAP B-GFP in pRS426 & $\begin{array}{l}\text { (Odorizzi et al., } \\
\text { 1998) }\end{array}$ \\
\hline DPAP-B-GFP & $D A P 2$ promoter driven DPAP B-GFP in $\mathrm{pRS} 425$ & This Study \\
\hline pPL4443 & S. castellii Bro1 V (aa 370-708) in pET151 & $\begin{array}{l}\text { (Pashkova et al., } \\
\text { 2013) }\end{array}$ \\
\hline pPL4981 & S. castellii Bro1V I377R (aa 370-708) in pET151 & (Pashkova et al., \\
\hline
\end{tabular}




\begin{tabular}{|l|l|l|}
\hline & $(\triangle \mathrm{UBD})$ & $2013)$ \\
\hline pPL4672 & Human HD-PTPV (aa 361-711) in pET151 & $\begin{array}{l}\text { (Pashkova et al., } \\
\text { 2013) }\end{array}$ \\
\hline pPL5293 & T7 promoter driven WT mono-Ub in pET21a & This Study \\
\hline GST-BOD & S. cerevisiae Bro1 BOD (aa 1-369) in pGST-parallel1 & This Study \\
\hline GST-BODV & $\begin{array}{l}\text { S. cerevisiae Bro1 BODV (aa 1-709) in pGST- } \\
\text { parallel1 }\end{array}$ & This Study \\
\hline GST-VPRR & $\begin{array}{l}\text { S. cerevisiae Bro1 VPRR (aa 370-844) in pGST- } \\
\text { parallel1 }\end{array}$ & This Study \\
\hline pET28b-MIT & S. cerevisiae Vps4 MIT (aa1-84) in pET28a & This Study \\
\hline pVPS4(I18D) & VPS4 promoter driven Vps4 (I18D) in pRS416 & $\begin{array}{l}\text { (Shestakova et al., } \\
\text { 2010) }\end{array}$ \\
\hline pVPS4(L64D) & VPS4 promoter driven Vps4 (L64D) in pRS416 & $\begin{array}{l}\text { (Shestakova et al., } \\
\text { 2010) }\end{array}$ \\
\hline $\begin{array}{l}\text { pET28b-MIT } \\
\text { I18D }\end{array}$ & S. cerevisiae Vps4 MIT I18D (aa1-84) in pET28a & This Study \\
\hline $\begin{array}{l}\text { pET28b-MIT } \\
\text { L64D }\end{array}$ & S. cerevisiae Vps4 MIT L64D (aa1-84) in pET28a & This Study \\
\hline
\end{tabular}


Supplemental Table 2. List of primers used in this study.

\begin{tabular}{|c|c|c|c|}
\hline Name & Sequence & Notes & $\begin{array}{l}\text { Refer } \\
\text { ence }\end{array}$ \\
\hline V5Prime370NcoI & caaccatggatgtctatgaaaaggaaagtatttac & $\begin{array}{l}\text { gener } \\
\text { ating } \\
\text { pCT3 } \\
4\end{array}$ & $\begin{array}{l}\text { This } \\
\text { study }\end{array}$ \\
\hline $\begin{array}{l}\text { V3Prime710EcoR } \\
\text { I }\end{array}$ & atatgaattcctactcggtctgctttgcaac & $\begin{array}{l}\text { gener } \\
\text { ating } \\
\text { pCT3 } \\
4\end{array}$ & $\begin{array}{l}\text { This } \\
\text { study }\end{array}$ \\
\hline $\begin{array}{l}413 \text { BglII-1 Mut } \\
\text { Frd }\end{array}$ & cactttccagagcggtggtagacctttcgaacag & $\begin{array}{l}\text { gener } \\
\text { ating } \\
\text { pCT3 } \\
5\end{array}$ & $\begin{array}{l}\text { This } \\
\text { study }\end{array}$ \\
\hline $\begin{array}{l}413 \text { BglII-1 Mut } \\
\text { Rev }\end{array}$ & taccaccgctctggaaagtgcctcatccaaag & $\begin{array}{l}\text { gener } \\
\text { ating } \\
\text { pCT3 } \\
5\end{array}$ & $\begin{array}{l}\text { This } \\
\text { study }\end{array}$ \\
\hline $\begin{array}{l}413 \text { BglII-2 Mut } \\
\text { Frd }\end{array}$ & caaagggagaaagtaggagacctctcttgcgagatg & $\begin{array}{l}\text { gener } \\
\text { ating } \\
\text { pCT3 } \\
5\end{array}$ & $\begin{array}{l}\text { This } \\
\text { study }\end{array}$ \\
\hline $\begin{array}{l}413 \text { BglII-2 Mut } \\
\text { Rev }\end{array}$ & tcctactttctccetttgcaaaccaagttcga & $\begin{array}{l}\text { gener } \\
\text { ating } \\
\text { pCT3 } \\
5\end{array}$ & $\begin{array}{l}\text { This } \\
\text { study }\end{array}$ \\
\hline $\begin{array}{l}413 \text { BglII-Intr } \\
\text { primer 5, }\end{array}$ & ggtggtagatctcgttttaagagcttggtgagcgc & $\begin{array}{l}\text { gener } \\
\text { ating } \\
\text { pCT3 } \\
6 \\
\end{array}$ & $\begin{array}{l}\text { This } \\
\text { study }\end{array}$ \\
\hline $\begin{array}{l}413 \text { PacI-Intr } \\
\text { primer 3' }\end{array}$ & ggtggtttaattaacgcatagatccgtcgagttcaagag & $\begin{array}{l}\text { gener } \\
\text { ating } \\
\text { pCT3 } \\
6 \\
\end{array}$ & $\begin{array}{l}\text { This } \\
\text { study }\end{array}$ \\
\hline $\begin{array}{l}\text { BRO3UTR5Prime } \\
\text { rEcoRI }\end{array}$ & atatgaattcgcatttcttatttcttaattttattgtagc & $\begin{array}{l}\text { gener } \\
\text { ating } \\
\text { pCT3 } \\
7\end{array}$ & $\begin{array}{l}\text { This } \\
\text { study }\end{array}$ \\
\hline $\begin{array}{l}\text { BRO3UTR3Prime } \\
\text { rSacI }\end{array}$ & atatccgcggcgaggatgatgacgattgg & $\begin{array}{l}\text { gener } \\
\text { ating } \\
\text { pCT3 } \\
7\end{array}$ & $\begin{array}{l}\text { This } \\
\text { study }\end{array}$ \\
\hline $\begin{array}{l}\text { Tef1 target BRO1 } \\
\text { 5'UTR }\end{array}$ & $\begin{array}{l}\text { tatgaggagaggccttttttccaatccagcttctctgtgtcttttagctttaggtcaaata } \\
\text { agtaaggtttcatggttgtttatgttcggatgtgatgtg }\end{array}$ & $\begin{array}{l}\text { gener } \\
\text { ating } \\
\text { CTY1 }\end{array}$ & $\begin{array}{l}\text { This } \\
\text { study }\end{array}$ \\
\hline
\end{tabular}




\begin{tabular}{|c|c|c|c|}
\hline & & -4 & \\
\hline $\begin{array}{l}\text { Tef1 target BRO1 } \\
3^{\prime}-370\end{array}$ & $\begin{array}{l}\text { gtttcttcaacttgctttctcaacagcgtcgetttttcttctgagtaaatactttccttttca } \\
\text { tagacatccatggttgtttatgttcggatgtgatgtg }\end{array}$ & $\begin{array}{l}\text { gener } \\
\text { ating } \\
\text { CTY2 }\end{array}$ & $\begin{array}{l}\text { This } \\
\text { study }\end{array}$ \\
\hline $\begin{array}{l}\text { Tef1 target BRO1 } \\
3^{\prime}-388\end{array}$ & $\begin{array}{l}\text { ctgggtagatttgtaaattcgatgaaggaagaatattccaaatttgctgtctcagtttct } \\
\text { tcaacttgcttcatggttgtttatgttcggatgtgatgtg }\end{array}$ & $\begin{array}{l}\text { gener } \\
\text { ating } \\
\text { CTY3 }\end{array}$ & $\begin{array}{l}\text { This } \\
\text { study }\end{array}$ \\
\hline $\begin{array}{l}\text { TEF1pBRO3UTR } \\
\text { Amp3Prime }\end{array}$ & cggcgaggatgatgacgattgg & $\begin{array}{l}\text { gener } \\
\text { ating } \\
\text { CTY4 }\end{array}$ & $\begin{array}{l}\text { This } \\
\text { study }\end{array}$ \\
\hline $\begin{array}{l}\text { GNTLR_414_dd } \\
\text { BOD_Frd }\end{array}$ & tttgtacagaggaattattcccctataggatgtctatgaaaaggaaagtatttactca & $\begin{array}{l}\text { gener } \\
\text { ating } \\
\text { pCT3 } \\
8\end{array}$ & $\begin{array}{l}\text { This } \\
\text { study }\end{array}$ \\
\hline $\begin{array}{l}\text { GNTLR_414_dd } \\
\text { BOD_Rev }\end{array}$ & taggggaataattcctctgtacaaa & $\begin{array}{l}\text { gener } \\
\text { ating } \\
\text { pCT3 } \\
8\end{array}$ & $\begin{array}{l}\text { This } \\
\text { study }\end{array}$ \\
\hline Bro1CTD_Rev & gagtagaaccagtgagtaatgaacc & $\begin{array}{l}\text { gener } \\
\text { ating } \\
\text { pCT3 } \\
9\end{array}$ & $\begin{array}{l}\text { This } \\
\text { study }\end{array}$ \\
\hline $\begin{array}{l}\text { BRO1pBro1CTD } \\
\_\Delta \mathrm{UB} \text { _Frd }\end{array}$ & $\begin{array}{l}\text { attactcactggttctactcatggatgtctatgaaaaggaaagtcgttactcagaaga } \\
\text { aaaagcgacgctgcgtagaaagcaag }\end{array}$ & $\begin{array}{l}\text { gener } \\
\text { ating } \\
\text { pCT3 } \\
9\end{array}$ & $\begin{array}{l}\text { This } \\
\text { study }\end{array}$ \\
\hline $\begin{array}{l}\text { SalI_TEF } \triangle B O D \_ \\
\text {Frd }\end{array}$ & atatgtcgacgacatggaggccagaataccetcc & $\begin{array}{l}\text { gener } \\
\text { ating } \\
\text { pCT4 } \\
1\end{array}$ & $\begin{array}{l}\text { This } \\
\text { study }\end{array}$ \\
\hline $\begin{array}{l}\text { BamHI_TEF } \triangle B O \\
\text { D_Rev }\end{array}$ & atatggatccctaactgctgtatttggagtacata & $\begin{array}{l}\text { gener } \\
\text { ating } \\
\text { pCT4 } \\
1\end{array}$ & $\begin{array}{l}\text { This } \\
\text { study }\end{array}$ \\
\hline $\begin{array}{l}\text { Gb_TEFNcoI- } \\
\Delta \mathrm{BOD} \text { _Frd }\end{array}$ & cacatccgaacataaacaaccatggatgtctatgaaaaggaaagt & $\begin{array}{l}\text { gener } \\
\text { ating } \\
\text { pCT4 } \\
2-43\end{array}$ & $\begin{array}{l}\text { This } \\
\text { study }\end{array}$ \\
\hline $\begin{array}{l}\text { Gb_TEFBamHI- } \\
\Delta \text { BOD_Rev }\end{array}$ & tggcggccgctctagaactagtggatccctaactgctgtatttggagtacata & $\begin{array}{l}\text { gener } \\
\text { ating } \\
\text { pCT4 } \\
2-43\end{array}$ & $\begin{array}{l}\text { This } \\
\text { study }\end{array}$ \\
\hline $\begin{array}{l}\text { Gb_TEFBamHI- } \\
\text { Vonly_Rev }\end{array}$ & cgctctagaactagtggatccctactcggtctgctttgcaactctc & $\begin{array}{l}\text { gener } \\
\text { ating }\end{array}$ & $\begin{array}{l}\text { This } \\
\text { study }\end{array}$ \\
\hline
\end{tabular}


bioRxiv preprint doi: https://doi.org/10.1101/2020.07.27.223255; this version posted February 16, 2021. The copyright holder for this preprint (which was not certified by peer review) is the author/funder, who has granted bioRxiv a license to display the preprint in perpetuity. It is made available under aCC-BY 4.0 International license.

\begin{tabular}{|l|l|l|l|}
\hline & & pCT4 & \\
& $2-43$ & \\
\hline
\end{tabular}


Supplemental Table 3. List of yeast strains used in this study.

\begin{tabular}{|c|c|c|}
\hline Name & Description & Reference \\
\hline SEY6210 & MAT $\alpha$, leu2-3,112 ura3-52 his3- $\Delta 200$ trp1- $\Delta 901$ lys2-801 suc2- $\Delta 9$ & $\begin{array}{l}\text { (Robinson } \\
\text { et al., } \\
1988 \text { ) }\end{array}$ \\
\hline SEY6210.1 & MATa, leu2-3,112 ura3-52 his3- $\Delta 200$ trp1- -901 lys2-801 suc2- $\Delta 9$ & $\begin{array}{l}\text { (Robinson } \\
\text { et al., } \\
1988 \text { ) }\end{array}$ \\
\hline EEY9 & SEY6210; snf7 $:: H I S 3$ & $\begin{array}{l}\text { (Babst et } \\
\text { al., 1997) }\end{array}$ \\
\hline GOY65 & SEY6210; brol $\triangle:: H I S 3$ & $\begin{array}{l}\text { (Odorizzi } \\
\text { et al., } \\
2003 \text { ) }\end{array}$ \\
\hline MBY3 & SEY6210; vps4A::TRP1 & $\begin{array}{l}\text { (Katzmann } \\
\text { et al., } \\
2003 \text { ) }\end{array}$ \\
\hline JPY403 & SEY6210; vps $4 \Delta:: T R P 1$ pep $4 \Delta:: L E U 2$ brol $\triangle:: H I S 3$ & This study \\
\hline CTY1 & SEY6210.1; brol $\triangle:: H I S 3-T E F 1 \mathrm{p}-B R O 1$ & This study \\
\hline CTY2 & $\begin{array}{l}\text { SEY6210.1; brol } \triangle:: H I S 3-T E F 1 \text { p-brol }{ }^{\triangle B O D} \text { (encoding Bro1 aa370- } \\
844) " b r o 1^{\triangle B O D "}\end{array}$ & This study \\
\hline CTY3 & $\begin{array}{l}\text { SEY6210.1; brol } \triangle: \because H I S 3-T E F 1 \mathrm{p}-\text { brol } \\
\text { aa388-844) " bro1 }{ }^{\triangle B O D \triangle U B D " 1}\end{array}$ & This study \\
\hline CTY4 & $\begin{array}{l}\text { SEY6210.1; brol } \triangle:: H I S 3-T E F 1 \text { p-brolV (encoding Bro1 aa370- } \\
\text { 709) "brolV" }\end{array}$ & This study \\
\hline CTY5 & 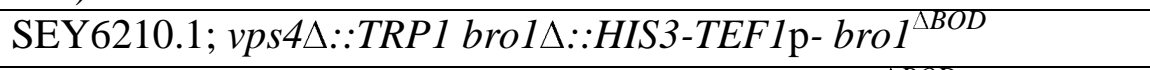 & This study \\
\hline CTY11 & 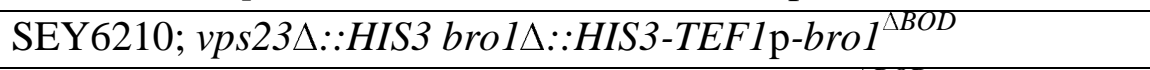 & This study \\
\hline CTY12 & SEY6210; snf7 $:: H I S 3$ brol $\triangle:: H I S 3-T E F 1 \mathrm{p}-$ brol ${ }^{\triangle B O D}$ & This study \\
\hline CTY13 & SEY6210; doa4A $: H I S 3$ brol $\triangle:: H I S 3-T E F 1 \mathrm{p}-$ brol $^{\triangle B O D}$ & This study \\
\hline CTY18 & 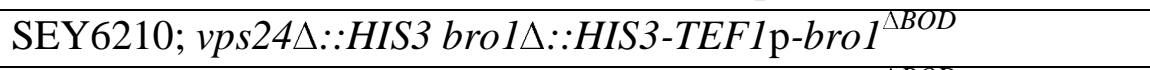 & This study \\
\hline CTY21 & 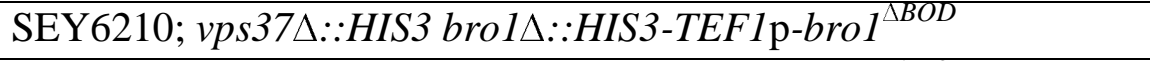 & This study \\
\hline CTY22 & SEY6210; $m v b 12 \triangle:: H I S 3$ brol $: \because H I S 3-T E F 1 \mathrm{p}-$ brol $^{\triangle B O D}$ & This study \\
\hline CTY24 & 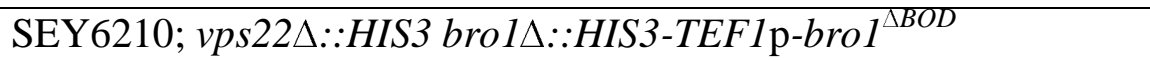 & This study \\
\hline CTY26 & SEY6210; vps $2 \triangle:: H I S 3$ brol $\triangle:: H I S 3-T E F 1 \mathrm{p}-$ brol $^{\triangle B O D}$ & This study \\
\hline CTY27 & SEY6210; vtal $\triangle:: H I S 3$ brol $\triangle:: H I S 3-T E F 1 \mathrm{p}-$ brol $1^{\triangle B O D}$ & This study \\
\hline CTY29 & 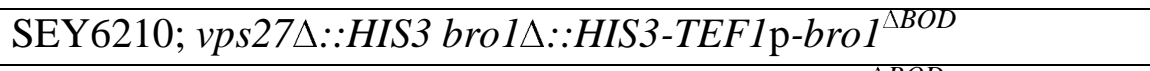 & This study \\
\hline CTY30 & SEY6210; hse1 $\triangle:: T R P 1$ brol $\triangle:: H I S 3-T E F 1 \mathrm{p}-$ brol $^{\triangle B O D}$ & This study \\
\hline
\end{tabular}


Supplemental Table 4. List of mutations analyzed in this study. Only mutations that were expressed and exhibited defective ATPase stimulation or MVB cargo sorting were pursued.

\begin{tabular}{|c|l|c|c|}
\hline ID & \multicolumn{1}{|c|}{ Mutation } & ATPase Stimulation & Yeast Expression \\
\hline M1 & L386R & + & + \\
\hline M2 & S414A, D415A & + & + \\
\hline M3 & S537A, L538A, L539A & + & + \\
\hline M4 & V505A, H508A, I512A & + & + \\
\hline M5 & F446A, E451A, F452A & + & + \\
\hline M6 & D454A, E457A, K461A & - & + \\
\hline M7 & V463A, L470A & - & + \\
\hline M8 & E686A, L691D & - & + \\
\hline M9 & T587D & + & + \\
\hline M10 & K481D & + & + \\
\hline
\end{tabular}


bioRxiv preprint doi: https://doi.org/10.1101/2020.07.27.223255; this version posted February 16,2021 . The copyright holder for this preprint (which was not certified by peer review) is the author/funder, who has granted bioRxiv a license to display the preprint in perpetuity. It is made available under aCC-BY 4.0 International license.

\begin{abstract}
Abbreviations:
ESCRT, Endosomal Sorting Complex Required for Transport; MVB, Multivesicular Body; ILV, intralumenal vesicle.
\end{abstract}




\section{References}

Adell, M.A., and D. Teis. 2011. Assembly and disassembly of the ESCRT-III membrane scission complex. FEBS Lett. 585:3191-3196.

Adell, M.A.Y., S.M. Migliano, S. Upadhyayula, Y.S. Bykov, S. Sprenger, M. Pakdel, G.F. Vogel, G. Jih, W. Skillern, R. Behrouzi, M. Babst, O. Schmidt, M.W. Hess, J.A. Briggs, T. Kirchhausen, and D. Teis. 2017. Recruitment dynamics of ESCRT-III and Vps4 to endosomes and implications for reverse membrane budding. Elife. 6 .

Ali, N., L. Zhang, S. Taylor, A. Mironov, S. Urbé, and P. Woodman. 2013. Recruitment of UBPY and ESCRT Exchange Drive HD-PTP-Dependent Sorting of EGFR to the MVB. Current Biology. 23:453-461.

Azmi, I., B. Davies, C. Dimaano, J. Payne, D. Eckert, M. Babst, and D.J. Katzmann. 2006. Recycling of ESCRTs by the AAA-ATPase Vps4 is regulated by a conserved VSL region in Vta1. J Cell Biol. 172:705-717.

Azmi, I.F., B.A. Davies, J. Xiao, M. Babst, Z. Xu, and D.J. Katzmann. 2008. ESCRT-III Family Members Stimulate Vps4 ATPase Activity Directly or via Vta1. Developmental Cell. 14:50-61.

Babst, M., D.J. Katzmann, E.J. Estepa-Sabal, T. Meerloo, and S.D. Emr. 2002. Escrt-III: An endosomeassociated heterooligomeric protein complex required for mvb sorting. Developmental Cell. 3:271-282.

Babst, M., T.K. Sato, L.M. Banta, and S.D. Emr. 1997. Endosomal transport function in yeast requires a novel AAA-type ATPase, Vps4p. The EMBO Journal. 16:1820-1831.

Babst, M., B. Wendland, E.J. Estepa, and S.D. Emr. 1998. The Vps4p AAA ATPase regulates membrane association of a Vps protein complex required for normal endosome function. The EMBO Journal. 17:2982-2993.

Baietti, M.F., Z. Zhang, E. Mortier, A. Melchior, G. Degeest, A. Geeraerts, Y. Ivarsson, F. Depoortere, C. Coomans, E. Vermeiren, P. Zimmermann, and G. David. 2012. Syndecan-syntenin-ALIX regulates the biogenesis of exosomes. Nature Cell Biology. 14:677-685.

Bend, R., L. Cohen, M.T. Carter, M.J. Lyons, D. Niyazov, M.A. Mikati, S.K. Rojas, R.E. Person, Y. Si, I.M. Wentzensen, E. Torti, J.A. Lee, K.M. Boycott, L. Basel-Salmon, C.R. Ferreira, C. GonzagaJauregui, and C. Regeneron Genetics. 2020. Phenotype and mutation expansion of the PTPN23 associated disorder characterized by neurodevelopmental delay and structural brain abnormalities. European Journal of Human Genetics. 28:76-87.

Bilodeau, P.S., J.L. Urbanowski, S.C. Winistorfer, and R.C. Piper. 2002. The Vps27p-Hse1p complex binds ubiquitin and mediates endosomal protein sorting. Nature Cell Biology. 4:534.

Buysse, D., A.-K. Pfitzner, M. West, A. Roux, and G. Odorizzi. 2020. The ubiquitin hydrolase Doa4 directly binds Snf7 to inhibit recruitment of ESCRT-III remodeling factors in \&lt;em\&gt;S. cerevisiae\&lt;/em\&gt. Journal of Cell Science. 133:jcs241455.

Carlton, J.G., M. Agromayor, and J. Martin-Serrano. 2008. Differential requirements for Alix and ESCRT-III in cytokinesis and HIV-1 release. Proceedings of the National Academy of Sciences. 105:10541.

Carlton, J.G., and J. Martin-Serrano. 2007. Parallels between cytokinesis and retroviral budding: A role for the ESCRT machinery. Science. 316:1908-1912.

Davies, B.A., I.F. Azmi, J. Payne, A. Shestakova, B.F. Horazdovsky, M. Babst, and D.J. Katzmann. 2010. Coordination of Substrate Binding and ATP Hydrolysis in Vps4-Mediated ESCRT-III Disassembly. Molecular Biology of the Cell. 21:3396-3408.

Davies, B.A., A.P. Norgan, J.A. Payne, M.E. Schulz, M.D. Nichols, J.A. Tan, Z. Xu, and D.J. Katzmann. 2014. Vps4 stimulatory element of the cofactor Vta1 contacts the ATPase Vps4 $\alpha 7$ and $\alpha 9$ to stimulate ATP hydrolysis. The Journal of biological chemistry. 289:28707-28718.

Dimaano, C., C.B. Jones, A. Hanono, M. Curtiss, and M. Babst. 2007. Ist1 Regulates Vps4 Localization and Assembly. Molecular Biology of the Cell. 19:465-474. 
Fisher, R.D., H.-Y. Chung, Q. Zhai, H. Robinson, W.I. Sundquist, and C.P. Hill. 2007. Structural and Biochemical Studies of ALIX/AIP1 and Its Role in Retrovirus Budding. Cell. 128:841-852.

Giddings, T.H. 2003. Freeze-substitution protocols for improved visualization of membranes in highpressure frozen samples. Journal of Microscopy. 212:53-61.

Gingras, M.C., D. Kharitidi, V. Chénard, N. Uetani, M. Bouchard, M.L. Tremblay, and A. Pause. 2009. Expression analysis and essential role of the putative tyrosine phosphatase His-domain-containing protein tyrosine phosphatase (HD-PTP). Int J Dev Biol. 53:1069-1074.

Hanson, P.I., and A. Cashikar. 2012. Multivesicular Body Morphogenesis. Annual Review of Cell and Developmental Biology. 28:337-362.

Hanson, P.K., A.M. Grant, and J.W. Nichols. 2002. NBD-labeled phosphatidylcholine enters the yeast vacuole via the pre-vacuolar compartment. Journal of Cell Science. 115:2725.

Johnson, N., M. West, and G. Odorizzi. 2017. Regulation of yeast ESCRT-III membrane scission activity by the Doa4 ubiquitin hydrolase. Mol Biol Cell. 28:661-672.

Kalinowska, K., M.-K. Nagel, K. Goodman, L. Cuyas, F. Anzenberger, A. Alkofer, J. Paz-Ares, P. Braun, V. Rubio, M.S. Otegui, and E. Isono. 2015. Arabidopsis ALIX is required for the endosomal localization of the deubiquitinating enzyme AMSH3. Proceedings of the National Academy of Sciences. 112:E5543.

Katzmann, D.J., M. Babst, and S.D. Emr. 2001. Ubiquitin-Dependent Sorting into the Multivesicular Body Pathway Requires the Function of a Conserved Endosomal Protein Sorting Complex, ESCRT-I. Cell. 106:145-155.

Katzmann, D.J., E.A. Epping, and W.S. Moye-Rowley. 1999. Mutational disruption of plasma membrane trafficking of Saccharomyces cerevisiae Yor1p, a homologue of mammalian multidrug resistance protein. Molecular and cellular biology. 19:2998-3009.

Katzmann, D.J., S. Sarkar, T. Chu, A. Audhya, and S.D. Emr. 2003. Multivesicular Body Sorting: Ubiquitin Ligase Rsp5 Is Required for the Modification and Sorting of Carboxypeptidase S. Molecular Biology of the Cell. 15:468-480.

Kieffer, C., J.J. Skalicky, E. Morita, I. De Domenico, D.M. Ward, J. Kaplan, and W.I. Sundquist. 2008. Two Distinct Modes of ESCRT-III Recognition Are Required for VPS4 Functions in Lysosomal Protein Targeting and HIV-1 Budding. Developmental Cell. 15:62-73.

Kim, J., S. Sitaraman, A. Hierro, B.M. Beach, G. Odorizzi, and J.H. Hurley. 2005. Structural Basis for Endosomal Targeting by the Bro1 Domain. Developmental Cell. 8:937-947.

Kimura, Y., J. Kawawaki, Y. Kakiyama, A. Shimoda, and K. Tanaka. 2014. The ESCRT-III Adaptor Protein Bro1 Controls Functions of Regulator for Free Ubiquitin Chains 1 (Rfu1) in Ubiquitin Homeostasis. Journal of Biological Chemistry. 289:21760-21769.

Kremer, J.R., D.N. Mastronarde, and J.R. McIntosh. 1996. Computer Visualization of Three-Dimensional Image Data Using IMOD. Journal of Structural Biology. 116:71-76.

Larios, J., V. Mercier, A. Roux, and J. Gruenberg. 2020. ALIX- and ESCRT-III-dependent sorting of tetraspanins to exosomes. J. Cell Biol. 219.

Lee, J., K.-J. Oh, D. Lee, B.Y. Kim, J.S. Choi, B. Ku, and S.J. Kim. 2016. Structural Study of the HDPTP Bro1 Domain in a Complex with the Core Region of STAM2, a Subunit of ESCRT-0. PloS one. 11:e0149113-e0149113.

Lee, J.-A., A. Beigneux, S.T. Ahmad, S.G. Young, and F.-B. Gao. 2007a. ESCRT-III Dysfunction Causes Autophagosome Accumulation and Neurodegeneration. Current Biology. 17:1561-1567.

Lee, S., A. Joshi, K. Nagashima, E.O. Freed, and J.H. Hurley. 2007b. Structural basis for viral latedomain binding to Alix. Nature Structural \&Amp; Molecular Biology. 14:194.

Longtine, M.S., A. McKenzie Iii, D.J. Demarini, N.G. Shah, A. Wach, A. Brachat, P. Philippsen, and J.R. Pringle. 1998. Additional modules for versatile and economical PCR-based gene deletion and modification in Saccharomyces cerevisiae. Yeast. 14:953-961.

Luhtala, N., and G. Odorizzi. 2004. Bro1 coordinates deubiquitination in the multivesicular body pathway by recruiting Doa4 to endosomes. The Journal of Cell Biology. 166:717. 
MacDonald, C., N.J. Buchkovich, D.K. Stringer, S.D. Emr, and R.C. Piper. 2012a. Cargo ubiquitination is essential for multivesicular body intralumenal vesicle formation. EMBO reports. 13:331.

MacDonald, C., J.A. Payne, M. Aboian, W. Smith, D.J. Katzmann, and R.C. Piper. 2015. A family of tetraspans organizes cargo for sorting into multivesicular bodies. Dev Cell. 33:328-342.

MacDonald, C., D.K. Stringer, and R.C. Piper. 2012b. Sna3 Is an Rsp5 Adaptor Protein that Relies on Ubiquitination for Its MVB Sorting. Traffic. 13:586-598.

Manteghi, S., M.-C. Gingras, D. Kharitidi, L. Galarneau, M. Marques, M. Yan, R. Cencic, F. Robert, M. Paquet, M. Witcher, J. Pelletier, and A. Pause. 2016. Haploinsufficiency of the ESCRT Component HD-PTP Predisposes to Cancer. Cell Reports. 15:1893-1900.

McCullough, J., R.D. Fisher, F.G. Whitby, W.I. Sundquist, and C.P. Hill. 2008. ALIX-CHMP4 interactions in the human ESCRT pathway. Proceedings of the National Academy of Sciences. 105:7687.

Merrill, S.A., and P.I. Hanson. 2010. Activation of human VPS4A by ESCRT-III proteins reveals ability of substrates to relieve enzyme autoinhibition. J Biol Chem. 285:35428-35438.

Mierzwa, B.E., N. Chiaruttini, L. Redondo-Morata, J. Moser von Filseck, J. König, J. Larios, I. Poser, T. Müller-Reichert, S. Scheuring, A. Roux, and D.W. Gerlich. 2017. Dynamic subunit turnover in ESCRT-III assemblies is regulated by Vps4 to mediate membrane remodelling during cytokinesis. Nature Cell Biology. 19:787-798.

Nikko, E., and B. André. 2007. Split-Ubiquitin Two-Hybrid Assay To Analyze Protein-Protein Interactions at the Endosome: Application to Saccharomyces cerevisiae Bro1 Interacting with ESCRT Complexes, the Doa4 Ubiquitin Hydrolase, and the Rsp5 Ubiquitin Ligase. Eukaryotic Cell. 6:1266.

Norgan, A.P., B.A. Davies, I.F. Azmi, A.S. Schroeder, J.A. Payne, G.M. Lynch, Z. Xu, and D.J. Katzmann. 2013. Relief of autoinhibition enhances Vta1 activation of Vps4 via the Vps4 stimulatory element. J Biol Chem. 288:26147-26156.

Obita, T., S. Saksena, S. Ghazi-Tabatabai, D.J. Gill, O. Perisic, S.D. Emr, and R.L. Williams. 2007. Structural basis for selective recognition of ESCRT-III by the AAA ATPase Vps4. Nature. 449:735-739.

Odorizzi, G., M. Babst, and S.D. Emr. 1998. Fab1p PtdIns(3)P 5-Kinase Function Essential for Protein Sorting in the Multivesicular Body. Cell. 95:847-858.

Odorizzi, G., D.J. Katzmann, M. Babst, A. Audhya, and S.D. Emr. 2003. Bro1 is an endosome-associated protein that functions in the MVB pathway in Saccharomyces cerevisiae. J Cell Sci. 116:18931903.

Oestreich, A.J., B.A. Davies, J.A. Payne, and D.J. Katzmann. 2006. Mvb12 Is a Novel Member of ESCRT-I Involved in Cargo Selection by the Multivesicular Body Pathway. Molecular Biology of the Cell. 18:646-657.

Pashkova, N., L. Gakhar, Stanley C. Winistorfer, Anna B. Sunshine, M. Rich, Maitreya J. Dunham, L. Yu, and Robert C. Piper. 2013. The Yeast Alix Homolog Bro1 Functions as a Ubiquitin Receptor for Protein Sorting into Multivesicular Endosomes. Developmental Cell. 25:520-533.

Pettersen, E.F., T.D. Goddard, C.C. Huang, G.S. Couch, D.M. Greenblatt, E.C. Meng, and T.E. Ferrin. 2004. UCSF Chimera--a visualization system for exploratory research and analysis. J Comput Chem. 25:1605-1612.

Pfitzner, A.-K., V. Mercier, X. Jiang, J. Moser von Filseck, B. Baum, A. Šarić, and A. Roux. 2020. An ESCRT-III Polymerization Sequence Drives Membrane Deformation and Fission. Cell. 182:1140-1155.e1118.

Piper, R.C., and P.J. Lehner. 2011. Endosomal transport via ubiquitination. Trends in Cell Biology. 21:647-655.

Reggiori, F., and H.R.B. Pelham. 2001. Sorting of proteins into multivesicular bodies: ubiquitindependent and -independent targeting. The EMBO Journal. 20:5176-5186.

Richter, C.M., M. West, and G. Odorizzi. 2013. Doa4 function in ILV budding is restricted through its interaction with the Vps20 subunit of ESCRT-III. J Cell Sci. 126:1881-1890. 
Robinson, J.S., D.J. Klionsky, L.M. Banta, and S.D. Emr. 1988. Protein sorting in Saccharomyces cerevisiae: isolation of mutants defective in the delivery and processing of multiple vacuolar hydrolases. Molecular and Cellular Biology. 8:4936.

Schindelin, J., I. Arganda-Carreras, E. Frise, V. Kaynig, M. Longair, T. Pietzsch, S. Preibisch, C. Rueden, S. Saalfeld, B. Schmid, J.-Y. Tinevez, D.J. White, V. Hartenstein, K. Eliceiri, P. Tomancak, and A. Cardona. 2012. Fiji: an open-source platform for biological-image analysis. Nature Methods. 9:676-682.

Schmidt, O., and D. Teis. 2012. The ESCRT machinery. Curr Biol. 22:R116-120.

Schrödinger, L. The PyMOL Molecular Graphics System, Version 2.0.

Sheffield, P., S. Garrard, and Z. Derewenda. 1999. Overcoming expression and purification problems of RhoGDI using a family of "parallel" expression vectors. Protein Expr Purif. 15:34-39.

Shestakova, A., A. Hanono, S. Drosner, M. Curtiss, B.A. Davies, D.J. Katzmann, and M. Babst. 2010. Assembly of the AAA ATPase Vps4 on ESCRT-III. Mol Biol Cell. 21:1059-1071.

Shields, S.B., A.J. Oestreich, S. Winistorfer, D. Nguyen, J.A. Payne, D.J. Katzmann, and R. Piper. 2009. ESCRT ubiquitin-binding domains function cooperatively during MVB cargo sorting. The Journal of cell biology. 185:213-224.

Shim, S., S.A. Merrill, and P.I. Hanson. 2008. Novel Interactions of ESCRT-III with LIP5 and VPS4 and their Implications for ESCRT-III Disassembly. Molecular Biology of the Cell. 19:2661-2672.

Sikorski, R.S., and P. Hieter. 1989. A system of shuttle vectors and yeast host strains designed for efficient manipulation of DNA in Saccharomyces cerevisiae. Genetics. 122:19-27.

Simons, R.W., F. Houman, and N. Kleckner. 1987. Improved single and multicopy lac-based cloning vectors for protein and operon fusions. Gene. 53:85-96.

Skowyra, M.L., P.H. Schlesinger, T.V. Naismith, and P.I. Hanson. 2018. Triggered recruitment of ESCRT machinery promotes endolysosomal repair. Science (New York, N.Y.). 360:eaar5078.

Sowada, N., M.O. Hashem, R. Yilmaz, M. Hamad, N. Kakar, H. Thiele, S.T. Arold, H. Bode, F.S. Alkuraya, and G. Borck. 2017. Mutations of PTPN23 in developmental and epileptic encephalopathy. Human Genetics. 136:1455-1461.

Stringer, D.K., and R.C. Piper. 2011. A single ubiquitin is sufficient for cargo protein entry into MVBs in the absence of ESCRT ubiquitination. The Journal of Cell Biology. 192:229.

Stuchell-Brereton, M.D., J.J. Skalicky, C. Kieffer, M.A. Karren, S. Ghaffarian, and W.I. Sundquist. 2007. ESCRT-III recognition by VPS4 ATPases. Nature. 449:740-744.

Sundd, M., N. Iverson, B. Ibarra-Molero, J.M. Sanchez-Ruiz, and A.D. Robertson. 2002. Electrostatic interactions in ubiquitin: stabilization of carboxylates by lysine amino groups. Biochemistry. 41:7586-7596.

Takahashi, Y., H. He, Z. Tang, T. Hattori, Y. Liu, M.M. Young, J.M. Serfass, L. Chen, M. Gebru, C. Chen, C.A. Wills, J.M. Atkinson, H. Chen, T. Abraham, and H.-G. Wang. 2018. An autophagy assay reveals the ESCRT-III component CHMP2A as a regulator of phagophore closure. Nature Communications. 9:2855.

Tan, J., B.A. Davies, J.A. Payne, L.M. Benson, and D.J. Katzmann. 2015. Conformational Changes in the Endosomal Sorting Complex Required for the Transport III Subunit Ist1 Lead to Distinct Modes of ATPase Vps4 Regulation. J Biol Chem. 290:30053-30065.

Tang, S., N.J. Buchkovich, W.M. Henne, S. Banjade, Y.J. Kim, and S.D. Emr. 2016. ESCRT-III activation by parallel action of ESCRT-I/II and ESCRT-0/Bro1 during MVB biogenesis. eLife. 5:e15507.

Vajjhala, P.R., E. Catchpoole, C.H. Nguyen, C. Kistler, and A.L. Munn. 2007. Vps4 regulates a subset of protein interactions at the multivesicular endosome. The FEBS Journal. 274:1894-1907.

Vietri, M., M. Radulovic, and H. Stenmark. 2020. The many functions of ESCRTs. Nature Reviews Molecular Cell Biology. 21:25-42.

Votteler, J., and W.I. Sundquist. 2013. Virus Budding and the ESCRT Pathway. Cell Host Microbe. 14:232-241. 
Webster, Brant M., P. Colombi, J. Jäger, and C.P. Lusk. 2014. Surveillance of Nuclear Pore Complex Assembly by ESCRT-III/Vps4. Cell. 159:388-401.

Wemmer, M., I. Azmi, M. West, B. Davies, D. Katzmann, and G. Odorizzi. 2011. Bro1 binding to Snf7 regulates ESCRT-III membrane scission activity in yeast. J Cell Biol. 192:295-306.

Williams, R.L., and S. Urbe. 2007. The emerging shape of the ESCRT machinery. Nat Rev Mol Cell Biol. 8:355-368.

Zhai, Q., M.B. Landesman, H.-Y. Chung, A. Dierkers, C.M. Jeffries, J. Trewhella, C.P. Hill, and W.I. Sundquist. 2011. Activation of the Retroviral Budding Factor ALIX. Journal of Virology. 85:9222. 


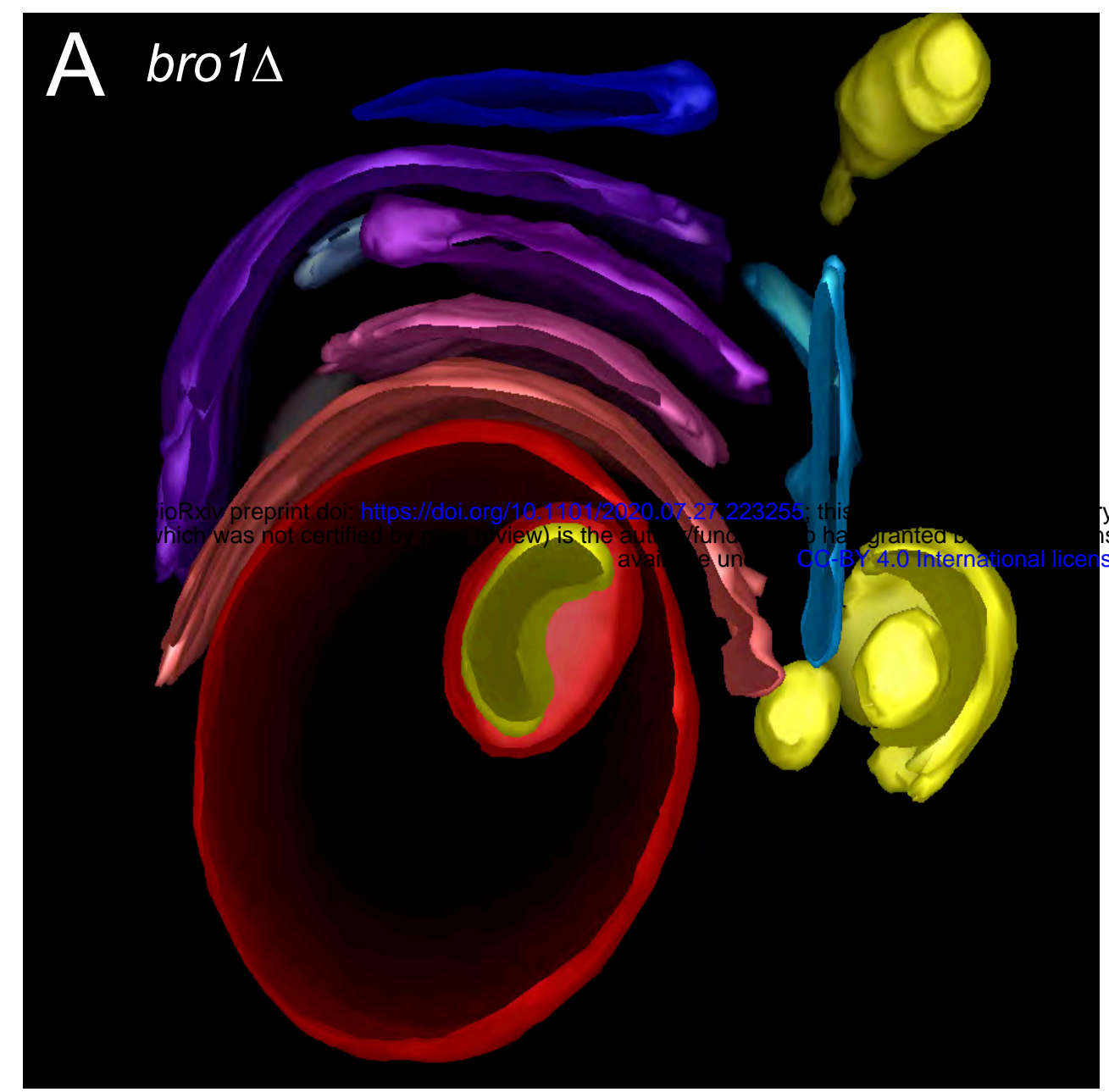

bro1 $\triangle B O D$

B

C

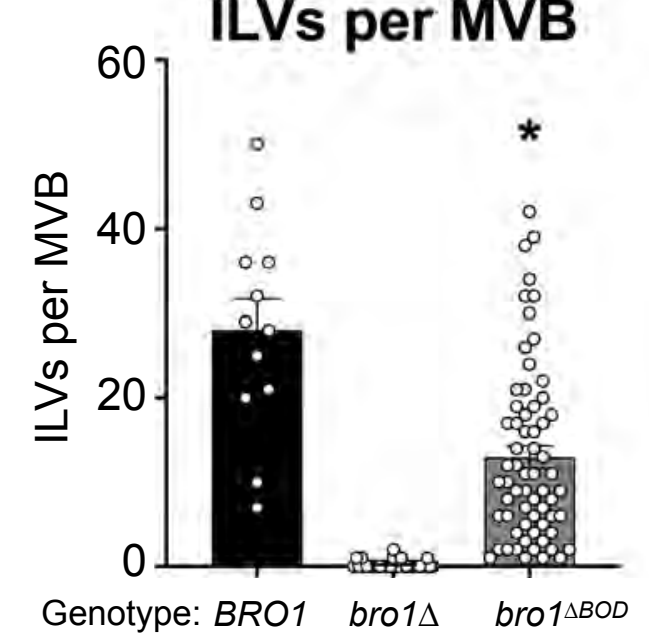

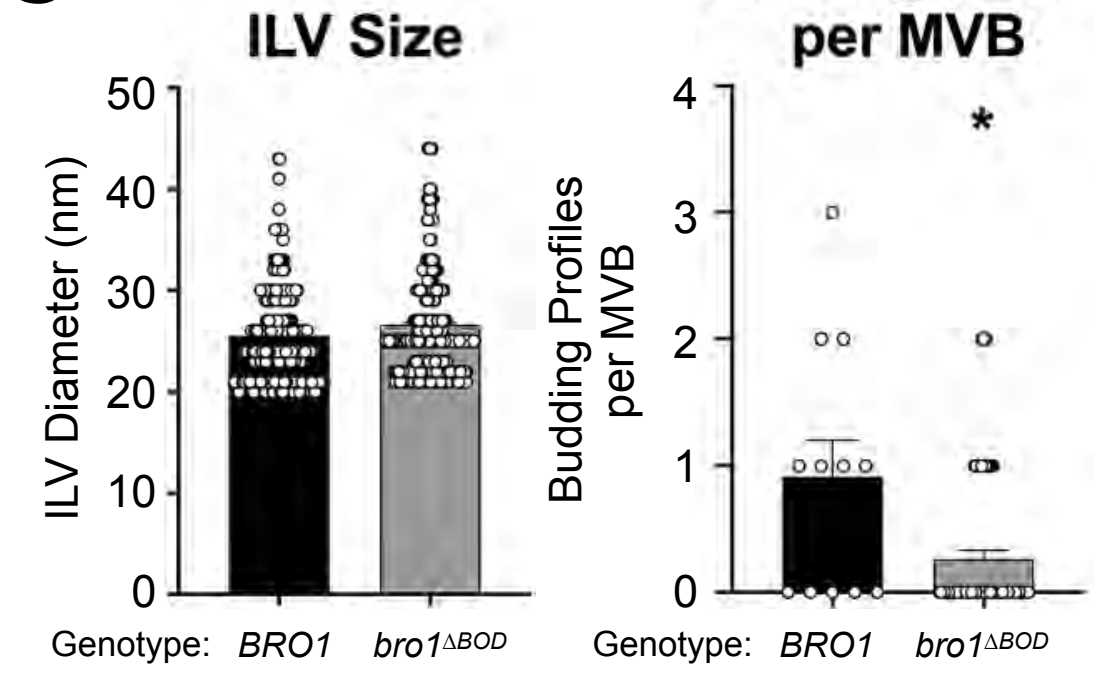

Budding Profile per MVB
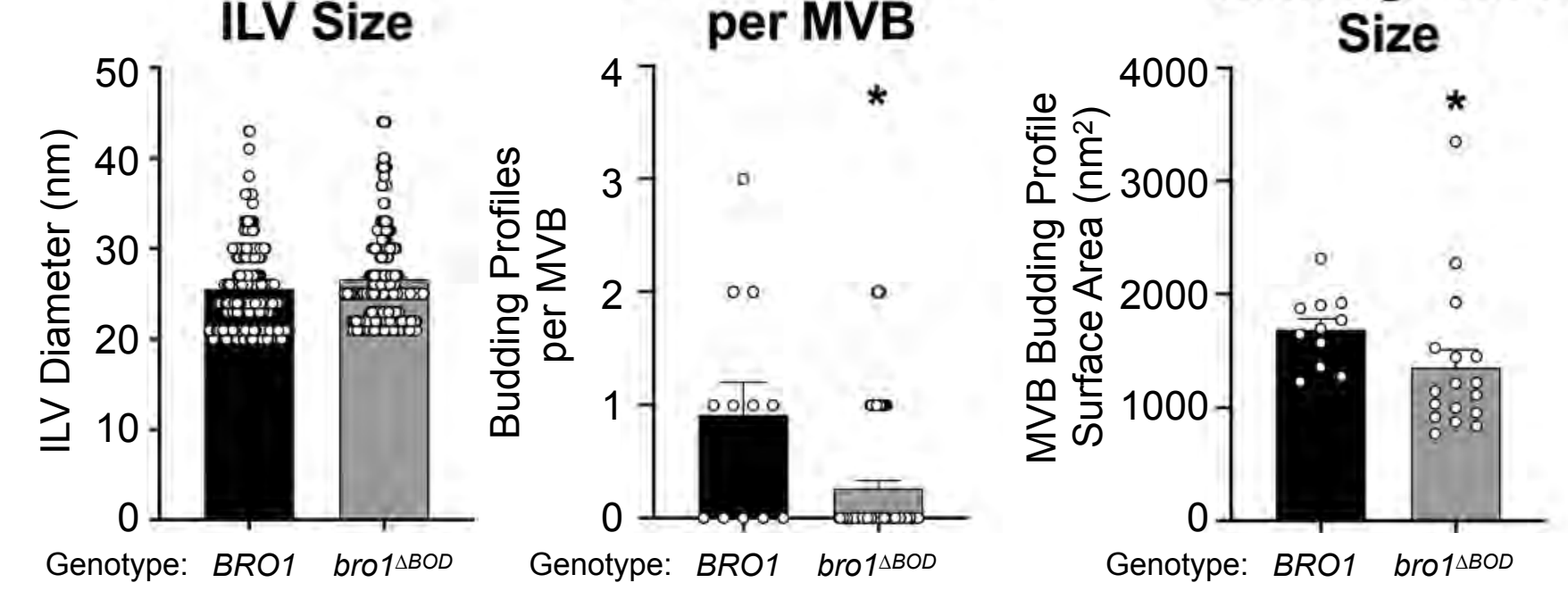

Budding Profile Size

Genotype: BRO1 bro1 $\triangle B O D$ 


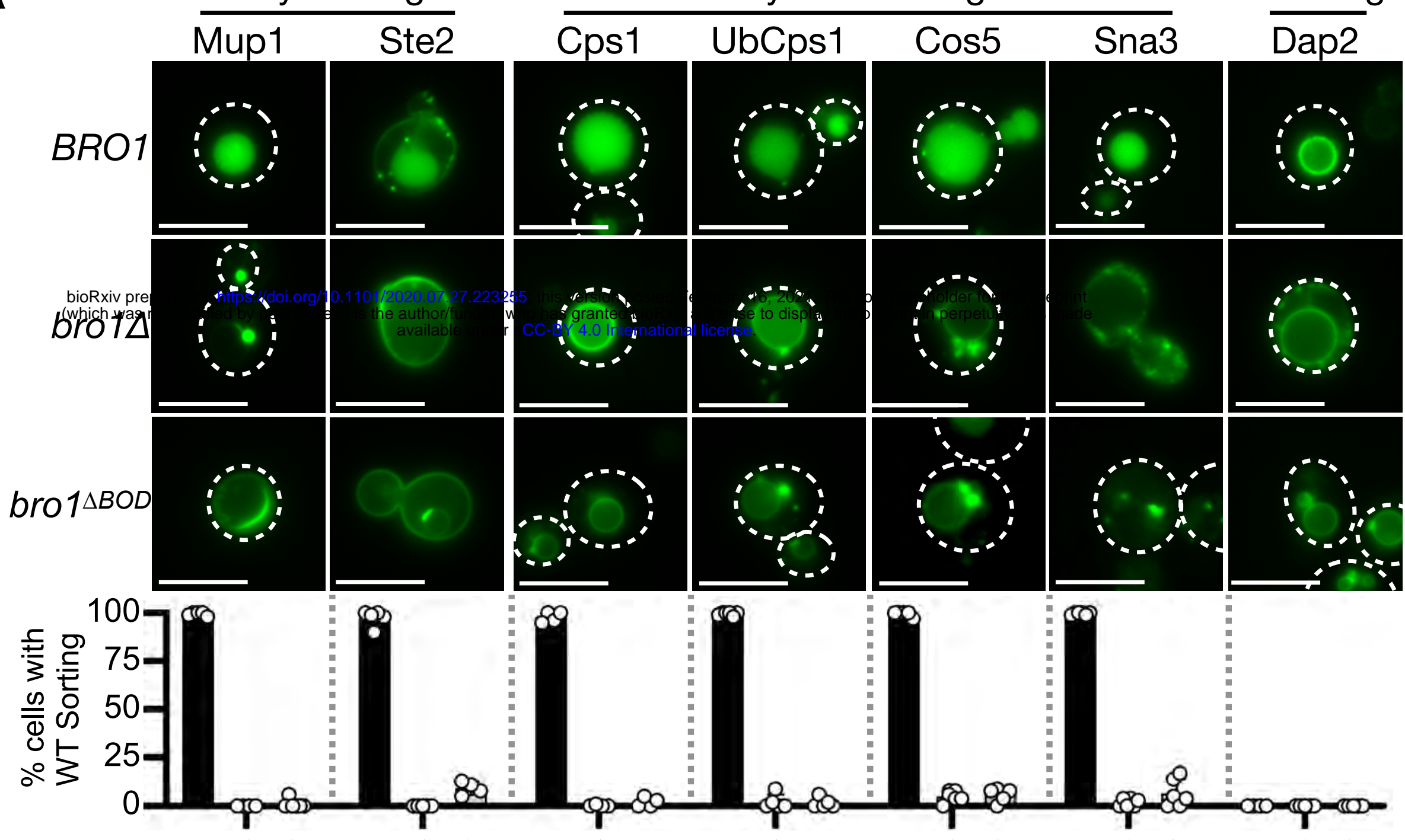

$B R O 1:+\Delta A$ $+\Delta \Delta$ $+\Delta \Delta$ $+\Delta \Delta$ $+\Delta \Delta$ $+\Delta \Delta+\Delta \Delta$ bro1 $\triangle B O D:-\quad+\quad-++-+$

B

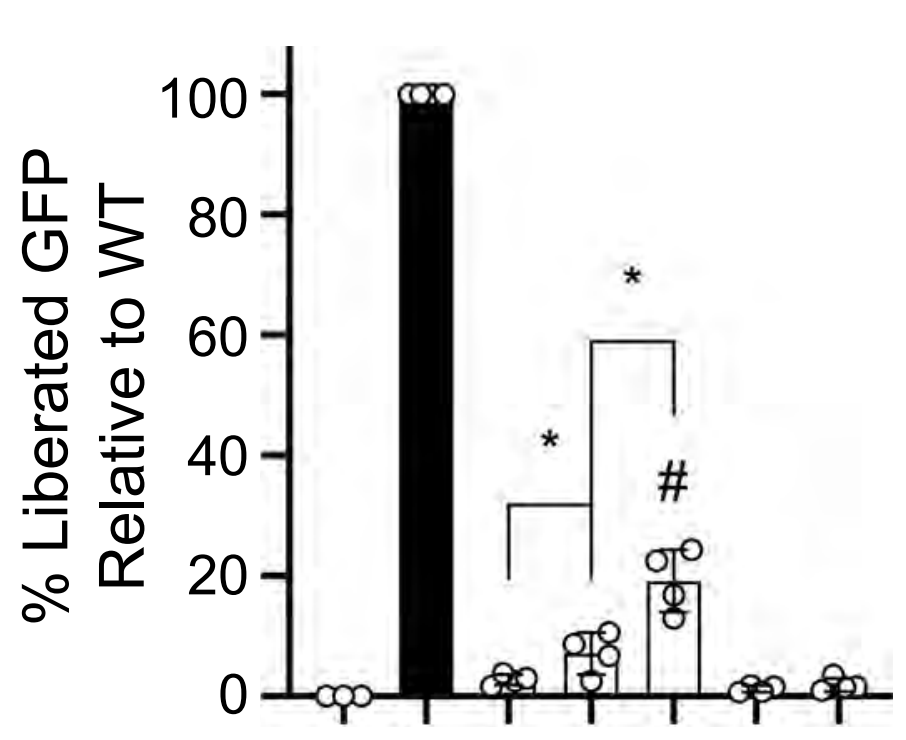
BRO1: $+++\Delta \Delta \Delta \Delta$ bro1 $\triangle B O D:$ - $-~-+++$ VPS4: $++\Delta+++\Delta$ SNF7: $+++++\Delta+$ Sna3-GFP: -++++++ Ub-Sna3-GFP = Sna3-GFP GFP - - -40

Pgk1 - - - - - - 50
C

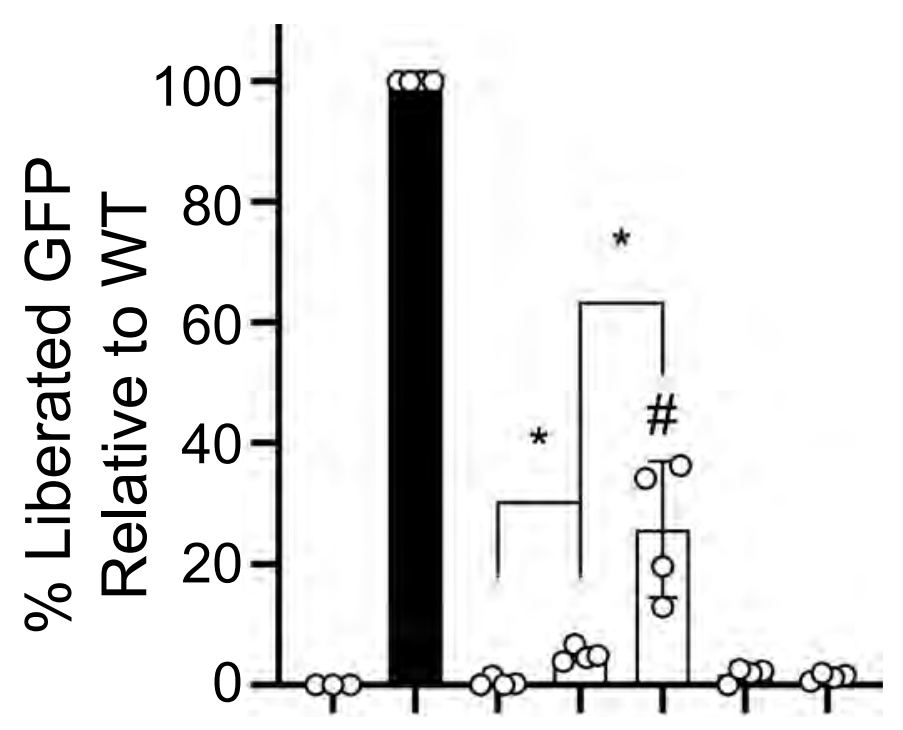

BRO1: + + + $\Delta \Delta \Delta \Delta$ bro1 $\triangle B O D:-2-+++$

VPS4: $++\Delta+++\Delta$

SNF7: $+++++\Delta+$ Mup1-GFP: -++++++ kDa Ub-Mup1- 
A

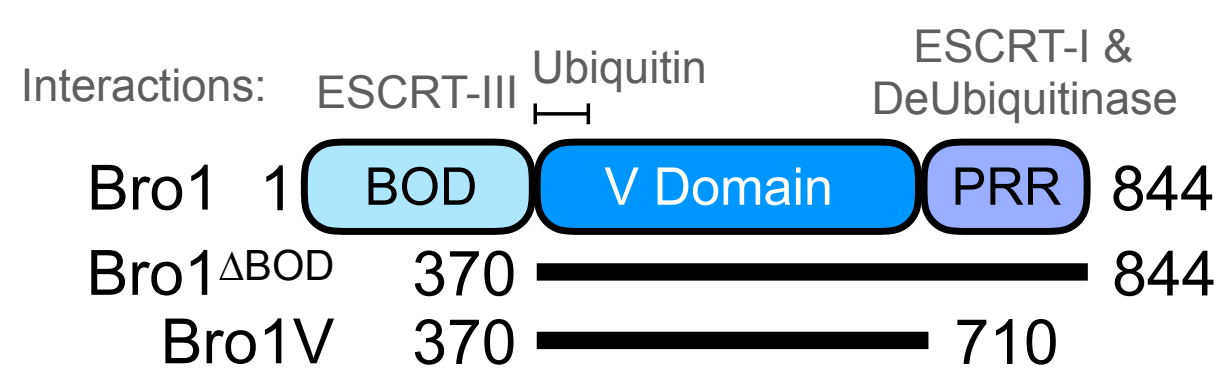

B
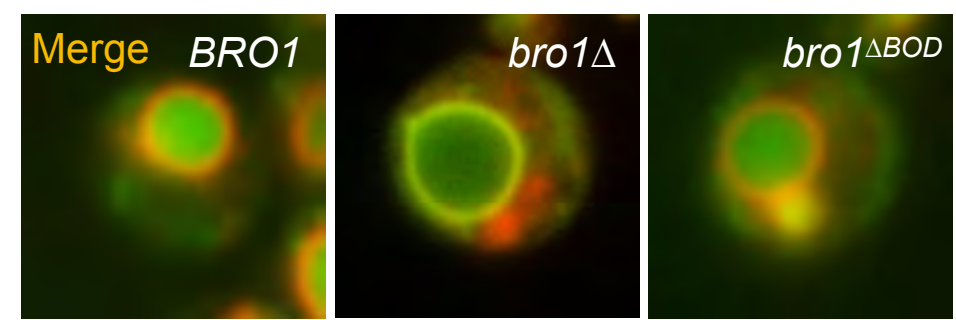

$\mathrm{C}$
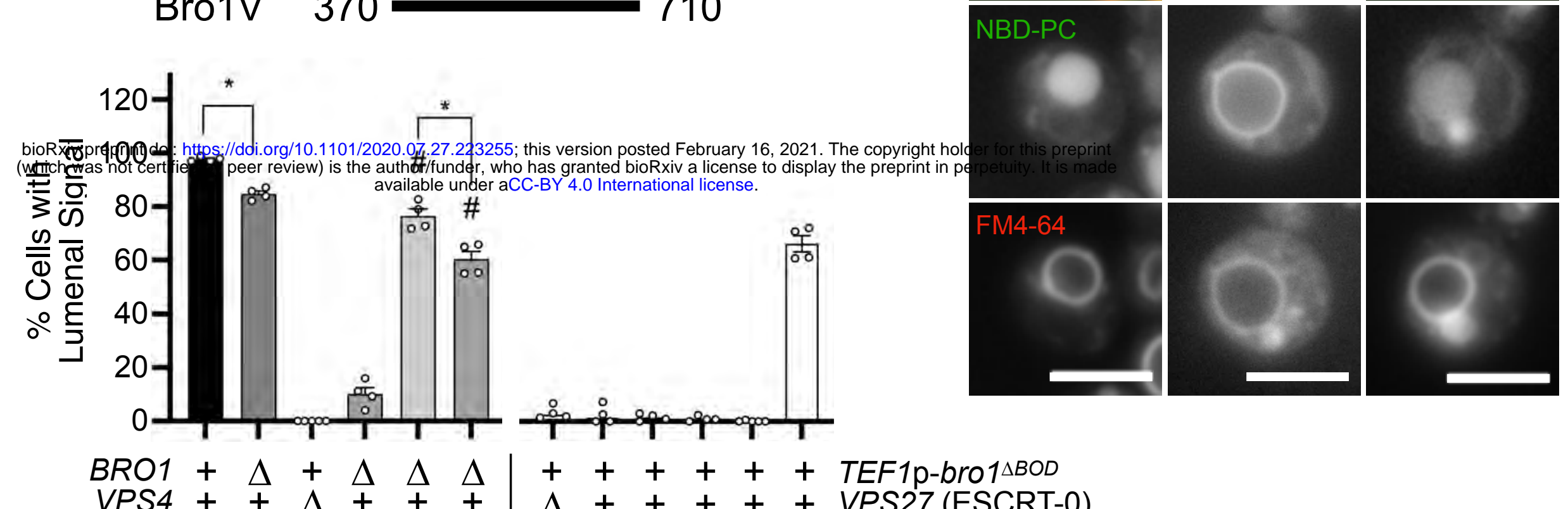

TEF1p-BRO1 - + - -5

$+\Delta++++$ VPS37 (ESCRT-I)

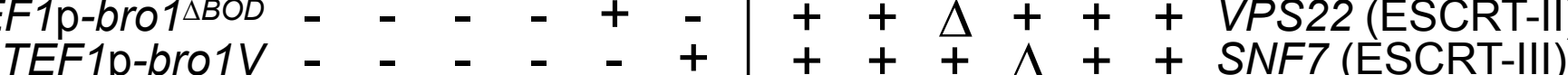

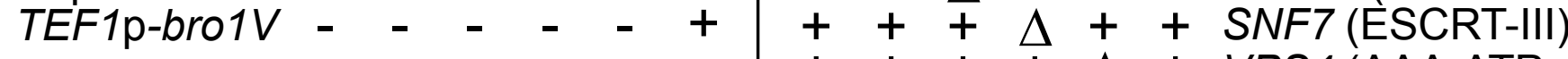

$++++\Delta+$ VPS4 (AAA-ATPase)

$+++++\Delta$ DOA4 (DUb)
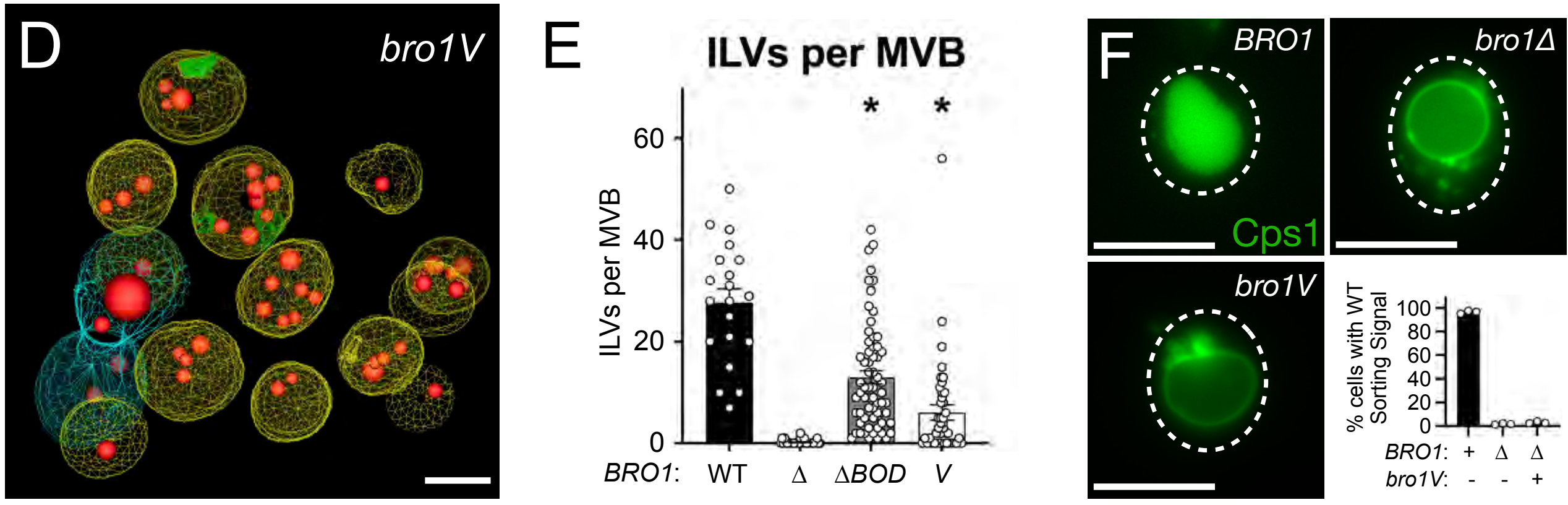
A

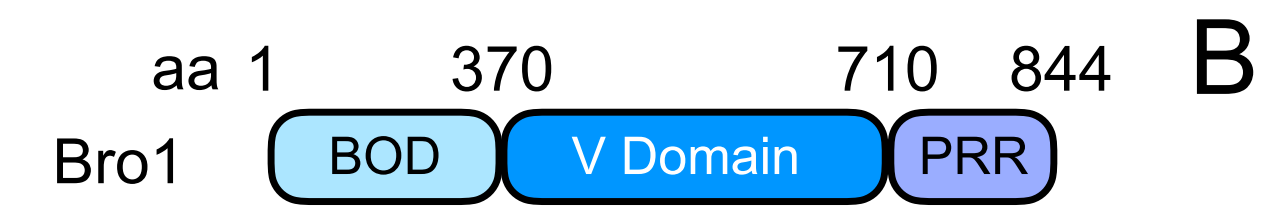

Immobilized:

Immobilized:
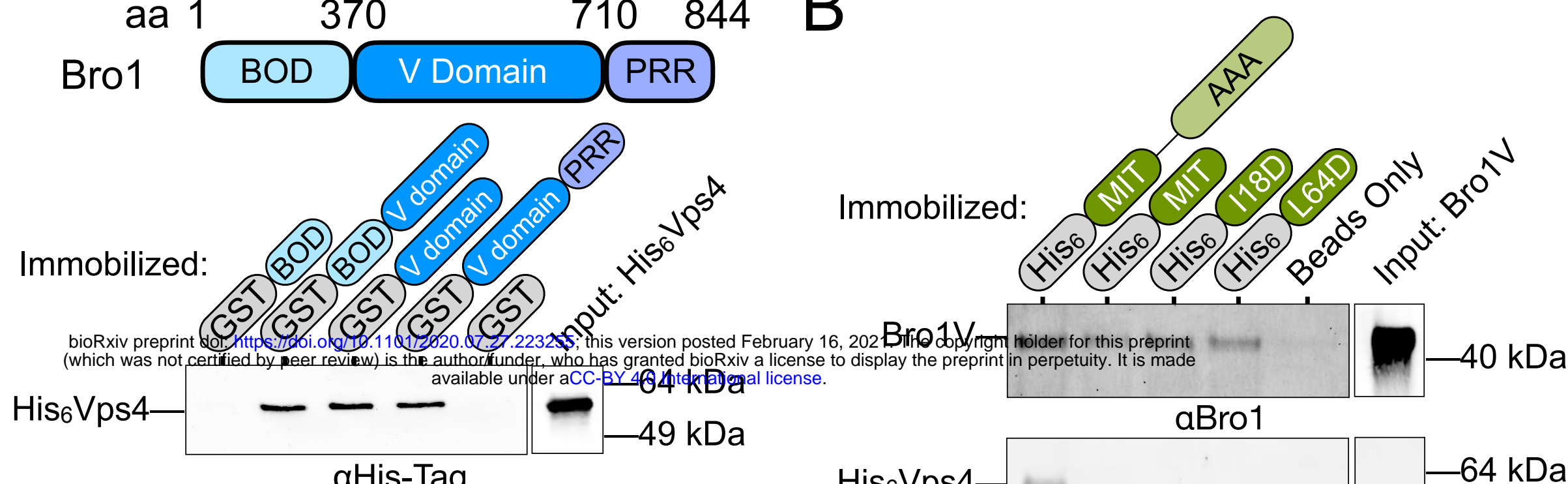

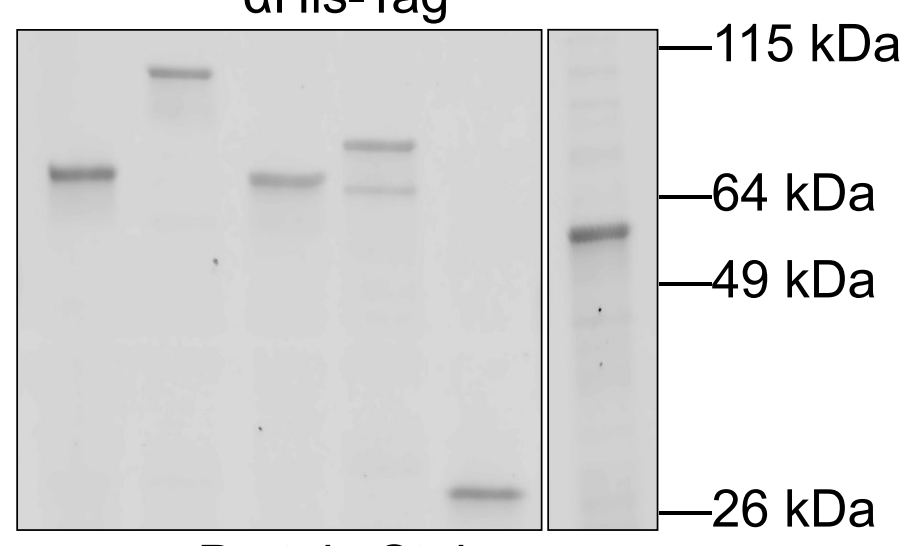

Protein Stain

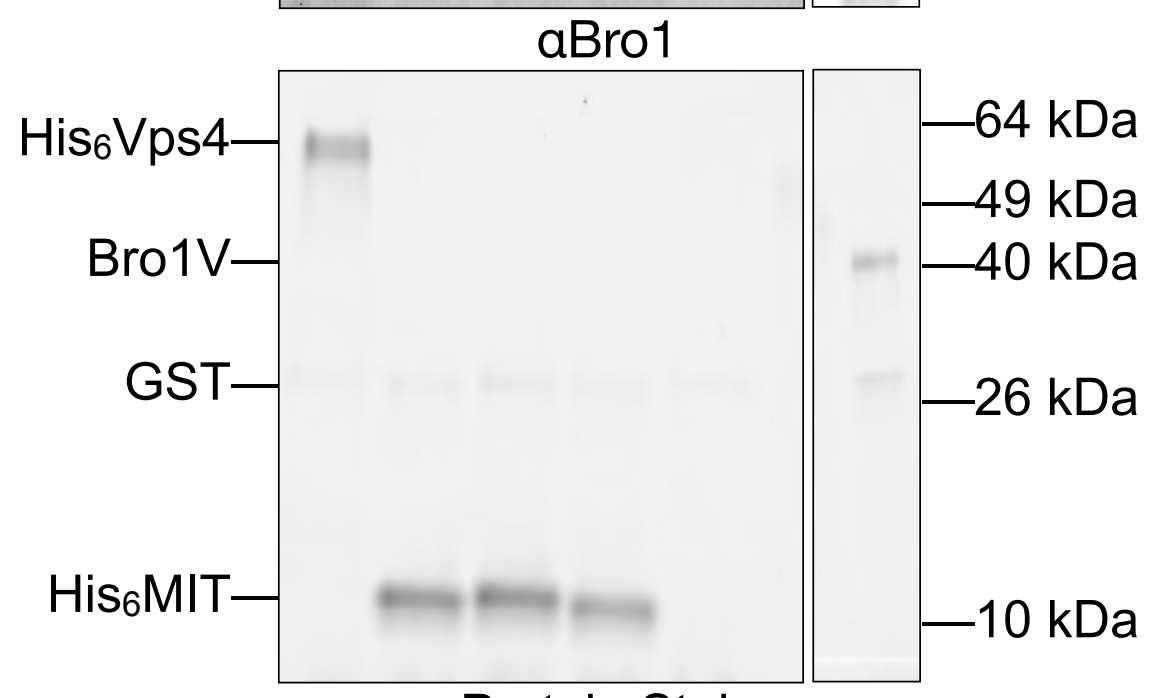

Protein Stain
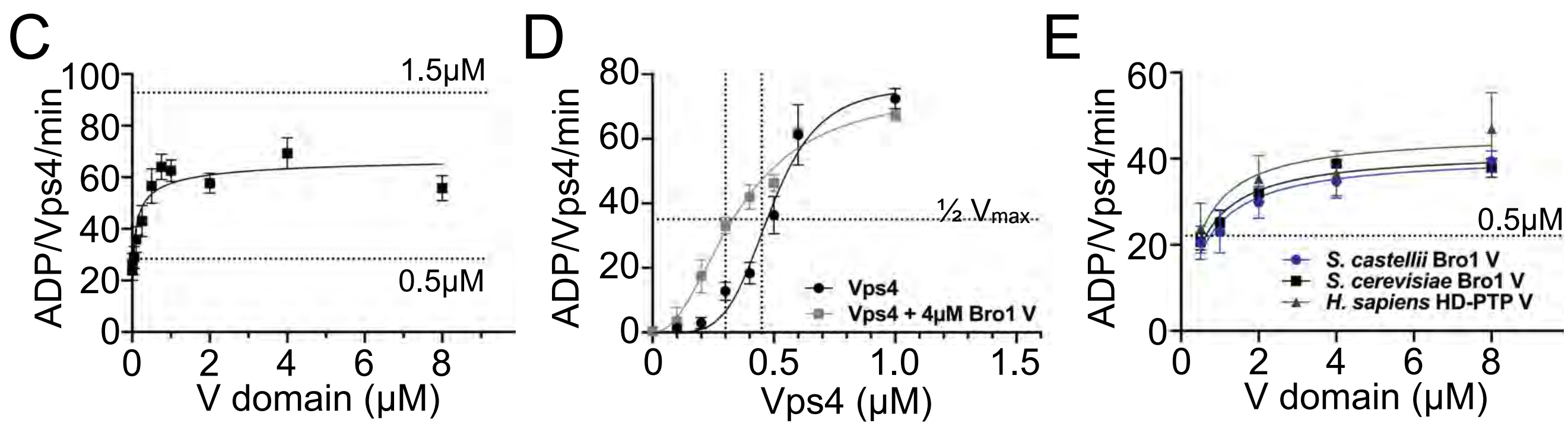
A

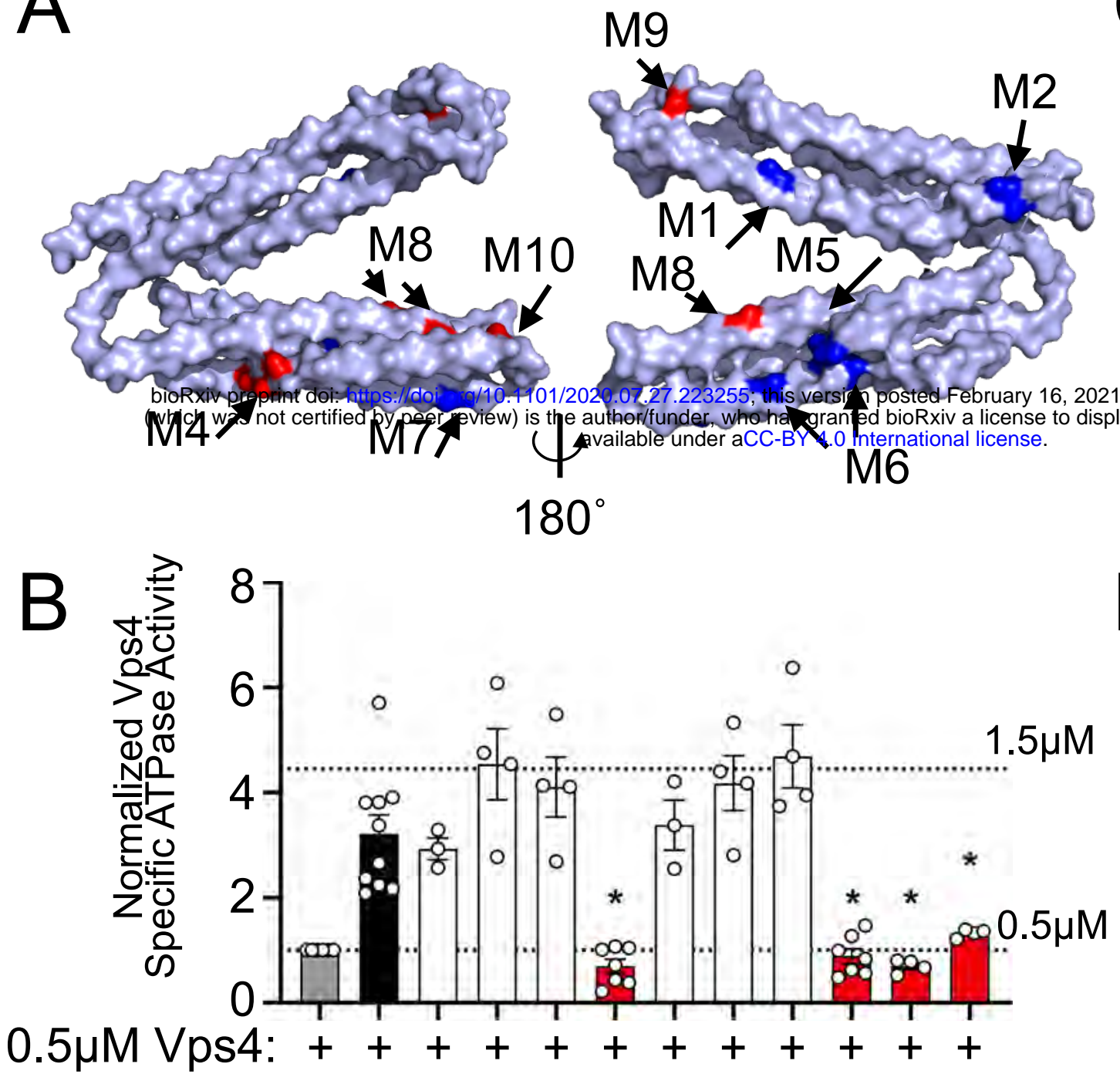

C

Bro1V : WT M4 M8 M9 M10

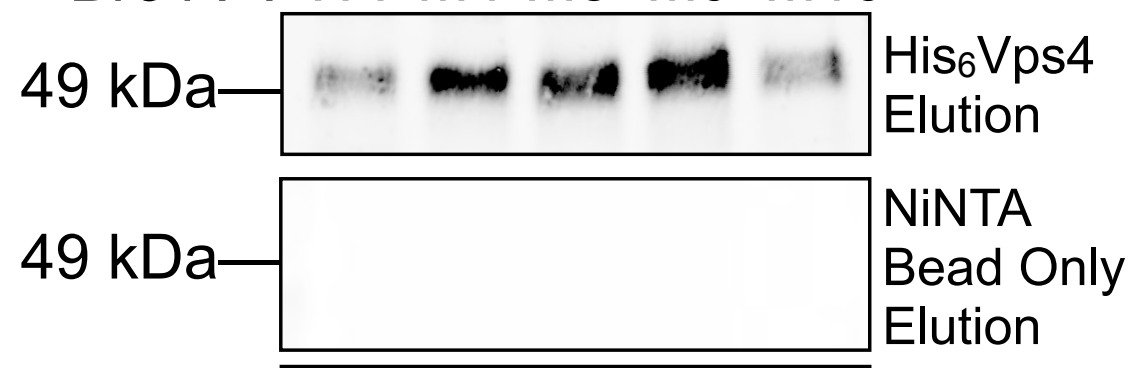

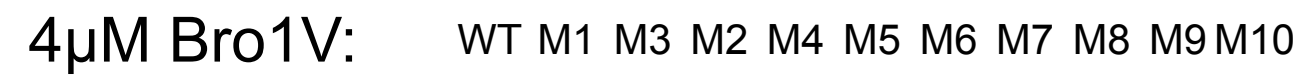

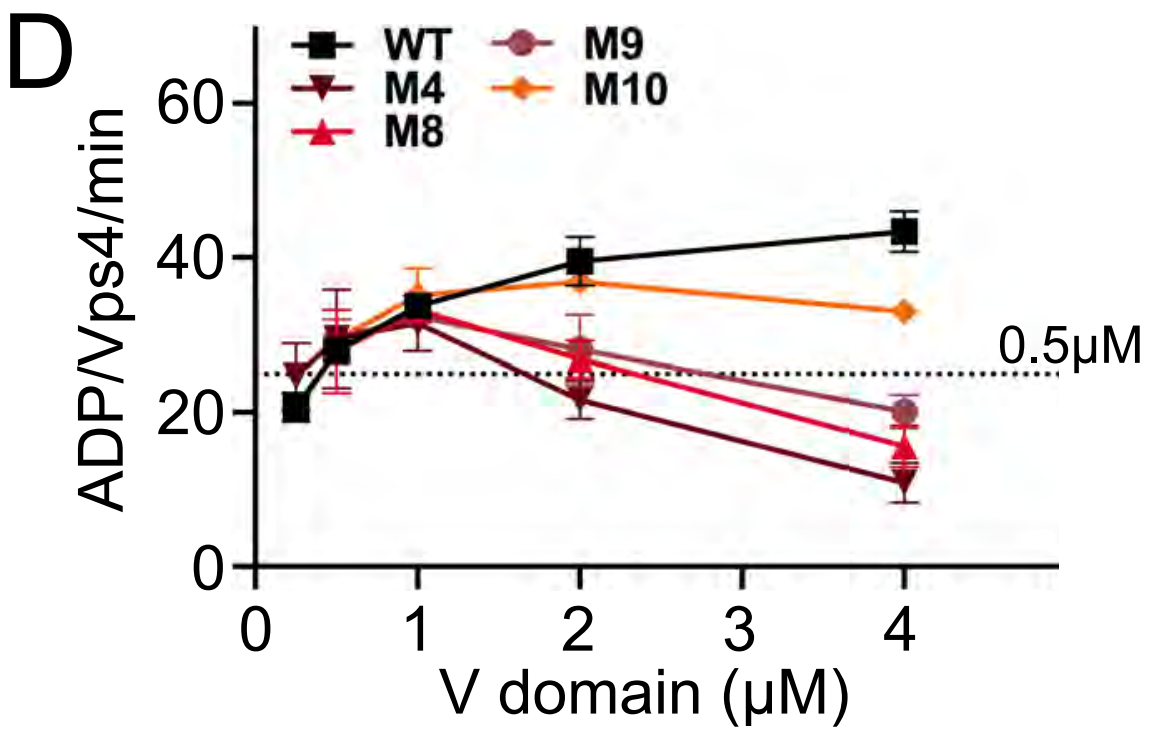


A

Cps1

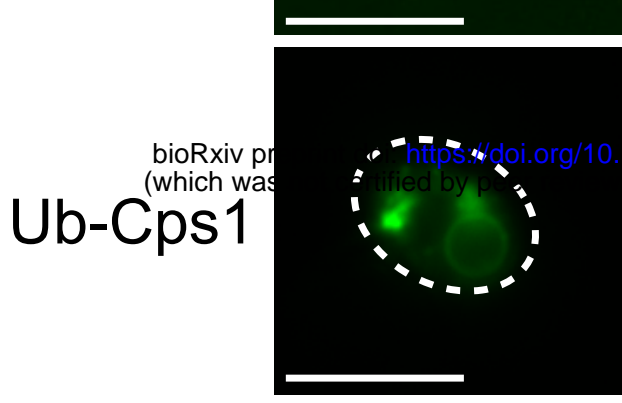

pRS414

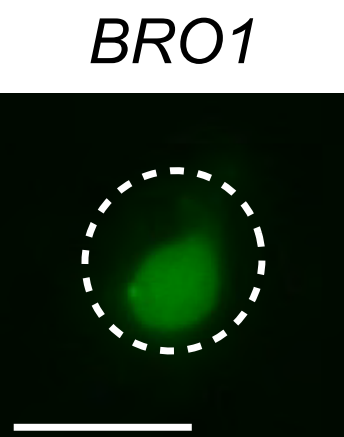

bro1M4
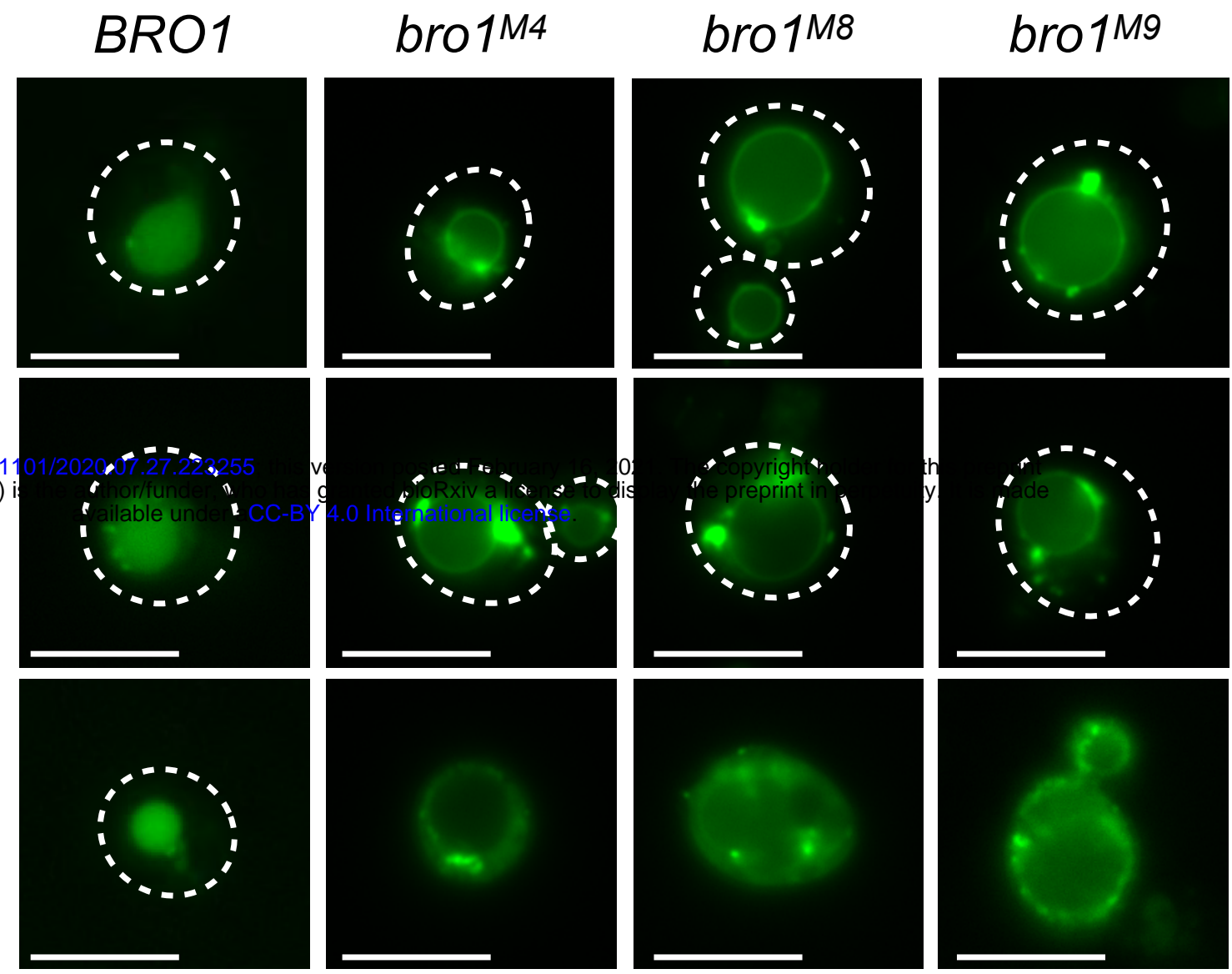

bro1M10

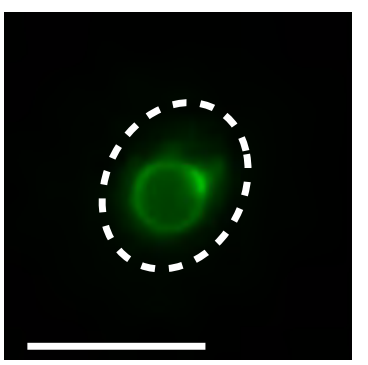

Sna3
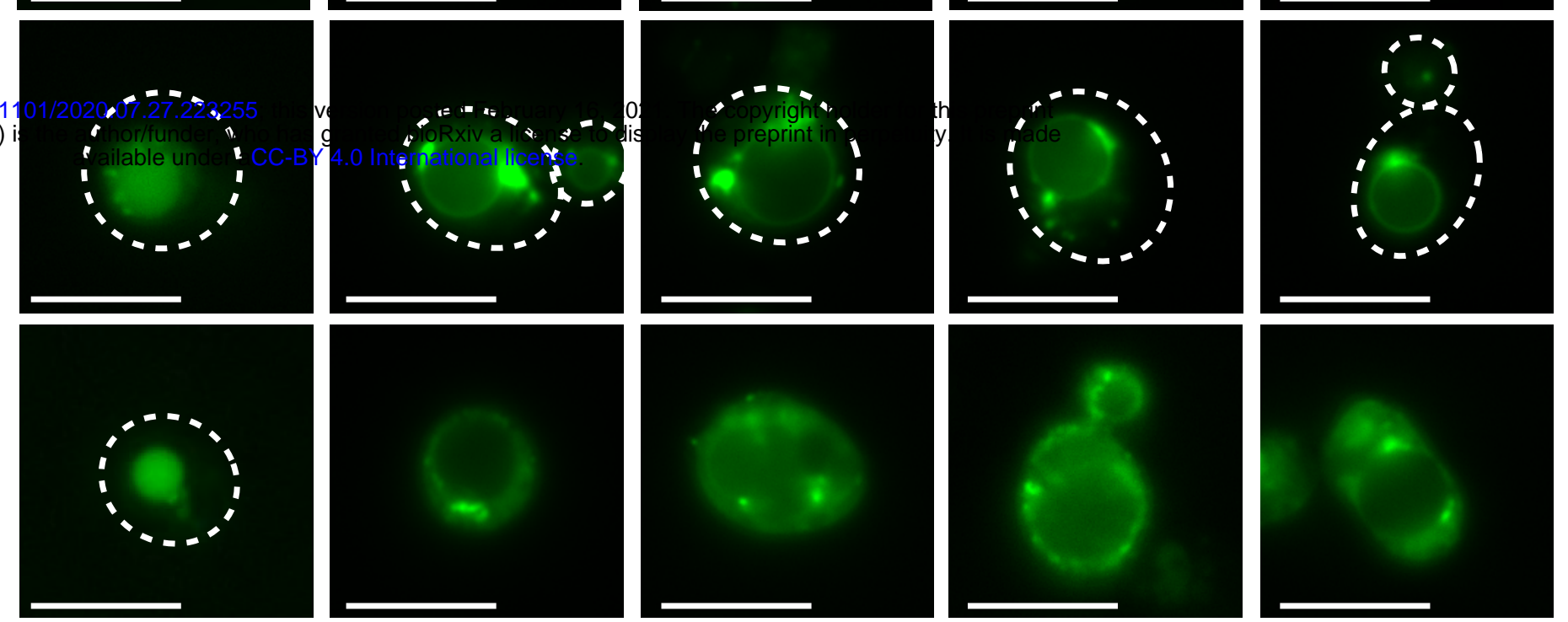

B

Cps1-GFP Ub-Cps1-GFP Sna3-GFP

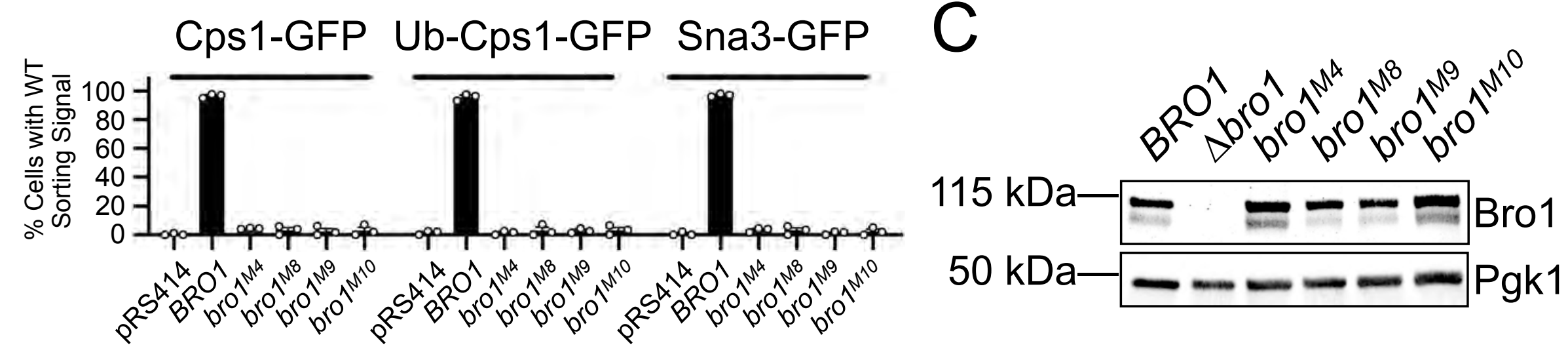

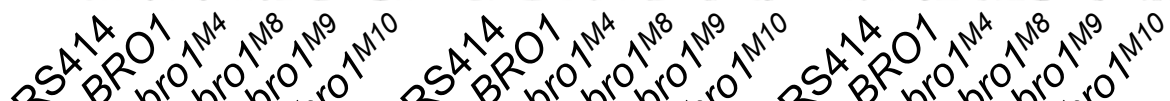

C 


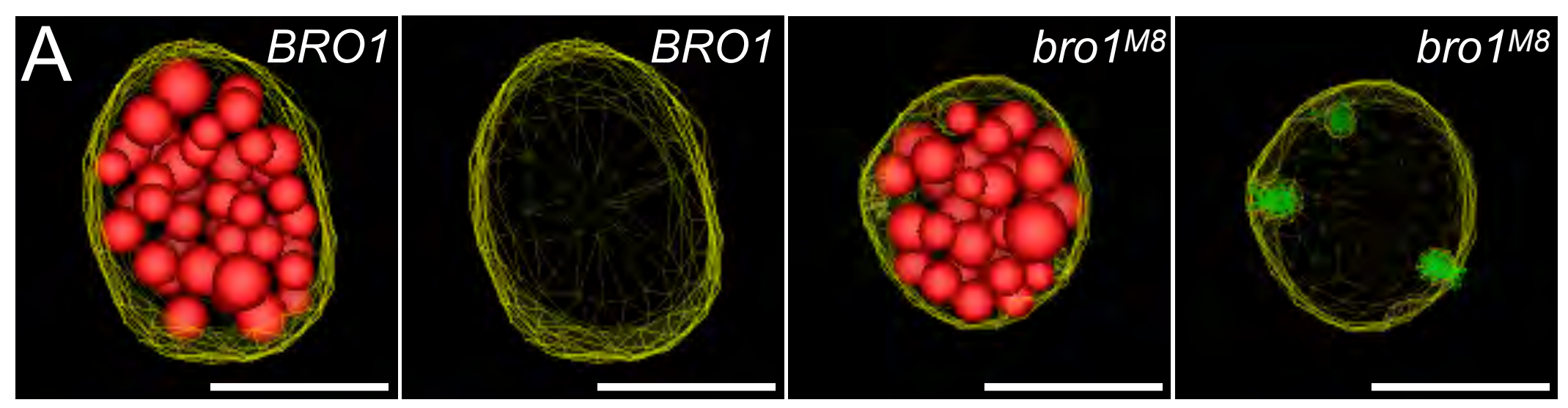

\section{B}

bioRxiv preprint doi: https://doi.org/10.1101/2020.07.27.223255; this version posted February 16, 2021. The copyright holder for this preprint

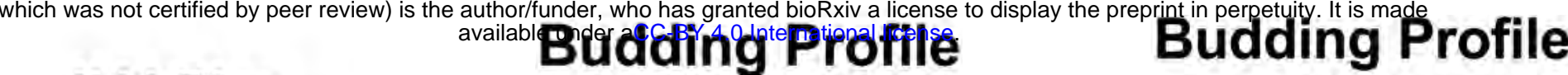

\section{ILV Size}

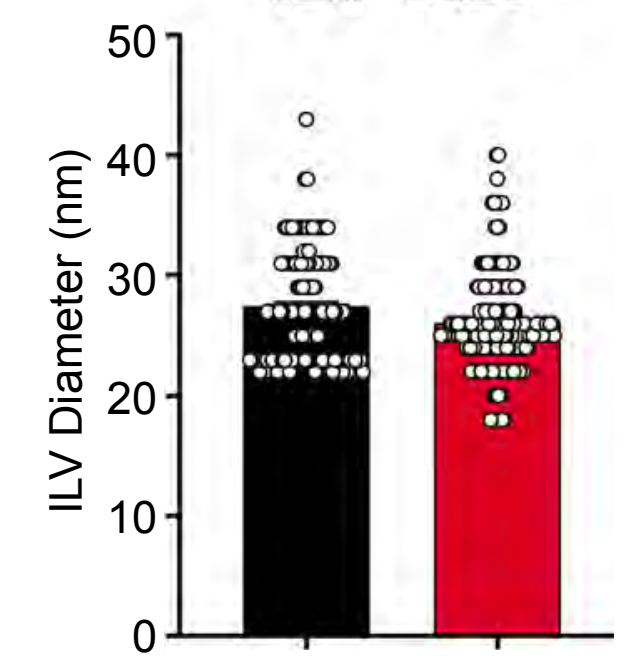

Genotype: BRO1 bro1M8

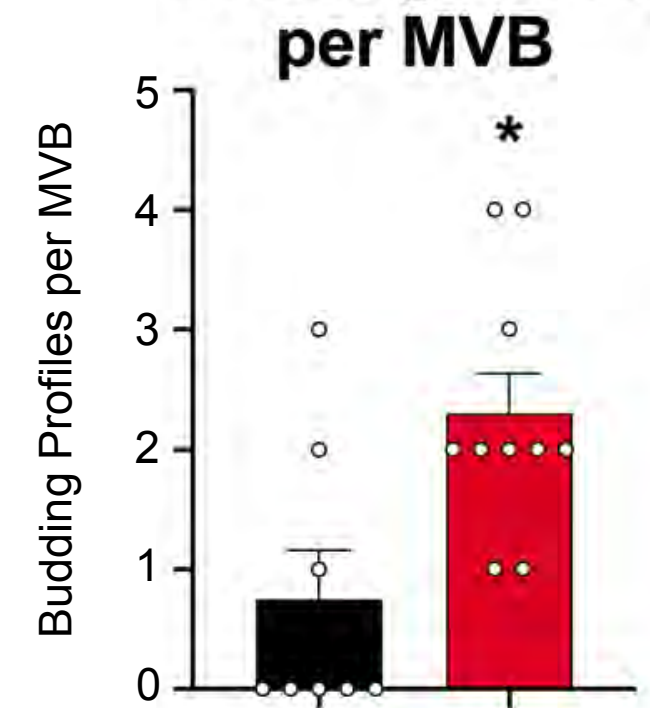

Genotype: BRO1 bro1M8

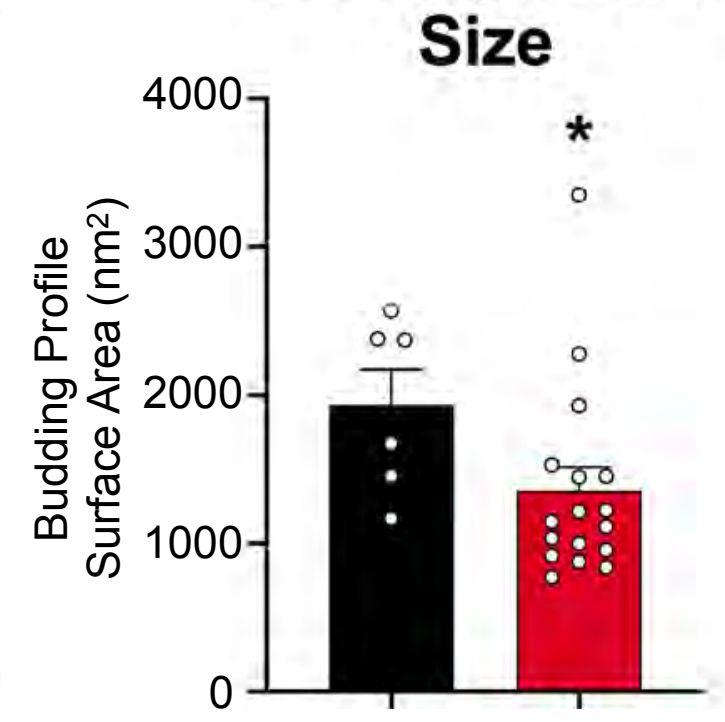

Genotype: BRO1 bro1M8 


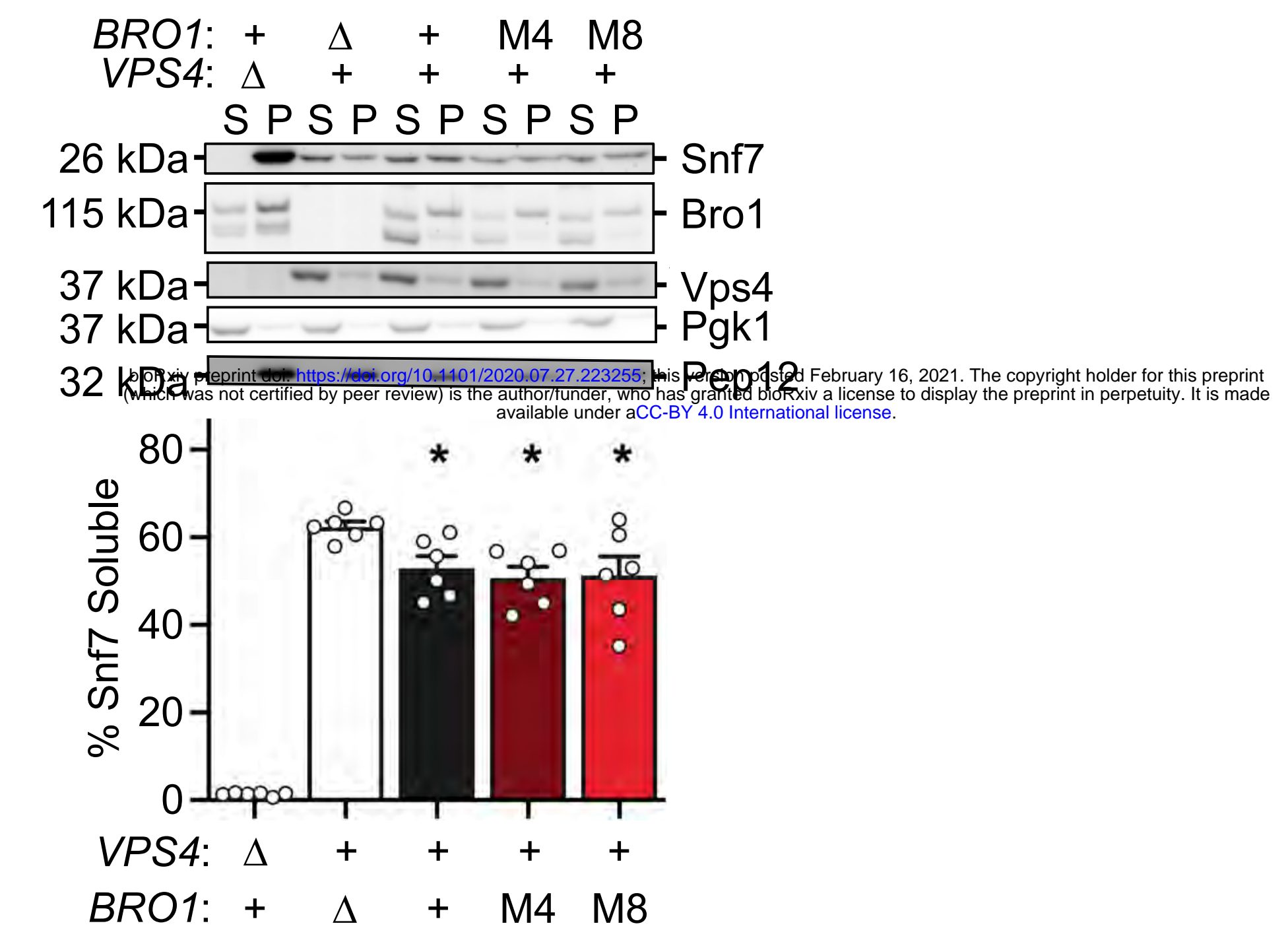


A

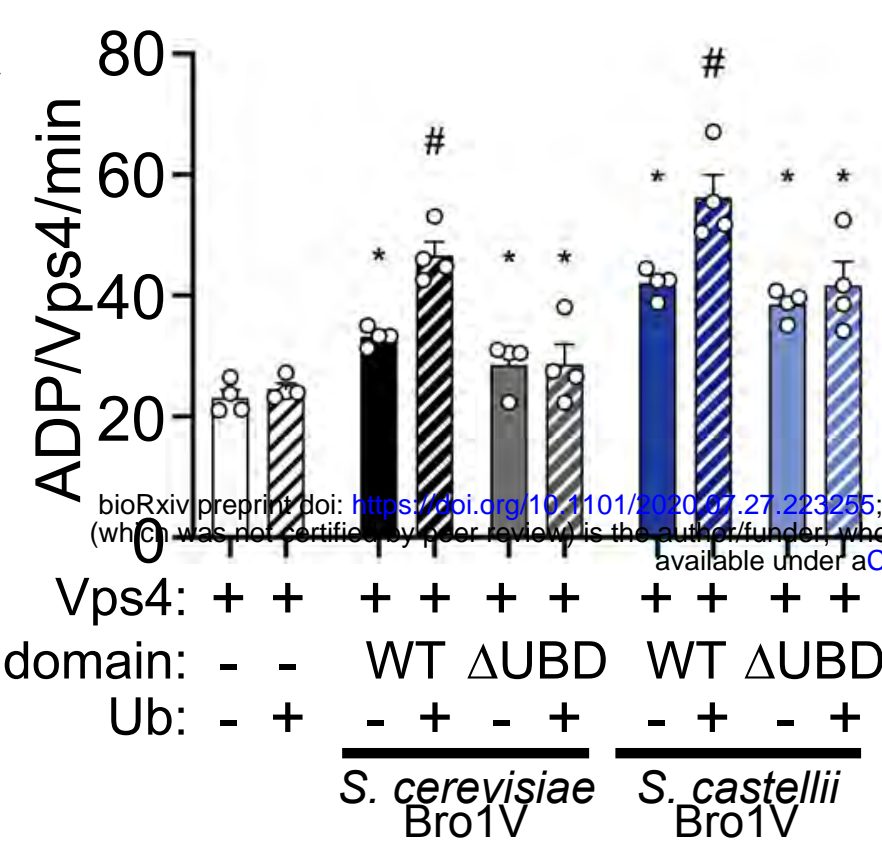

B

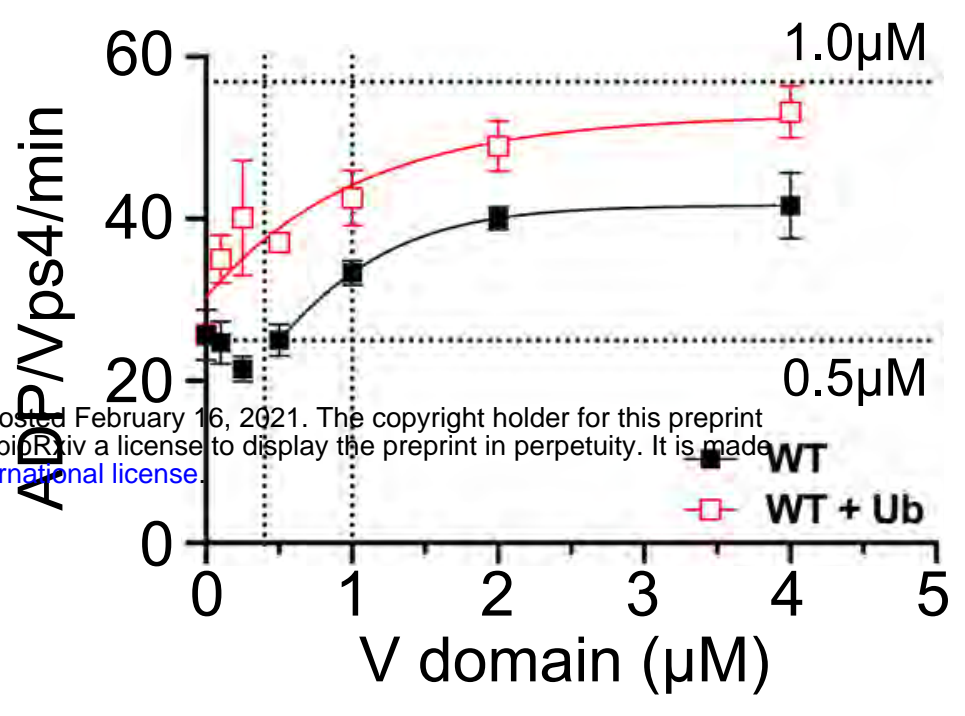

C

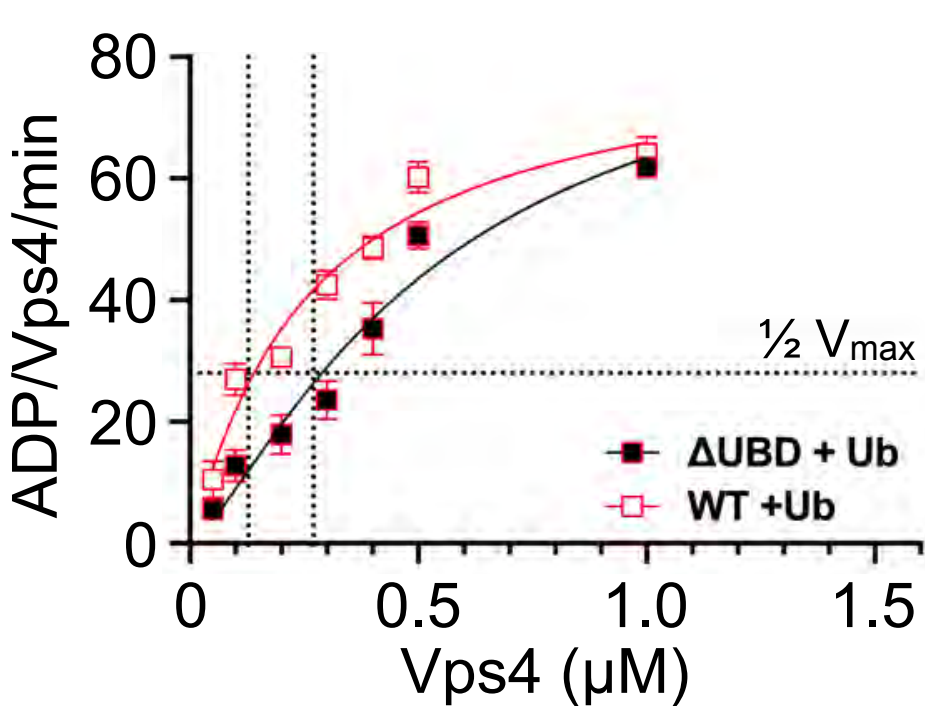

$E$

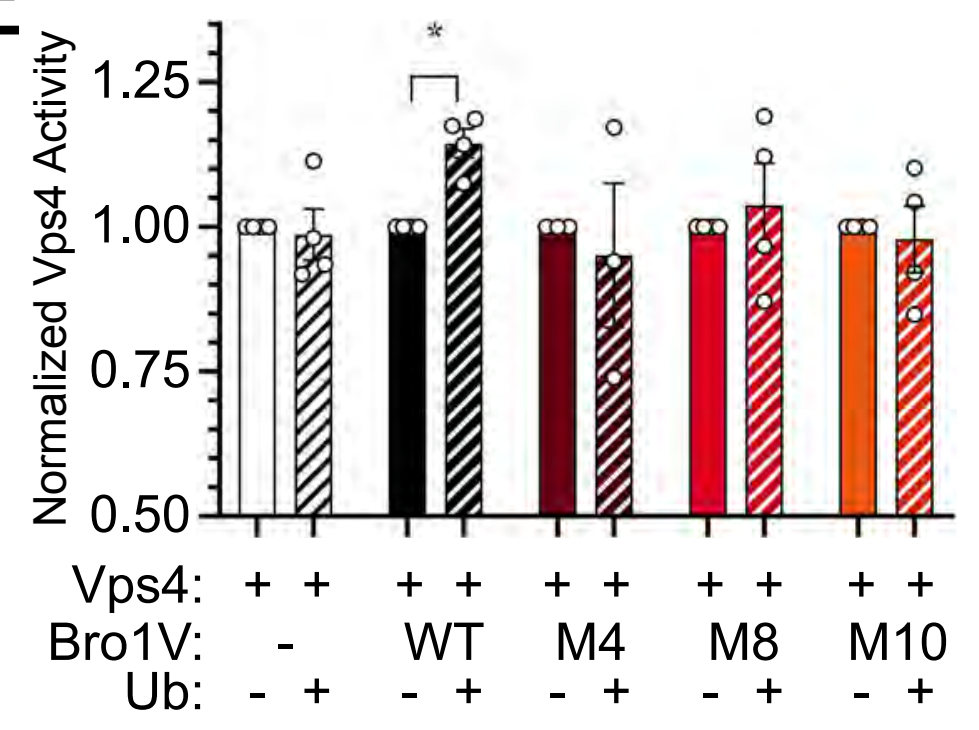

$\mathrm{D}$

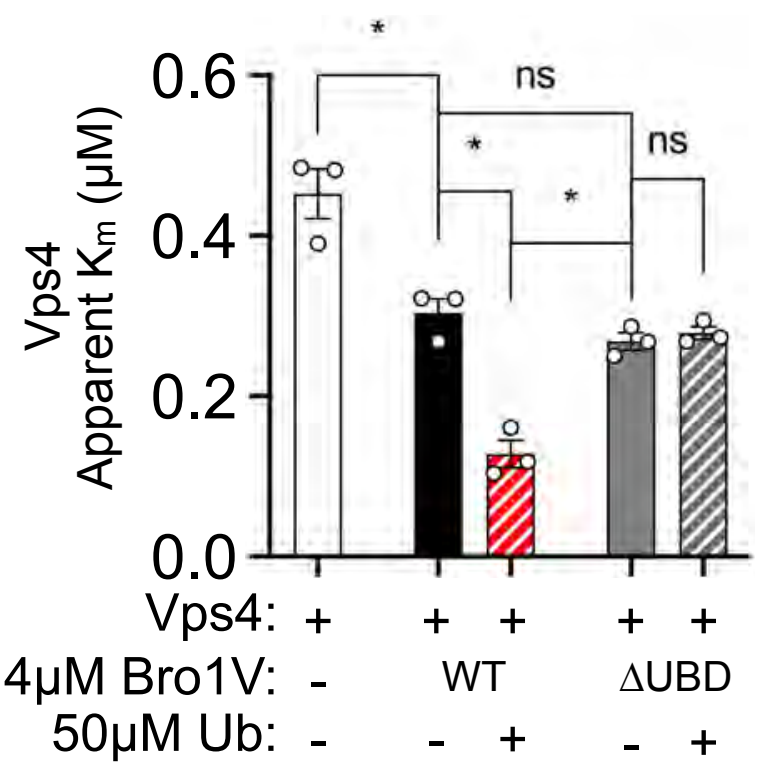

F

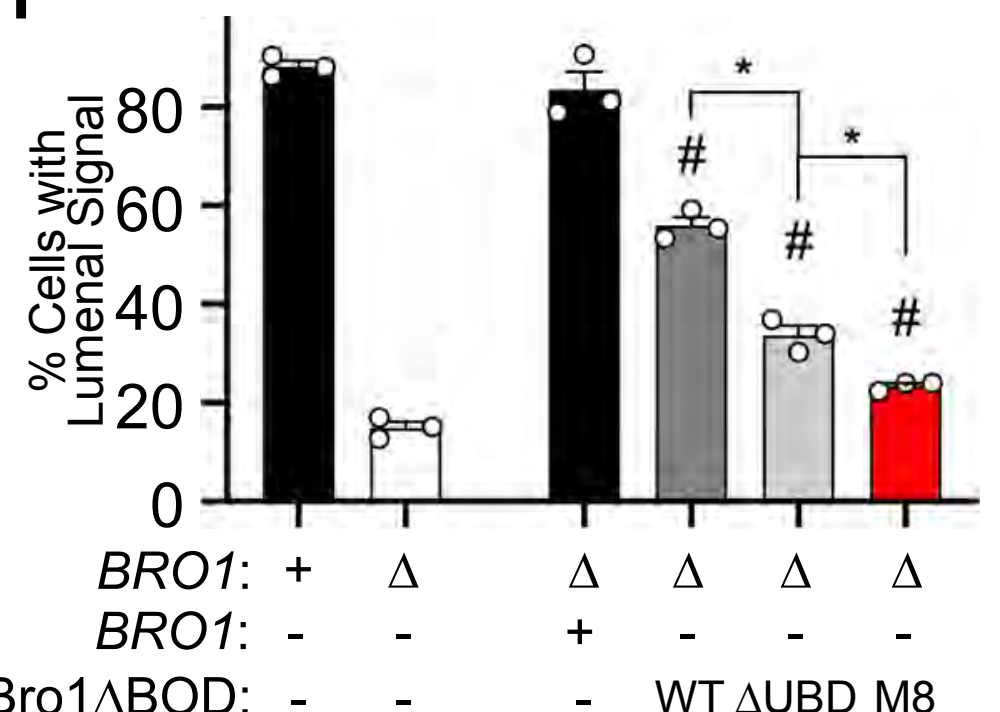

Bro1 $\triangle$ BOD: - $\quad$ - $\quad$ - WT $\triangle$ UBD M8 
A

Wild Type

Ub

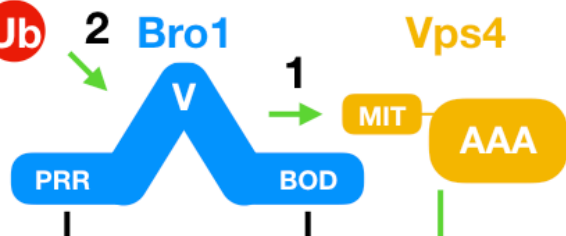

B

bro1 $\triangle B O D$

C

bro14

Ub.

Bro1 $^{\triangle B O D} \quad$ Vps4

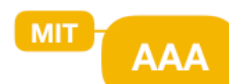

PRR

Ana

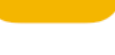

\section{ESCRT-0, -I, -II \\ ESCRT-III}

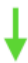

MVB biogenesis

with efficient cargo sorting

$$
\begin{aligned}
& \text { 255; this version nosted February 16, 2021. The copyright holder for this preprint } \\
& \text { in perpetuity. It is made ganted bio Rxiv a license }
\end{aligned}
$$

ESCRT-0, -I, -II
ESCRT-III

ILV formation

\& inefficient MVB sorting
Vps4

MIT AAA<smiles>[CH][CH]</smiles>

ESCRT-III

Rare ILV formation \& disrupted MVB sorting 